Aus der Klinik für Unfallchirurgie, Orthopädie und Plastische Chirurgie

(Prof. Dr. med. W. Lehmann)

der Medizinischen Fakultät der Universität Göttingen

\title{
Der Einfluss von Baicalein auf die metaphysäre Frakturheilung im Osteoporosemodell der Ratte
}

\author{
INAUGURAL - DISSERTATION \\ zur Erlangung des Doktorgrades \\ der Medizinischen Fakultät der \\ Georg-August-Universität zu Göttingen \\ vorgelegt von \\ Marie Weber \\ aus \\ Trier
}

Göttingen 2018 
Dekan:

I. Referent/in:

II. Ko-Referent/in:

III. Drittreferent/in:
Prof. Dr. rer. nat. H. K. Kroemer

Prof. Dr. med. S. Sehmisch

Prof. Dr. rer. nat. H. Jarry

Prof. Dr. med. Dr. med. dent. K. G. Wiese

Datum der mündlichen Prüfung: 16.07.2019 
Hiermit erkläre ich, die Dissertation mit dem Titel „Der Einfluss von Baicalein auf die metaphysäre Frakturheilung im Osteoporosemodell der Ratte“ eigenständig angefertigt und keine anderen als die von mir angegebenen Quellen und Hilfsmittel verwendet zu haben.

Göttingen, den 


\section{Inhaltsverzeichnis}

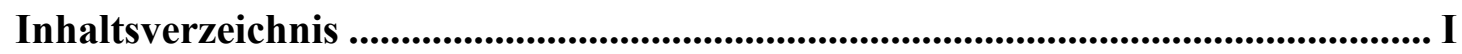

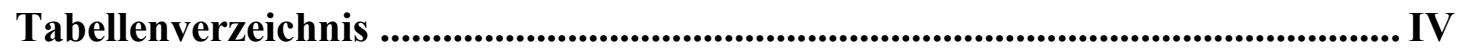

Abbildungsverzeichnis .......................................................................................................... VI

Abkürzungsverzeichnis ................................................................................. IX

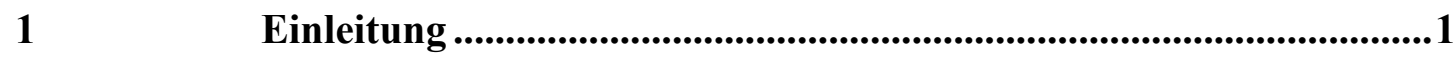

Einführung in das Thema und Fragestellung ..................................... 1

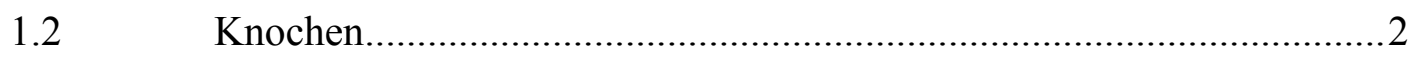

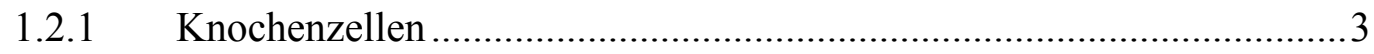

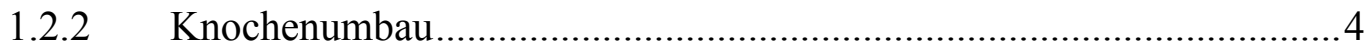

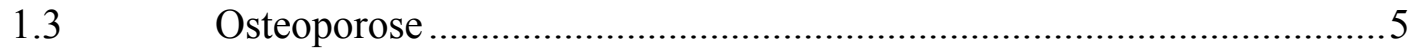

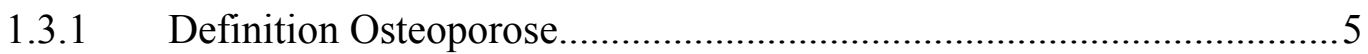

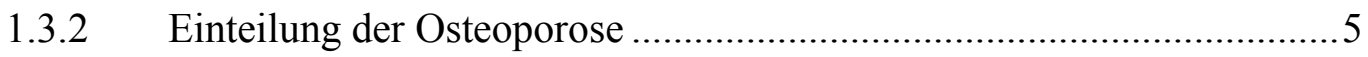

1.3.4 Ätiologie und Pathogenese der primären Osteoporose .........................6

1.3.5 Risikofaktoren für Osteoporose und osteoporotische Frakturen ............7

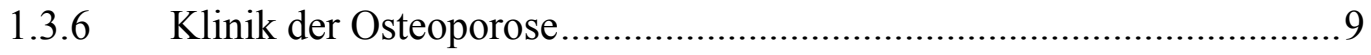

1.3.7 Diagnostik der Osteoporose ......................................................... 10

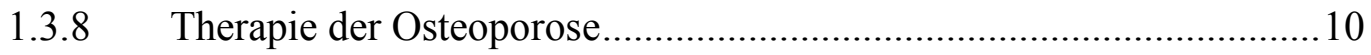

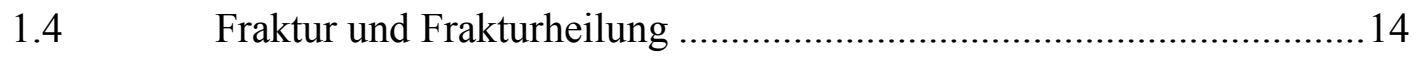

1.4.1 Frakturmechanismen ................................................................. 14

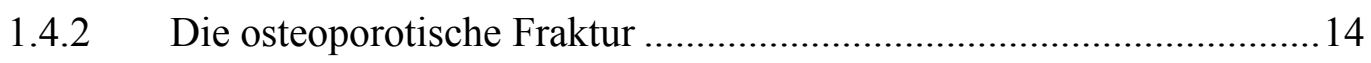

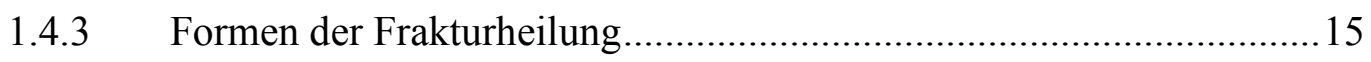

1.4.4 Frakturheilung und Osteoporose ...................................................15

1.4.5 Frakturheilung im metaphysären Osteotomie-Modell ........................16

$2 \quad$ Material und Methoden .........................................................................17

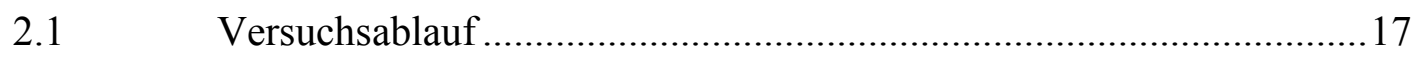

$2.2 \quad$ Versuchstiere und Versuchstierhaltung............................................. 19

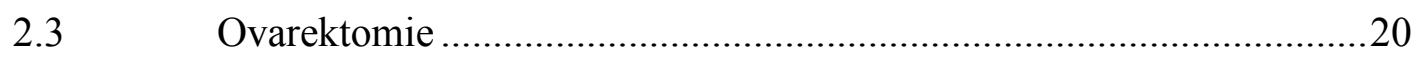

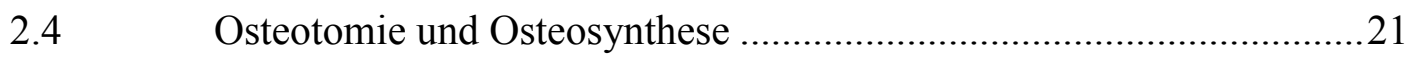

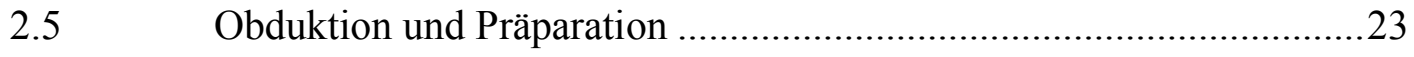

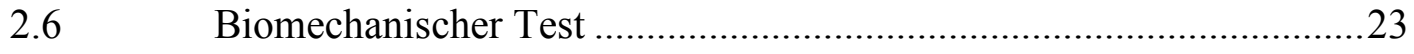

2.6.1 Prinzip des biomechanischen Tests ...............................................23

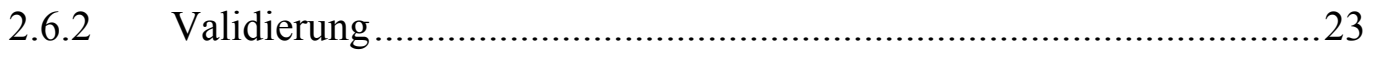




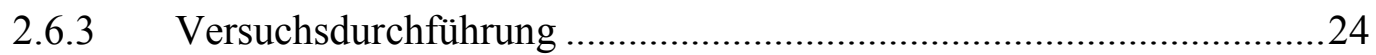

2.6.4 Auswertung der Kraft-Weg-Diagramme ...........................................25

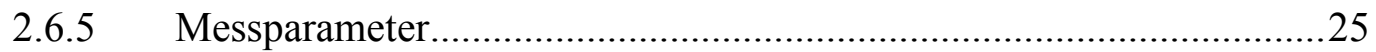

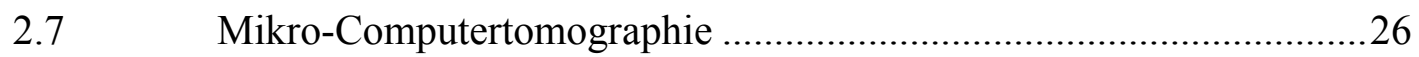

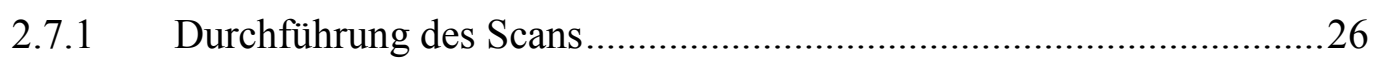

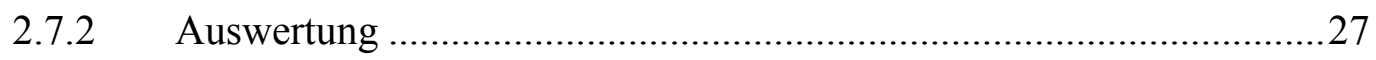

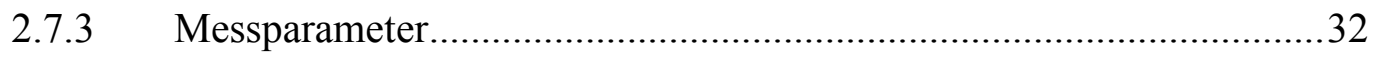

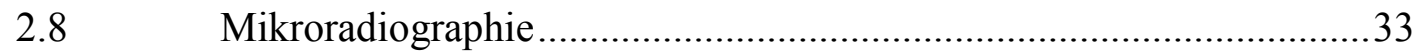

2.8.1 Anfertigung der histologischen Schnitte und der Mikroradiographien 33

2.8.2 Auswertung der Mikroradiographien ....................................................33

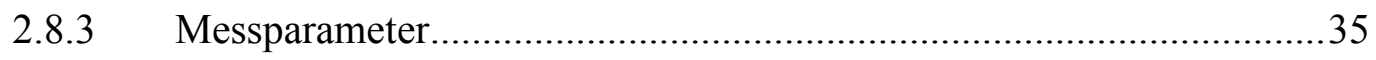

2.9 Prinzip der polychromen Sequenzmarkierung …..............................37

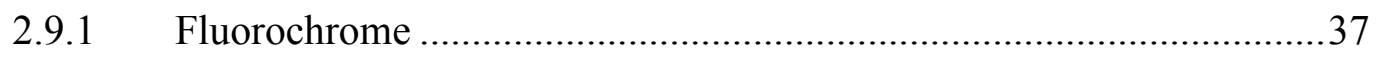

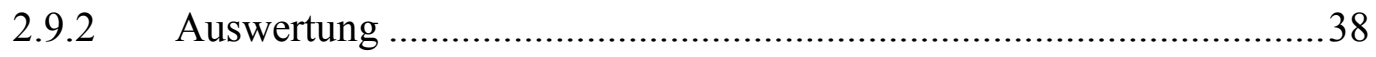

2.9.3 Zeitpunkt der frühesten Überbrückung des Frakturspalts ...................40

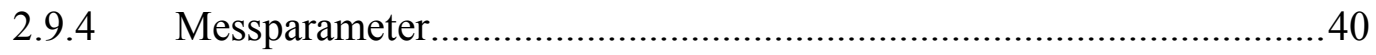

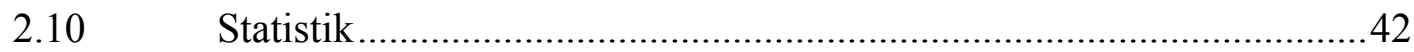

3

Ergebnisse ...........................................................................43

Körpergewicht der Tiere im Verlauf.............................................. 44

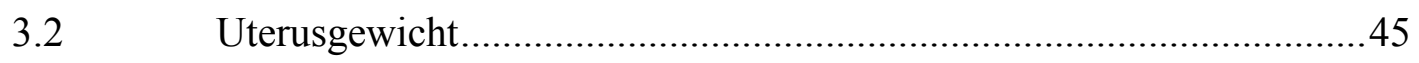

Ergebnisse des biomechanischen Tests ............................................45

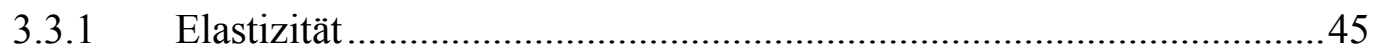

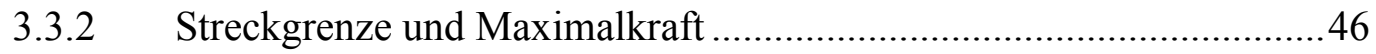

3.4 Ergebnisse der Mikrocomputertomographie ...................................4 47

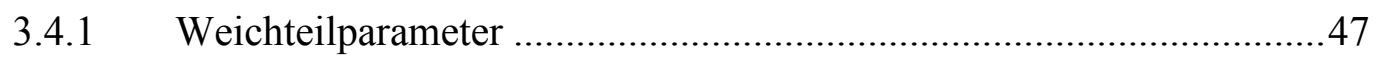

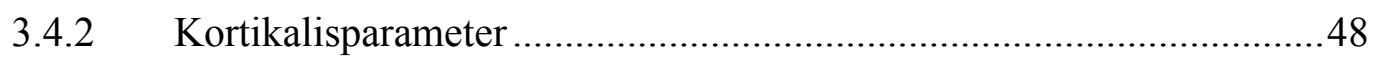

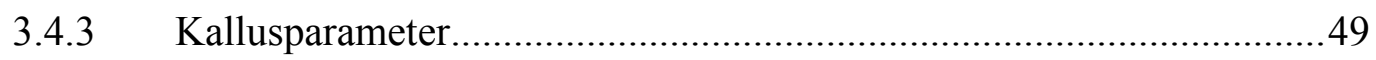

3.4.4 Parameter, die den gesamten Knochen betreffen ..............................51

3.4.5 Parameter, die das gesamte Gewebe betreffen ..................................52

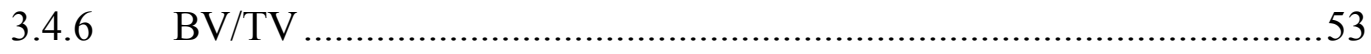

3.5 Ergebnisse der Mikroradiographie ................................................53

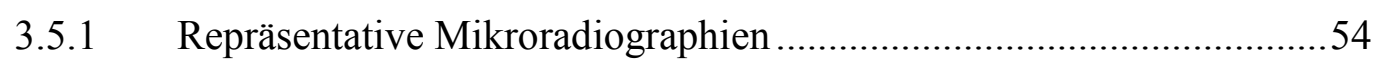

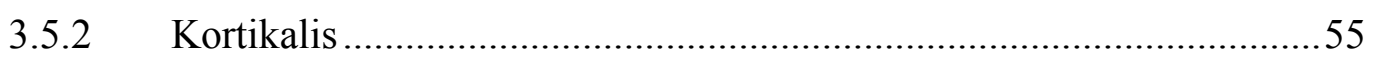




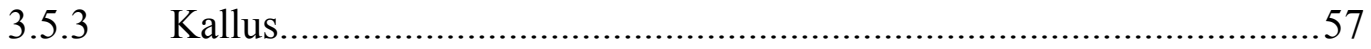

3.6 Ergebnisse der polychromen Sequenzmarkierung ............................60

3.6.1 Zeitpunkt der frühesten Überbrückung des Frakturspalts ...................60

3.6.2 Repräsentative Bilder der polychromen Sequenzmarkierung ..............61

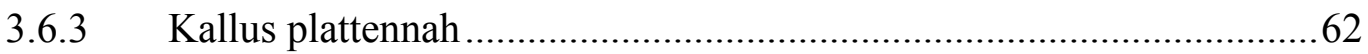

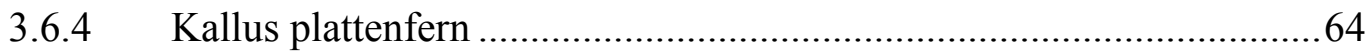

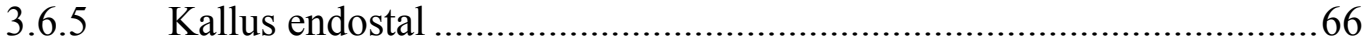

3.6.6 Gesamtfläche kompletter Kallus ...................................................67

$4 \quad$ Diskussion............................................................................................69

4.1 Die ovarektomierte Ratte als Osteoporosemodell und das metaphysäre Frakturmodell .............................................................. 70

4.2 Biomechanischer Kompressionstest................................................ 71

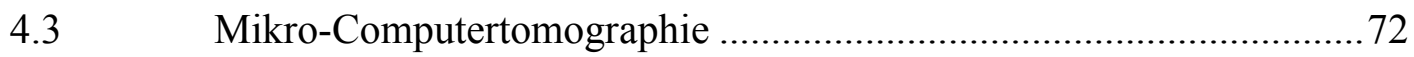

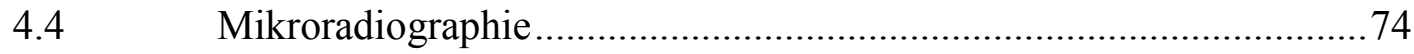

4.5 Polychrome Sequenzmarkierung ..................................................... 76

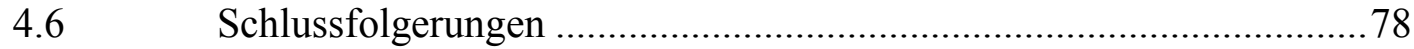

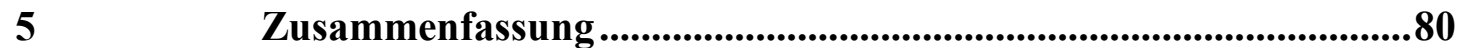

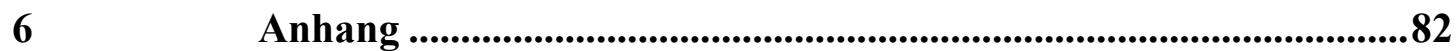

Körpergewicht der Tiere im Verlauf ............................................ 82

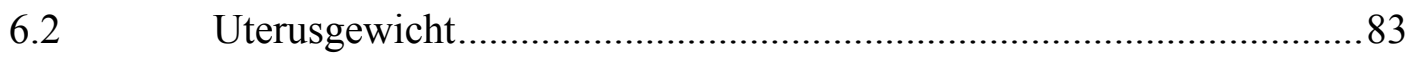

6.3 Ergebnisse des biomechanischen Tests ........................................... 83

6.4 Ergebnisse der Mikro-Computertomographie..................................8 84

6.5 Ergebnisse der Mikroradiographie ................................................. 86

6.6 Ergebnisse der polychromen Sequenzmarkierung ............................87

$7 \quad$ Literaturverzeichnis ...................................................................90 


\section{Tabellenverzeichnis}

\section{Im Text:}

Tabelle 1: Darstellung der Gruppen und der Behandlung der Ratten, Anzahl der Versuchstiere zum Zeitpunkt nach Versuchsende ................................ 19

Tabelle 2: Scanparameter des Scanprotokolls .......................................................26

Tabelle 3: Darstellung der Messparameter der Auswertung mit Einheit und

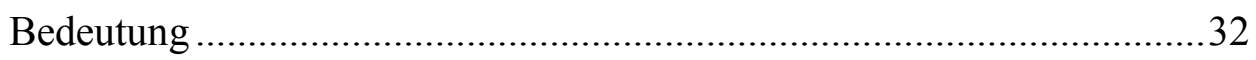

Tabelle 4: Messparameter gesamter Knochen, Einheit und Berechnung ...................35

Tabelle 5: Messparameter Kortikalis, Einheit und Berechnung ...............................36

Tabelle 6: Messparameter Kallus, Einheit und Berechnung .....................................36

Tabelle 7: Darstellung der Applikationszeitpunkte, Anfärbungszeiträume und Dosierungen der verschiedenen Fluorochrome .......................................37

Tabelle 8: Messparameter Kallus plattennah, Einheit und Berechnung ....................40

Tabelle 9: Messparameter Kallus plattenfern, Einheit und Berechnung ...................41

Tabelle 10: Messparameter Kallus endostal, Einheit und Berechnung .......................41

Tabelle 11: Messparameter Kallus komplett, Einheit und Berechnung ......................41

\section{Im Anhang:}

Tabelle 1: Darstellung der Mittelwerte \pm Standardabweichung der Körpergewichte der Tiere über die Versuchswochen in Gramm .....................................82

Tabelle 2: Darstellung der Mittelwerte \pm Standardabweichung der Uterusgewichte jeder Versuchsgruppe am Tag der Obduktion

Tabelle 3: Darstellung der Mittelwerte \pm Standardabweichung der Messgrößen des biomechanischen Tests

Tabelle 4: Darstellung der Mittelwerte \pm Standardabweichung der Messgrößen der Weichteile

Tabelle 5: Darstellung der Mittelwerte \pm Standardabweichung der Messgrößen der Kortikalis

Tabelle 6: Darstellung der Mittelwerte \pm Standardabweichung der Messgrößen des Kallus

Tabelle 7: Darstellung der Mittelwerte \pm Standardabweichung der Messgrößen des gesamten Knochens 
Tabelle 8: Darstellung der Mittelwerte \pm Standardabweichung der Messgrößen des gesamten Gewebes

Tabelle 9: Darstellung der Mittelwerte \pm Standardabweichung der Kortikalismessgrößen 86

Tabelle 10: Darstellung der Mittelwerte \pm Standardabweichung der Kallusmessgrößen

Tabelle 11: Darstellung der Mittelwerte \pm Standardabweichung der Messgrößen des plattennahen Kallus

Tabelle 12: Darstellung der Mittelwerte \pm Standardabweichung der Messgrößen des plattenfernen Kallus .88

Tabelle 13: Darstellung der Mittelwerte \pm Standardabweichung der Messgrößen des endostalen Kallus .88

Tabelle 14: Darstellung der Mittelwerte \pm Standardabweichung der Messgröße für den gesamten Kallus 


\section{Abbildungsverzeichnis}

Abb. 1: Darstellung des Versuchsablaufes ab Zeitpunkt der Ovarektomie 18

Abb. 2: Dokumentation der Ovarektomie und der Anbringung der

Osteosyntheseplatte im Zuge der Osteotomie

Abb. 3: Darstellung der Lage der Osteosyntheseplatte auf der Tibia im 3D-Bild des

Micro-CT 22

Abb. 4: Positionierung der Tibia auf der Trägerplatte in der Werkstoffprüfmaschine 24

Abb. 5: Optimal adaptierter Kontrast im 2D-Bild des Micro-CT..... .28

Abb. 6: Entsprechendes Grauwerthistogramm mit optimal adaptiertem Kontrast ......28

Abb. 7: Optimal adaptierte Transparenz mittels Opacity Function im 3D-Bild..........28

Abb. 8: Entsprechendes Grauwerthistogramm mit optimal adaptierter Transparenz..28

Abb. 9: Darstellung der Phantom-Dichtewerte im Grauwerthistogramm und Density

Mapping.

Abb. 10: Positionierung des Messrahmens über der Osteotomielinie ... .30

Abb. 11: Eingrenzung eines Grauwertbereiches am Beispiel des Weichteilbereiches 31

Abb. 12: Visualisierung des Kallusbereiches im 2D-Bild 32

Abb. 13: Eingrenzung eines Grauwertbereiches am Beispiel des Kallusbereiches......32

Abb. 14: Position des histologischen Schnittes unter dem Mikroradioskop .................34

Abb. 15: Flächendefinition unter dem Fluoreszenzmikroskop.

Abb. 16: Schematische Darstellung der Frakturüberbrückung durch die Fluorochrom-Markierung .... 40

Abb. 17: Darstellung des mittleren Körpergewichts der Tiere jeder Gruppe pro Versuchswoche vom Beginn bis zum Ende des Versuchs

Abb. 18: Darstellung des mittleren Uterusgewichtes der Tiere jeder Versuchsgruppe am Tag der Obduktion

Abb. 19: Darstellung der Ergebnisse der Messgröße Elastizität...................................46

Abb. 20: Darstellung der Ergebnisse der Messgröße Streckgrenze ..............................46

Abb. 21: Darstellung der Ergebnisse der Messgröße Maximalkraft............................46

Abb. 22: Darstellung der Ergebnisse des Messparameters Weichteil-Dichte ..............47

Abb. 23: Darstellung der Ergebnisse des Messparameters Weichteil-Volumen ..........48

Abb. 24: Darstellung der Ergebnisse des Messparameters Kortikalis-BMD ...............48

Abb. 25: Darstellung der Ergebnisse des Messparameters Kortikalis-Volumen.........49 
Abb. 26: Darstellung der Ergebnisse des Messparameters Kallus-BMD . 49

Abb. 27: Darstellung der Ergebnisse des Messparameters Kallus-Volumen ... .50

Abb. 28: Darstellung der Ergebnisse des Messparameters Knochen-BMD . 51

Abb. 29: Darstellung der Ergebnisse des Messparameters Knochen-Volumen ..... 51

Abb. 30: Darstellung der Ergebnisse des Messparameters gesamtes Gewebe Dichte 52

Abb. 31: Darstellung der Ergebnisse des Messparameters gesamtes Gewebe Volumen. 52

Abb. 32: Darstellung der Ergebnisse des Messparameters Bone Volume/ Tissue Volume. .53

Abb. 33: NON OVX; repräsentative Mikroradiographie .54

Abb. 34: OVX; repräsentative Mikroradiographie .54

Abb. 35: $1 \mathrm{mg}$ Baicalein; repräsentative Mikroradiographie .54

Abb. 36: 10 mg Baicalein; repräsentative Mikroradiographie. 54

Abb. 37: 100 mg Baicalein; repräsentative Mikroradiographie. .54

Abb. 38: Darstellung der Ergebnisse des Messparameters Kortikalis-Dicke distal plattennah .55

Abb. 39: Darstellung der Ergebnisse des Messparameters Kortikalis-Dicke distal plattenfern

Abb. 40: Darstellung der Ergebnisse des Messparameters Kortikalis-Dichte distal plattennah

Abb. 41: Darstellung der Ergebnisse des Messparameters Kortikalis-Dichte distal plattenfern .56

Abb. 42: Darstellung der Ergebnisse des Messparameters Kallus-Dicke plattennah..57

Abb. 43: Darstellung der Ergebnisse des Messparameters Kallus-Dicke plattenfern .57 Abb. 44: Darstellung der Ergebnisse des Messparameters Kallus-Dichte plattennah.58 Abb. 45: Darstellung der Ergebnisse des Messparameters Kallus-Dichte plattenfern 59 Abb. 46: Darstellung der Ergebnisse des Messparameters Kallus-Dichte endostal ....59

Abb. 47: NON OVX; repräsentative polychrome Sequenzmarkierung. 61

Abb. 48: OVX; repräsentative polychrome Sequenzmarkierung 61

Abb. 49: $1 \mathrm{mg}$ Baicalein; repräsentative polychrome Sequenzmarkierung.. 61

Abb. 50: $10 \mathrm{mg}$ Baicalein; repräsentative polychrome Sequenzmarkierung 61

Abb. 51: $100 \mathrm{mg}$ Baicalein; repräsentative polychrome Sequenzmarkierung. . .61

Abb. 52: Darstellung der Ergebnisse der Messgröße Gesamtfläche Kallus 
plattennah...... .62

Abb. 53: Darstellung der Ergebnisse der Messgröße CG-Kallus-Fläche plattennah...63

Abb. 54: Darstellung der Ergebnisse der Messgröße AK-Kallus-Fläche plattennah ..63

Abb. 55: Darstellung der Ergebnisse der Messgröße Gesamtkallus-Fläche plattenfern 64

Abb. 56: Darstellung der Ergebnisse der Messgröße CG- Kallus-Fläche plattenfern .64 Abb. 57: Darstellung der Ergebnisse der Messgröße AK-Kallus-Fläche plattenfern..65 Abb. 58: Darstellung der Ergebnisse der Messgröße Gesamtfläche Kallus endostal..66 Abb. 59: Darstellung der Ergebnisse der Messgröße CG-Kallus-Fläche endostal ......66 Abb. 60: Darstellung der Ergebnisse der Messgröße AK-Kallus-Fläche endostal......67 Abb. 61: Darstellung der Ergebnisse der Messgröße Gesamtfläche kompletter Kallus . .67 


\section{Abkürzungsverzeichnis}

\begin{tabular}{|c|c|}
\hline $\mathrm{AK}$ & Alizarinkomplexon \\
\hline ANOVA & Analysis of Variance \\
\hline ATP & Adenosintriphosphat \\
\hline $\mathrm{AZ}$ & Aktenzeichen \\
\hline BAP & Bone Alkaline Phosphatase \\
\hline BMD & Bone Mineral Density \\
\hline BMI & Body Mass Index \\
\hline BMP & Bone Morphogenetic Protein \\
\hline BMU & Basic Multicellular Unit \\
\hline BSG & Blutsenkungsgeschwindigkeit \\
\hline $\mathrm{CG}$ & Calcein-Grün \\
\hline COPD & Chronisch obstruktive Lungenerkrankung \\
\hline $\mathrm{COX}$ & Cyclooxygenase \\
\hline CT & Computertomographie \\
\hline DMSO & Dimethylsulfoxid \\
\hline DVO & Dachverband Osteologie \\
\hline DXA & Dual-X-ray-Absorptiometrie \\
\hline FBP & Filtered Back Projection \\
\hline FGF & Fibroblast Growth Factor \\
\hline FRAX $®$ & Fracture Risk Assessment Tool \\
\hline FOV & Field of View \\
\hline g-GT & Gamma-Glutamyl-Transferase \\
\hline GVal & GValue \\
\hline $\mathrm{h}$ & Stunde \\
\hline $\mathrm{H}^{+}$ & Wasserstoffion \\
\hline hs-CRP & Hochsensitives C-reaktives Peptid \\
\hline $\mathrm{HU}$ & Hounsfield Unit \\
\hline $\mathrm{IE}$ & Internationale Einheit \\
\hline IGF & Insuline-like Growth Factor \\
\hline $\mathrm{IgG} 2$ & Imunnglobulin G; Subklasse 2 \\
\hline
\end{tabular}




\begin{tabular}{|c|c|}
\hline IL & Interleukin \\
\hline Konz. & Konzentration \\
\hline $\mathrm{kVp}$ & Kilovoltpeak \\
\hline Max. & Maximum \\
\hline M-CSF & Monozytenkolonien-stimulierender Faktor \\
\hline mGy & Milligray \\
\hline$\mu \mathrm{A}$ & Mikroampere \\
\hline $\mathrm{N}$ & Newton \\
\hline $\mathrm{NaCl}$ & Natriumchlorid \\
\hline $\mathrm{NF}-\kappa \mathrm{B}$ & Nuclear factor kappa-light-chain-enhancer of activated B-cells \\
\hline NHANES & National Health and Nutrition Examination Survey \\
\hline $\mathrm{NIH}$ & National Institutes of Health \\
\hline NON OVX & Nicht-ovarektomiert \\
\hline $\mathrm{OP}$ & Operation \\
\hline OPG & Osteoprotegerin \\
\hline Osteo & Osteotomie \\
\hline OVX & Ovarektomie \\
\hline PDGF & Platelet Derived Growth Factor \\
\hline $\mathrm{pH}$ & potentia hydrogenii \\
\hline PTH & Parathormon \\
\hline QCT & Quantitative Computertomographie \\
\hline RANK & Receptor Activator of NF- $\kappa \mathrm{B}$ \\
\hline RANKL & Receptor Activator of NF- $\kappa \mathrm{B}$ Ligand \\
\hline rhPTH & Rekombinantes humanes Parathormon \\
\hline s.c. & subcutan \\
\hline SERM & selektiver Östrogen-Rezeptor-Modulator \\
\hline SOTI & Spinal Osteoporosis Therapeutic Intervention \\
\hline TGF- $\beta$ & Transforming Growth Factor beta \\
\hline TNF- $\alpha$ & Tumornekrosefaktor alpha \\
\hline TRAP & Tartrate-resistent Acid Phosphatase \\
\hline TROPOS & Treatment of Peripheral Osteoporosis \\
\hline WHO & World Health Organisation \\
\hline $\mathrm{XO}$ & Xylenolorange \\
\hline
\end{tabular}




\section{Einleitung}

\subsection{Einführung in das Thema und Fragestellung}

Osteoporose kann mittlerweile als globale Herausforderung im medizinischen und gesundheitsökonomischen Sektor betrachtet werden. Im Rahmen des „,WHO Scientific Group Technical Report" wird die Zahl der von Osteoporose Betroffenen auf 200 Millionen weltweit geschätzt [Kanis 2007], wovon sich 49 Millionen in Industriestaaten befinden [Wade et al. 2014]. Es ist anzunehmen, dass 40\% aller Frauen in ihrem Leben einmal eine Fragilitäts-Fraktur auf Grund osteoporotischer Veränderungen erleiden werden [Chapurlat 2008]. Damit ist das Risiko einer 50-Jährigen, eine Osteoporose-induzierte Fraktur zu erleiden, höher, als das Risiko, eine atherosklerotische kardiovaskuläre Erkrankung (4,1\%- 30,7\% abhängig vom Riskoprofil) oder Brustkrebs (etwa 11\%) zu entwickeln [Bleibler et al. 2014]. Patienten sehen sich nach einem Frakturereignis mit einer deutlichen Mobilitätseinschränkung, verminderter gesundheitsbezogener Lebensqualität und erhöhter Mortalität konfrontiert. Als Konsequenz des progredienten demographischen Wandels in Deutschland wird auch die sozioökonomische Belastung im Zusammenhang mit dem Krankheitsbild Osteoporose steigen. Im Jahr 2010 wurde die Zahl der osteoporotischen Frakturen unter Frauen ab 50 Jahren in Deutschland auf 349.560 geschätzt. Mit einem prognostizierten Bevölkerungswachstum von 13,1\% bis 2020 ginge folglich eine Steigerung der Fraktur-Rate um 15,2 \% einher [Gauthier et al. 2012]. Für eine 50-jährige Osteoporose-Patientin sind die lebenslangen Kosten einer Frakturbehandlung 3,3-mal so hoch wie die Frakturkosten einer gesunden, gleichaltrigen Frau [Bleibler et al. 2014]. Diese Daten demonstrieren die immense Bedeutung einer effektiven Therapie Osteoposroseassoziierter Frakturen. Der Fokus aktueller Studien liegt allerdings vorrangig auf der Prävention dieser Frakturereignisse. Verschiedene therapeutische Ansätze zur Optimierung der Frakturheilung sehen die Applikation von rekombinanten Wachstumsfaktoren wie PDGF [Hollinger et al. 2008], oder die Gen-Therapie [Egermann et al. 2005] vor. Einige dieser Strategien scheitern allerdings im klinischen Gebrauch an Produktions-Problemen und mangelhafter Kosteneffektivität. Daher gilt es, neue Methoden zur kostenwirksamen und nachhaltigen Verbesserung der Frakturheilung von Osteoporose-Patienten zu etablieren.

Das Ziel dieser Arbeit ist es, den Lipoxygenase-Inhibitor Baicalein als neue Therapieoption zu evaluieren. Es wird der Effekt auf die metaphysäre Frakturheilung der Tibia an ovarektomierten Ratten untersucht. Für das Flavonoid Baicalein ist bereits eine anti-inflammatorische sowie anti-kanzerogene Wirkung bestätigt [Chen et al. 2013; Gandhi 2013; Zhang et al. 2013]. Die 
Applikation von Baicalein im Rattenmodell wird als reproduzierbar und wirkungsvoll eingestuft, da der Metabolismus des Medikaments und seiner Metabolite experimentell detailliert untersucht wurde [Akao et al. 2013; Tong et al. 2012; Wang et al. 2012].

\subsection{Knochen}

Der Knochen als Stützgewebe des Körpers zeichnet sich durch verschiedene essenzielle Eigenschaften aus: Druckfestigkeit, erreicht durch einen hohen Anteil an Kalzium-PhosphatKristallen (Hydroxylapatit), und Elastizität, ermöglicht durch ein trajektionell strukturiertes System aus Kollagenfibrillen. Als das größte Reservoir für Mineralien bildet die Knochenmatrix einen Speicher für nahezu das gesamte Kalzium im menschlichen Körper, welches sich abhängig von der Körpergröße auf 1-2 kg beläuft [Welsch 2010], 85\% des Phosphats und 50\% des Magnesiums [Bartl 2011].

Die Knochensubstanz besteht zu 45\% aus Mineralien, zu 30\% aus organischem Material und zu 25\% aus Wasser [Lüllmann-Rauch 2012]. Die Zusammensetzung der Knochenmatrix ist stark von hormonalen, nutritiven und metabolischen Faktoren abhängig.

Die Makrostruktur des Knochens richtet sich nach der Zugehörigkeit zum appendikulären Skelett der langen Röhrenknochen in den Extremitäten beziehungsweise zum axialen Skelett der Wirbelsäule, des proximalen Femurs, der Rippen und des Beckens. Die Röhrenknochen setzten sich aus dem Schaft (Diaphyse), den Enden (Epiphysen) und den Abschnitten dazwischen (Metaphysen) zusammen.

Im Allgemeinen differenziert man zwischen Lamellenknochen, welcher bei Erwachsenen überwiegt und Geflechtknochen. Die Außenschicht (Kortikalis) des Lamellenknochens wird durch die Substantia compacta gebildet, welche einen soliden Gewebeverband darstellt. Meist beläuft sich die Kortikalisdicke auf 0,5-3 mm, sie kann aber gegebenenfalls auch $15 \mathrm{~mm}$ ausmachen (Femur) [Drenckhahn und Kugler 2008]. Der so genannte spongiöse Knochen (Substantia spongiosa) beschränkt sich auf das Knocheninnere und bildet ein gitterartiges Trabekelgerüst mit einer mittleren Dicke von 0,2 mm [Drenckhahn und Kugler 2008]. Das Endost kleidet die große Oberfläche der Spongiosa aus, während die Kortikalis von Periost überzogen ist. Die Kompakta ist in Knochenlamellen organisiert.

Im Gegensatz zum Lamellenknochen wird der Geflechtknochen vor allem während der Knochenentstehung und der Frakturheilung gebildet. Statt einer Lamellenstruktur besteht der Geflechtknochen aus unstrukturiert verflochtenen Kollagenfasern. Im adulten Organismus findet man diese Knochendifferenzierung nur noch im Felsenbein, in bestimmten Bereichen der Schädelknochen und im neu gebildeten Kallus im Falle einer sekundären Frakturheilung (vgl. 1.4.3.2). 


\subsubsection{Knochenzellen}

\subsubsection{Osteozyten}

Osteozyten sind endgültig ausdifferenzierte, von mineralisierter Knochenmatrix umgebene Osteoblasten, die sich von multipotenten mesenchymalen Stammzellen des Knochenstromas ableiten [Bartl 2011]. Die noch unvollständig geklärte Aufgabe der Osteozyten scheint in der Erhaltung der Knochenmatrix zu liegen. Außerdem fungieren sie als Mechanosensoren, welche durch mechanische Beanspruchung ausgelöst werden und über eine Signalkaskade mit den Osteoblasten an der Oberfläche des Knochens in Verbindung stehen [Lüllmann-Rauch 2011]. Weiterhin wurde beschrieben, dass das druch Osteozyten produzierte Glykoprotein 130 für die Parathormon-induzierte Osteoblasten-Differenzierung benötigt wird [Standal et al. 2014]. Ferner können Osteozyten eine unterstützende Funktion bei der Knochenheilung einnehmen, da sie die Rekrutierung von Osteoklasten-Vorläuferzellen am Ort des Umbaus induzieren [Wu et al. 2014].

\subsubsection{Osteoblasten}

Die mesenchymalen Osteoblasten fungieren als Knochenbildner sowohl in wachsenden als auch in reifen Knochen. Die Zellen sezernieren aktiv Kollagen, Proteoglykane, Osteocalcin, Osteonectin, BMP und weitere Proteine sowie Wachstumsfaktoren. Stimuliert wird die Knochenproduktion mittels IGFs, TGF- $\beta$, FGFs, PDGF, BMPs, Prostaglandinen, Fluoriden, Statinen, Strontium und Parathormon, während Leptin die Osteoblasten hemmt [Bartl 2011]. Die durch Osteoblasten produzierte, zunächst unverkalkte Matrix wird als Osteoid bezeichnet und bedeckt 10-15\% der Oberfläche eines adulten Knochens [Welsch 2010]. Die Anlagerung des Osteoids erfolgt appositionell, also an die vollständig mineralisierte Matrix, entweder im Inneren des Knochens oder unter dem Periost. Dabei stellt die alkalische Phosphatase anorganisches Phosphat bereit und spaltet gleichzeitig Pyrophsophat, welches hemmend auf die Mineralisation wirken würde [Lüllmann-Rauch 2012]. Weiterhin sind Osteoblasten unabdingbar für die Aktivierung der Osteoklasten, induziert durch Parathormon, und damit des Knochenabbaus. Im Folgenden gehen die Osteoblasten entweder apoptotisch zu Grunde oder differenzieren sich zu Osteozyten im Ruhezustand, so genannten bone-lining cells.

\subsubsection{Osteoklasten}

Osteoklasten sind mehrkernige Riesenzellen, die sich von den Monozyten des Knochenmarks ableiten. Es entstehen zunächst einkernige Osteoklastenvorläuferzellen, welche unter Einfluss von Vitamin D3, RANKL sowie IL 1 und IL 6 zu den reifen Osteoklasten fusionieren. Deren Funktion besteht vor allem im Abbau der mineralisierten Knochenmatrix. Abschließend erfolgt 
die Endozytose der Matrix-Fragmente. Sämtliche Funktionen sowie Proliferation, Differenzierung und Überleben der Osteoklasten werden durch M-CSF gesteuert, welches als essenzieller Induktor für RANK fungiert [Boyce 2013]. Osteoklasten weisen unterschiedliche Aktivitätszyklen auf und gehen zumeist nach 2-wöchiger Tätigkeit apoptotisch zugrunde [Lüllmann-Rauch 2012].

\subsubsection{Knochenumbau}

Das bone remodelling findet das gesamte Leben lang statt. Ausgelöst wird es durch die mechanosensitiven Osteozyten, die eine Belastungsänderung wahrnehmen. Jährlich findet ein Umsatz von 18\% des gesamten Skelettkalziums statt [Welsch 2010]. Der Knochenumbau läuft in Zyklen von etwa 120 Tagen ab [Bartl 2011] und dient mehreren Zielen: der Bereitstellung von Kalzium, Reparatur von Mikroschäden, Adaptierung der Kompakta- und SpongiosaArchitektur an aktuelle Belastungen sowie der Vorbeugung der Materialermüdung. Den Umbau führt eine Einheit von Osteoblasten und Osteoklasten aus (basic multicellular unit), die im Sinne eines Bohrkopfes voranschreiten. Die Zusammenkunft dieser Einheiten wird durch viele Faktoren, wie Sphingosin-1-Phosphat, Ephrine und IL-6, gesteuert [Sims et al. 2013]. In der Kompakta entspricht der durch die Osteoklasten gefressene Bohrkanal den zukünftigen Osteonen. Jährlich werden ungefähr 25\% des spongiösen Knochens umgebaut, während nur 2,5\% des kortikalen Knochenanteils einem Remodelling unterliegen. Ein Knochenschwund, der aus einer negativen Bilanz zwischen Knochenabbau und Aufbau resultiert, konzentriert sich demnach vorerst auf Knochen mit einem hohen Spongiosaanteil, wie die Lendenwirbelsäule und das proximale Femur [Bartl 2011].

\subsubsection{Regulierung des Knochenumbaus}

Die Koordination von Osteoblasten und Osteoklasten unterliegt einer komplexen Interaktion verschiedener Faktoren. Eine zentrale Rolle spielt das RANKL-OsteoprotegerinZytokinsystem [Bartl 2011]. Osteoprotegerin, ein Mitglied der TNF-Rezeptor-Superfamilie, sezerniert durch Osteoblasten, inhibiert die Differenzierung der Osteoklasten aus Progenitorzellen und hemmt damit die Knochenresorption. Der Receptor Activator of $N F-\kappa B-$ Ligand (RANKL), ein membranständiges Protein der Osteoblasten, stimuliert über seinen zellulären Rezeptor (RANK) die Osteoklastendifferenzierung. Osteoprotegerin fungiert als Köder-Rezeptor für RANKL und verhindert damit seine Bindung an RANK. Während Parathormon und Glukokortikoide zu einer erhöhten RANKL- und einer verminderten OPGProduktion führen, bewirken TGF- $\beta$ und Östrogen eine forcierte OPG-Produktion. Auch Vitamin D3 verstärkt die Herstellung von RANKL [Leibbrandt et al. 2008]. Im Falle eines 
Ungleichgewichtes zwischen aktivierend und inhibierend wirkenden Faktoren im RANKLOPG-Zytokinsystem kann es, zum Beispiel durch Östrogenmangel, zu einer negativen Bilanz des Knochenumsatzes und dadurch zu einer Abnahme der Knochemasse kommen [LüllmannRauch 2012].

\subsection{Osteoporose}

\subsubsection{Definition Osteoporose}

Die weithin anerkannte Definition der Osteoporose wurde durch das NIH Consensus Development Panel on Osteoporosis im Jahr 2001 formuliert: „Die Osteoporose ist eine systemische Skeletterkrankung, die durch eine niedrige Knochenmasse und eine Verschlechterung der Mikroarchitektur des Knochengewebes charakterisiert ist, mit der Folge vermehrter Knochenbrüchigkeit.“ [Bartl 2011].

Bezieht man sich auf die WHO Kriterien ist die Osteoporose definiert als eine Knochenmineraldichte (bone mineral density (BMD)) die 2,5 Standardabweichungen oder mehr unter dem statistischen Mittelwert für junge gesunde Frauen liegt. Diese Einteilung bezeichnet man als T-Score. Die BMD wird dabei unter Zuhilfenahme des Dual Energy X-ray Absorptiometry (DXA) gemessen (DXA-Methode). Die WHO empfiehlt den T-Score sowohl als Kriterium für die pharmazeutische Intervention als auch als Eintrittsbeschränkung in therapeutische Studien [WHO 2004].

\subsubsection{Einteilung der Osteoporose}

Die Osteoporose lässt sich in zwei große Formenkreise differenzieren. Zur Primären Osteoporose zählen sowohl die juvenile und die postmenopausale als auch die Altersosteoporose. Andere Ausprägungen, wie die Steroid- und Inaktivitätsosteoporose, und die durch Hyperthyreose, Hypogonadismus, Thyreoidektomie, Magenresektion und Medikamente verursachte Osteoporose werden als sekundäre Osteoporose definiert.

Die postmenopausale Osteoporose stellt dabei wahrscheinlich die häufigste Erkrankung des skelettalen Systems dar und ist vorrangig bei Frauen jenseits des 50.-60.-Lebensjahres zu finden. Ab dem 60. Lebensjahr ist etwa jede fünfte Frau von der Krankheit betroffen [Moch et al. 2008]. Während die postklimakterische Osteoporose meist als Typ I definiert wird, wird die altersbedingte oder senile Involutionsosteoporose als Typ II bezeichnet.

Sie sekundären Osteoporoseformen haben meist gemischte Ursachen und machen lediglich 5\% der Osteoporosefälle aus [Bartl 2011]. 


\subsubsection{Epidemiologie}

Die Einstufung der Osteoporose als eine der 10 wichtigsten Volkskrankheiten durch die WHO verdeutlicht das globale Ausmaß dieser Erkrankung [Bartl 2011]. Weltweit sind 200 Millionen Menschen an Osteoporose erkrankt [Kanis 2007]. In Europa sind Schätzungen zufolge 22 Millionen Frauen und 5,5 Millionen Männer von Osteoporose betroffen [Hernlund et al 2013]. Vor dem Hintergrund der WHO-Definition der Osteoporose mithilfe einer erniedrigten Knochenmineraldichte (DXA T-Score < -2,5) liegt laut dem Entwurf der aktuellen DVOLeitlinien bei etwa 15\% der postmenopausalen Frauen im Alter von 50-60 Jahren Osteoporose vor. In der Altersgruppe der über 70-jährigen Frauen sind 45\% von Osteoporose betroffen, während 2,4\% der Männer zwischen 50 und 60 Jahren und 17\% der Männer über 70 Jahren an osteoporotischen Veränderungen im Schenkelhals leiden [DVO 2014]. Bereits jede 2. Frau und jeder 5. Mann erleiden im Leben eine Fraktur, die auf Osteoporose zurückzuführen ist [Kampmann 2008]. Im Durchschnitt treten erste Wirbelbrüche bei Frauen 5-10 Jahre nach Beginn der Menopause auf [Scharf et al. 2011].

In der Altersgruppe der über 50-Jährigen in Deutschland liegt die Osteoporose Inzidenz insgesamt bei 2.1\%. Die Zahl der Neuerkrankungen in Deutschland beläuft sich laut der Bone Evaluation Study auf 885000 jährlich, während 6,3 Millionen Menschen im Jahr 2009 bereits erkrankt waren [Hadji et al. 2009].

\subsection{4 Ätiologie und Pathogenese der primären Osteoporose}

\subsubsection{Postmenopausale Osteoporose (Typ I)}

Diese Form der Osteoporose ist die häufigste und tritt bereits perimenopausal auf. Daher sind vorrangig Frauen ab dem 50.-60. Lebensjahr betroffen [Moch et al. 2008]. Der Abbau des kortikalen Knochens findet bei postklimakterischen Frauen mit einer Rate von 2-3\% jährlich statt. Dieser Abbau tritt zusätzlich zu einer ohnehin altersabhängig einsetzenden sukzessiven Knochenreduktion von 0,3-0,5\% im Jahr nach Überschreiten des 50. Lebensjahres ein. Bereits altersbedingt erfolgt ein Verlust der Knochenmasse von ungefähr 50\% im Vergleich zum Knochenstatus im 3. Lebensjahrzehnt. Der 5-10 Jahre früher beginnende Abbau von spongiösem Knochen beläuft sich postmenopausal auf 4-8\%. Diese Vorgänge in beiden Knochenteilen kommen aber nach 5-10 Jahren zum Ende [Niethard et al. 2009].

Der Östrogenausfall führt bei den Betroffenen zur Vermehrung von Zytokinen wie IL-6 und infolgedessen zu gesteigerter Osteoklasten-Aktivität und -Rekrutierung. Zusätzlich steigt die Sensibilität für das resorptiv wirkende Parathormon [Bartl 2011]. Kommt es dann auf Grund der Nettoresorptionserhöhung zu einer negativen Knochenbilanz, entsteht Osteoporose. 
Messungen zeigen, dass das die RANKL-RANK-OPG Achse eine übergeordnete Rolle in der Pathogenese der Osteoporose spielt (vgl. 1.2.2.1). Sowohl die Biomarker RANKL, RANK und Osteoprotegerin, als auch IL-6 sind bei Osteoporose Patientinnen signifikant erhöht [Jabbar et al. 2011]. Diese Zytokine können also als Indikatoren für eine verringerte BMD verwendet werden.

Der konsekutive Knochenschwund macht sich vorerst als Spongiosaverlust bemerkbar, der vor allem im spongiosareichen Wirbelkörper und im Oberschenkelknochen eine Neigung zu Frakturen auch ohne adäquates Trauma hervorruft.

Gegenüber Männern kommen bei Frauen verstärkende Faktoren, wie eine generell geringere Konzentration des aktiven Vitamin $\mathrm{D}\left(1,25(\mathrm{OH})_{2}\right.$-Vitamin- $\left.\mathrm{D}_{3}\right)$ durch verringerte renale Synthese und eine reduzierte Kalziumresorption im Gastrointestinal Trakt hinzu [Enderle et al. 2003].

\subsubsection{Senile Involutionsosteoporose (Typ II)}

Diese Art der Osteoporose ist vergleichbar mit der altersbedingten Atrophie verschiedener Organe. Pathogenetisch kommt es zu einer verringerten Osteoblastenaktivität. Auf Grund der verminderten Neubildung von Knochenmasse kommt es langfristig zu einem Knochenschwund. Ursächlich zeigen sich bei dieser Altersosteoporose vor allem die Immobilität und ein sekundärer Hyperparathyreoidismus, als Folge der verschlechterten Nierenfunktion und dem daraus resultierenden tubulären Kalzium-Verlust, sowie der verringerten enteralen Kalzium-Resorption. Diese Vorgänge beruhen auf der verminderten Vitamin-D-Hydroxylierung in der Niere [Moch et al. 2008]. Die Typ II-Osteoporose tritt bei Frauen doppelt so häufig auf wie bei Männern und beginnt ab dem 70. Lebensjahr [Bartl 2011].

\subsubsection{Risikofaktoren für Osteoporose und osteoporotische Frakturen}

\subsubsection{Nicht modifizierbare Risikofaktoren}

Der typische Risikopatient entspricht wohl einer schlanken, hellhäutigen Frau mit geringer körperlicher Aktivität und wenig Sonnenexposition. Die Patientin ernährt sich Kalzium- und Vitamin-D-arm, raucht und hat mehrere Kinder gestillt.

Wie bereits beschrieben, spielen sowohl das Geschlecht, als auch das Alter eine entscheidende Rolle bei der Abschätzung des Risikos einer Osteoporose (vgl. 1.3.4.1 und 1.3.4.2). Der vorrangige Risikofaktor bei Frauen besteht im Östrogenmangel nach den Wechseljahren. Im Alter kommen Kalzium-Verlust in Niere und Darm sowie Immobilität hinzu.

Abgesehen davon bestimmen genetische Faktoren das Osteoporose-Risiko in großem Ausmaß. Daher wird eine proximale Femur Fraktur in der Anamnese der Eltern als prognostisch 
relevante Größe für das Osteoporose-Risiko angesehen [Bartl 2011]. Basierend auf Zwillingsund Familienstudien wurde die Aussage getroffen, dass die interindividuell variierende BMD in 50-85\% der Fälle durch genetische Faktoren determiniert ist [Sobieszczanska et al. 2013]. Relevant sind auch die Allele für Gene des Östrogenrezeptors, des Vitamin D und solche, die den Kollagenstoffwechsel steuern [Seebach und Marzi 2011]. Die Aberrationen sind auf etwa 20 Millionen bisher bekannte Polymorphismen im menschlichen Genom zurückzuführen [Ralston et al. 2010]. Tatsächliche Folge einer Mutation in einem einzigen Gen sind allerdings nur die seltenen und schweren Formen der Osteoporose wie Osteogenesis imperfecta, Osteopetrose, Sclerosteose und Knochenschwund ausgelöst durch eine Östrogen-RezeptorDefizienz.

Als weitere nicht beeinflussbare Risikofaktoren sind Gravidität und Stillzeit zu erwähnen. Während der Laktationszeit verliert die Mutter circa 300-400 mg Kalzium pro Tag. Ein Großteil dieser Menge wird nach dem Abstillen wieder zurückgewonnen. Wird die Stillzeit eines Kindes über ein Jahr hinaus verlängert, steigt das Osteoporose-Risiko allerdings signifikant an [Okyay et al. 2013]. Zusätzlich dazu erhöht die in der Schwangerschaft zuletzt unvermeidbare Immobilität den Knochenabbau.

\subsubsection{Modifizierbare Risikofaktoren}

$\mathrm{Zu}$ den multiplen beeinflussbaren Größen, die eine Osteoporose forcieren können, gehört zweifellos das Körpergewicht. Es wurde gezeigt, dass untergewichtige Frauen (BMI <20) ein gesteigertes Risiko für osteoporotische Frakturen haben. Bei Patientinnen die an Anorexia Nervosa leiden, kann eine signifikante Veränderung des Östrogen-Spiegels und Hypogonadismus nachgewiesen werden [Nachtigall et al. 2013]. Dies hat einen ähnlichen Effekt auf den Knochen wie die Stoffwechselumstellung postmenopausaler Frauen. In einer Studie wurden Frauen ab dem 40. Lebensjahr untersucht. Während 52,1\% der untergewichtigen Frauen an einem osteoporotisch veränderten Femurhals litten, belief sich diese Zahl unter den Normalgewichtigen nur auf 20,3\% und unter den Übergewichtigen lediglich auf 15,7\%. Unter den adipösen Patientinnen betrug der Prozentsatz nur 9,4\% [Rithirangsriroj et al. 2012].

Des Weiteren stellt chronischer Bewegungsmangel einen großen Risikofaktor für Osteoporose dar. Sportliche Aktivität führt bei präpubertären Kindern zu einem Zuwachs an Knochenmasse von 4-5\% [Nachtigall et al. 2013]. Der knochenaufbauende Osteoblastenreiz durch Komprimierung der Trabekel fällt bei fehlender Bewegung weg und hat dadurch eine negative Knochenbilanz zur Folge [Seebach und Marzi 2011].

Die Ernährung nimmt ebenfalls eine große Rolle in der Beeinflussung des Knochenstoffwechsels ein. Sowohl der Kalzium-, als auch der Vitamin-D-Spiegel sind oft zu 
niedrig bei Frauen aller Altersgruppen. In einer Studie wurde ermittelt, dass $84 \%$ der Patienten in Deutschland insuffiziente $(20-30 \mathrm{ng} / \mathrm{ml})$ Vitamin-D-Spiegel aufweisen. Außerdem ist eine Hypovitaminose D unter Patienten mit Fettleibigkeit, Bluthochdruck und Osteoporose wahrscheinlicher [Maier et al. 2013]. Dies führt zur Mobilisierung von Kalzium aus dem Knochenspeicher mittels Parathormon und damit zu einem Abbau der Knochensubstanz.

Die DVO sieht Nikotinkonsum und COPD ebenfalls als Risiko3faktoren für Osteoporose an [DVO 2014; Ogura-Tomomatsu et al. 2012]. Während das Risiko für eine Hüftfraktur bei Raucherinnen im 50. Lebensjahr noch dem der Nicht-Raucherinnen entspricht, steigt deren Risiko gegenüber dem der nicht-rauchenden Frauen im 60. Lebensjahr auf $17 \%$ und mit dem 80. Lebensjahr sogar auf 71\% [Law et al. 1997].

Die DVO-Leitlinien von 2014 beschreiben weitere Risikofaktoren wie Homozystein-, Folsäure- und Vitamin B12-Mangel, das hochsensitive C-reaktive Peptid (hs-CRP) als Marker für niedrigtraumatische Frakturen, sowie eine hohe Kadmiumzufuhr [DVO 2014].

\subsubsection{Klinik der Osteoporose}

Das Leitsymptom der Osteoporose ist der akute Rückenschmerz, welcher sich meist im Zusammenhang mit einer Fraktur oder Wirbelkörpersinterung mit subperiostaler Einblutung zeigt. Dieser akute Schmerz tritt meist auf Höhe der Wirbel Th 11-12 auf, während chronische Schmerzen sich eher auf die Lendenwirbelsäule beschränken.

Die osteoporotisch bedingten Hauptfrakturen sind Wirbelkörperfrakturen, proximale Femurfrakturen, distale Radiusfrakturen und Humerusfrakturen. Die Inzidenz der nicht vertebralen Frakturen in Deutschland liegt in der Altersgruppe von 50-79 bei 1,9\% für Frauen und $0,7 \%$ für Männer. Vertebrale Frakturen kommen mit einer Häufigkeit von $1 \%$ bei Frauen und $0,6 \%$ bei Männern vor [DVO 2014].

Im Zuge der Hyperkyphose und Hyperlordose, die durch die osteoporotische Deformierung der Wirbelsäule entsteht, kann man das so genannte „Tannenbaumphänomen“ beobachten, da schräg vom Rücken zu den Flanken verlaufende Hautfalten auftreten [Grifka und Kuster 2011]. Weiterhin zeigt sich ein hervorstehender Bauch durch Ausweichen des Abdomens als Folge der Reduktion der Körpergröße [Niethard et al. 2009]. Als kissing spine bzw. Baastrup-Zeichen wird das schmerzhafte Berühren der Processus spinosi der Wirbelkörper bezeichnet [Bartl 2011]. Mit diesen anatomischen Veränderungen geht auch die Verschlechterung der pulmonalen Vitalparameter einher [Dimai 2009].

Ein weiteres klinisches Zeichen für Osteoporose können Zahnschmerz und Zahnausfall bedingt durch die degenerativen Veränderungen des Alveolarknochens sein [Bartl 2011]. 


\subsubsection{Diagnostik der Osteoporose}

Die grundlegende Diagnostik der Osteoporose stützt sich auf die folgenden fünf Säulen. Zu diesen gehört vorerst die Anamnese in Begleitung mit der Risikoerfassung, weiterhin die klinische Untersuchung und ein konventionelles Röntgen der Brust- und Lendenwirbelsäule, eine Knochendichtemessung mittels DXA-Methode und ferner eine Laboruntersuchung. Im Zuge der Anamnese werden Risikofaktoren wie ein fortgeschrittenes Alter und das Erreichen der Wechseljahre sowie der Ernährungsstatus und das Körpergewicht, die Einnahme Osteoporose-begünstigender Medikamente (Glitazone, Aromatasehemmer, Protonenpumpenhemmer) und Grunderkrankungen (Morbus Cushing) erfasst.

In der Osteoporose-Diagnostik hat ein Werkzeug zur Abschätzung des 10-Jahres-Frakturrisikos einen besonderen Stellenwert eingenommen, welches auf den individuellen Risikofaktoren und den Frakturinzidenz-Daten der eigenen Bevölkerungsgruppe basiert [Dimai 2009]. FRAX® ist ein computergestützter Algorithmus, der durch die WHO eingeführt wurde, um die TherapieEntscheidung eines Osteoporose Patienten nicht alleine auf Grund der BMD treffen zu müssen [Silverman et al. 2014].

Die Knochendichtemessung (Osteodensitometrie) wird mit Hilfe der Dual-RöntgenAbsorptiometrie (DXA) vorgenommen, die zur klaren Abgrenzung unterschiedlicher Gewebeformen geeignet ist und als Goldstandard gilt [Blake und Fogelman 2009].

Die Röntgenuntersuchung gibt Aufschluss über eine Wirbelkörperfraktur, welche mit einer Abnahme der Vorder-, Mittel-, oder Hinterkante eines Wirbels von mindestens 20\% einhergeht. Da bei 50\% der Wirbelkörperfrakturen eine BMD vorliegt, die definitionsgemäß nicht einer Osteoporose entspricht, ist eine konventionelle Röntgenaufnahme unabdingbar [Dimai 2009]. Im Zuge der Laboruntersuchung sollen hauptsächlich sekundäre Ursachen der Osteoporose ausgeschlossen werden.

\subsubsection{Therapie der Osteoporose}

Therapiebedarf besteht, wenn eine Osteoporose-induzierte Fraktur, ein T-Score von -2,0 oder weniger oder mindestens ein Risikofaktor zusammen mit einem T-Score von -1,5 oder weniger vorliegt [Scharf 2011].

\subsubsection{Basistherapie}

Grundsätzlich wird die Reduktion bzw. Vermeidung von Risikofaktoren im Rahmen einer Osteoporosetherapie empfohlen. Dementsprechend werden Einflussfaktoren wie Nikotin, Alkohol und körperliche Inaktivität verringert und protektive Größen, wie eine suffiziente 
Kalziumzufuhr mit der Nahrung (1000-1500 mg/Tag) und die Supplementierung von Vitamin D (800-1000 IE/Tag) unterstützt [DVO 2014].

Ein gutes Schmerzmanagement bei Osteoporose-Patienten ist von äußerster Wichtigkeit, da jegliche Bewegungseinschränkung eine zusätzliche Inaktivitätsosteoporose begünstigt [Nachtigall et al. 2013].

\subsubsection{Spezifische Therapie}

Die Therapieindikation für eine spezielle Pharmakotherapie der Osteoporose wird durch die DVO-Leitlinie 2014 folgendermaßen definiert:

Eine Therapie sei angezeigt in Folge einer ,[...] inadäquaten singulären Wirbelkörperfraktur 2. oder 3. Grades nach Genant (25-40\% bzw. $>40 \%$ Höhenminderung) [...] oder multiplen Wirbelkörperfrakturen 1. bis 3. Grades [...]." [DVO 2014, Seite 114]. Außerdem als Konsequenz peritrochantärer Hüftfrakturen und Frakturen des Femurhalses bei gleichzeitigem T-Score von $-2,0$ oder weniger.

Im Zuge einer prophylaktischen Therapie ohne vorangegangenes Frakturereignis, wird ,[...] ein geschätztes 10-Jahresfrakturrisiko von durchschnittlich ca. 30\% und mehr für Hüftfrakturen und vertebrale Frakturen [...]“" als Therapieindikation akzeptiert [DVO 2014, Seite 116].

Im Rahmen der Therapie postklimakterischer Patientinnen ist die fraktursenkende Wirkung dieser Medikamente am besten belegt: Alendronat, Bazedoxifen, Denosumab, Ibandronat, Östrogene, Teriparatid (rhPTH 1-34), Parathormon (PTH 1-84), Raloxifen, Risedronat, Strontiumranelat sowie Zoledronat [DVO 2014].

Daher werden diese Präparate im Folgenden kurz erläutert.

\section{a) Osteoanabole Substanzen}

$\mathrm{Zu}$ dieser Gruppe von Präparaten gehören Fluoride und Parathormon.

Fluoride unterstützen die Synthese der Knochenmatrix und die Aktivierungsfrequenz der BMUs [Dupuis et al 1994]. Die Belastbarkeit des entstandenen Knochengewebes ist allerdings mangelhaft und der Einsatz von Fluoriden umstritten [Meunier et al. 1998].

Parathormon wirkt durch Stimulierung der Osteoblasten anabol und verbessert sowohl die vertebrale, als auch die femorale BMD [Henriksen et al 2013].

\section{b) Bisphosphonate (Alendronat, Risedronat, Zoledronat, Ibandronat)}

Bisphosphonate stellen die am häufigsten verschriebene Substanzklasse in der Osteoporosetherapie dar [Eriksen et al. 2014]. Diese Präparate inhibieren die Knochenresorption durch Hemmung der Aktivierung von BMUs und Osteoklasten. 
Bisphosphonate verbessern die BMD bei gleichzeitig reduziertem Risiko für vertebrale und nicht-vertebrale Frakturen [Eriksen et al. 2014]. Allerdings haben sich Bisphosphonate bei der Fraktur-Heilung als kontraproduktiv erwiesen [Savaridas et al. 2013].

\section{c) Sexualhormonersatztherapie}

Diese Therapieoption ist gut etabliert bei der Prophylaxe Osteoporose-induzierter Frakturen, ist aber wegen des erhöhten Risikos für Thrombembolien und die Ausbildung eines MammaKarzinoms auf das Patientenkollektiv perimenopausaler Frauen beschränkt [Scharf 2011; Gurney et al. 2014].

d)Selektive Östrogen-Rezeptor-Modulatoren (SERM)

$\mathrm{Zu}$ dieser Stoffgruppe zählen Bazedoxifen und Raloxifen. Es handelt sich um Östrogenrezeptoragonisten am Knochen und im Lipidstoffwechsel, welche allerdings eine antagonistische Wirkung auf Brustgewebe und Gebärmutter haben. Damit wird die Erhöhung des IL-6 in Folge des Wegfalls von Östrogen nach der Menopause gestoppt und damit einhergehend auch der konsekutive Knochenschwund [Keck 2003].

\section{e) Kalzitonin}

Kalzitonin wird, in rekombinanter Form, vor allem wegen des schnellen Ansprechens bei Knochenschmerzen nach Wirbelkörperfrakturen eingesetzt [Binkley et al. 2012]. Das Hormon wird aus den C-Zellen der Schilddrüse sekretiert und hemmt die Osteoklastenaktivität.

\section{f) Strontiumranelat}

Strontiumranelat hat eine sowohl knochenbildende, als auch resorptionshemmende Wirkung [Grifka und Kuster 2011]. Untersuchungen im Zuge der Studien SOTI und TROPOS haben eine Reduktion des Risikos für Hüft- und Wirbelkörperfrakturen bei postmenopausalen Frauen bestätigt und eine langfristige Strontiumranelat-Therapie der chronischen Osteoporose als effektiv erwiesen [Cianferotti et al. 2013; Reginster et al. 2012].

\section{g) RANKL-Antikörper}

Denosumab ist ein humaner monoklonaler $\mathrm{IgG}_{2}$-Antikörper, der den RANK-Liganden hemmt [Grifka und Kuster 2011]. Durch die antiresorptiv wirkende Osteoklasten-Hemmung kommt es zur Erhöhung der BMD, Verbesserung der kortikalen und trabekulären Knochenstärke und einer signifikanten Reduktion des Frakturrisikos [Josse et al. 2013; Scotland et al. 2011]. 


\subsubsection{Baicalein}

Die Therapie postmenopausaler Osteoporose-Patientinnen mittels Lipoxygenase-Inhibitoren repräsentiert einen neuen Ansatz in der Osteoporose Behandlung. Lipoxygenasen sind Bestandteil des Eikosanoidstoffwechsels und katalysieren die Umsetzung von Arachidonsäure in Leukotriene. Diese Mediatoren wirken bronchokonstriktorisch und chemotaktisch auf Leukozyten.

Die Lipoxyegenasen 5, 12 und 15 werden im Zuge einer Entzündungsreaktion vermehrt exprimiert und forcieren in der Folge die Produktion der pro-inflammatorischen Zytokine IL-6 und TNF- $\alpha$ [Wen et al. 2007]. Die Konsequenz besteht in einer Abnahme der Knochendichte (vgl. 1.3.4) [Krönke et al. 2009]. Im Verlauf kommt es zu einer gesteigerten adipozytären Differenzierung der mesenchymalen Osteoblasten-Vorläuferzellen und weiterhin zu einer Induktion der Osteoklasten. Dies resultiert in einer deutlichen Reduktion der Knochenmasse [Manolagas und Jilka 1995; Krönke et al. 2009]. Bei postmenopausalen Frauen kommt es nach Abnahme des Östrogenspiegels zur Erhöhung der Zytokinexpression und folglich zu einer Verminderung der BMD [Zhao 2012]. Es wurde gezeigt, dass eine signifikante Korrelation zwischen verschiedenen Polymorphismen der 12/15-Lipoxygenase-Allele und sowohl postklimakterischer Osteopenie als auch dem Frakturrisiko und Adipositas besteht [Harsløf et al. 2011; Xiao et al. 2012]. Auf Grund des gesicherten Zusammenhangs zwischen den 5Lipoxygenasen und einer verschlechterten Frakturheilung, vermittelt durch RANKL induzierte Osteoklasten-Formierung, ist ein osteoanaboler Einfluss von Lipoxygenase-Inhibitoren auf die BMD anzunehmen [Lee et al. 2012].

Baicalein gehört zu einer Gruppe von Phytochemikalien und ist ein Flavonoid des BaikalHelmkrautes (Scrutellaria baicalensis). Für diesen selektiven 12/15-Lipoxygenase-Inhibitoren wurde eine anti-inflammatorische sowie eine anti-kanzerogene Wirkung nachgewiesen [Chen et al. 2013]. Weiterhin weist das Flavonoid antioxidative und neuroprotektive Eigenschaften auf [Ghandi 2013]. Mit Hilfe des Wnt/beta-Catenin-Signalweges wird außerdem die In-Vitro Differenzierung von Osteoblasten induziert [Kim et al. 2012].

Der Effekt selektiver Lipoxygenase-Inhibitoren auf eine manifeste Osteoporose ist hingegen nicht ausreichend geklärt. 


\subsection{Fraktur und Frakturheilung}

Da die Frakturheilung unter der Therapie mit dem Lipoxygenase-Inhibitor Baicalein im Mittelpunkt dieser Dissertation steht, werden die Grundlagen der Frakturlehre mit Fokussierung auf die osteoporotische Fraktur im Folgenden erörtert.

Eine Fraktur ist definiert als eine vollständige Unterbrechung der Kontinuität eines Knochens auf Grund einer Belastung, welche die spezifische Elastizitätsgrenze übersteigt. Demgegenüber handelt es sich bei einer Fissur lediglich um eine unvollständige Kontinuitätsunterbrechung [Niethard et al. 2009].

\subsubsection{Frakturmechanismen}

Vier verschiedene Mechanismen der Frakturentstehung können voneinander abgegrenzt werden.

Direkte Frakturen entstehen als Folge einer äußeren Gewalteinwirkung auf den Knochen, welcher exakt am Ort der Krafteinwirkung frakturiert.

Indirekte Frakturen sind Konsequenz interner Hebelkräfte durch Drehung, Biegung, Stauchung bzw. Abriss, so dass die Fraktur entfernt vom Bereich der primären Gewalteinwirkung auftritt. Ermüdungs- bzw. Stressfrakturen entstehen nach persistenter mechanischer Überlastung des Knochens zum Beispiel als Folge von sportlicher Überbeanspruchung.

Pathologische Frakturen resultieren aus der krankhaften Veränderung des Knochens nach meist inadäquater äußerer Gewalteinwirkung. Diese pathologischen Veränderungen können durch lokale Knochentumoren oder -metastasen bedingt sein oder Ergebnis einer generalisierten Skelettsystemerkrankung sein. Zu letzterer gehört auch die Osteoporose.

\subsubsection{Die osteoporotische Fraktur}

Die Osteoporose-induzierte Fraktur hat multiple Ursachen, die nicht auf die solitäre Verminderung der Knochendichte zu reduzieren sind. Über die BMD hinaus sind auch die Kontaktpunkte der Spongiosatrabekel deutlich reduziert. Weiterhin steht das Verhältnis von kompaktem und spongiösem Knochen im Ungleichgewicht. Außerdem kommt es durch die resorptive Tätigkeit der Osteoklasten zur Perforation der Trabekel und damit zu Mikrofrakturen, die der osteoporotischen Fraktur vorausgehen. Ferner bedingt ein insuffizienter Aufbau der Knochensubstanz durch sowohl mangelhafte Mineralisation der Knochenmatrix als auch unzureichende Reparaturmechanismen und fehlerhafte Kollagenproduktion ein qualitativ schlechtes Knochengewebe, was letztlich in der osteoporotischen Fraktur mündet [Bartl 2011]. Die häufigsten von Osteoporose-induzierten 
Frakturen betroffenen Knochen sind die Wirbelkörper, das proximale Femur, der distale Radius sowie der Humerus (vgl. 1.3.6).

\subsubsection{Formen der Frakturheilung}

Generell unterscheidet man zwischen einer osteonalen und nichtosteonalen Frakturheilung. Letztere ist durch eine überschießende Kallusbildung gekennzeichnet, während eine primäre Kortikalisheilung ausbleibt. Typisch ist ein langsamer Knochenumbau bei meist großem Frakturspalt. Dem steht die osteonale Frakturheilung gegenüber, die primär oder sekundär verlaufen kann.

\subsubsection{Direkte/primäre Frakturheilung}

Im Zuge dieser Frakturheilung migrieren Osteone durch den Frakturspalt direkt in das andere Fragmentende und lassen so eine Frakturheilung ohne Kallusbildung und Knochenumbau zu. Diese Kontaktheilung wird durch eine operative Osteosynthese angestrebt und benötigt eine Adaptation der Frakturenden von weniger als 1mm [Lüllmann-Rauch 2012]. Außerdem ist eine vollständige Ruhigstellung der Fragmentenden und eine genaue Reposition der Bruchfragmente vonnöten. Der Prozess streckt sich über 1-1,5 Jahre hin und resultiert in einer der wiederhergestellten Belastbarkeit des Knochens.

\subsubsection{Indirekte/sekundäre Frakturheilung}

$\mathrm{Zu}$ einer sekundären Frakturheilung kommt es bei Vorliegen eines breiteren Frakturspalts. Sie erfolgt in mehreren Phasen und ist durch die Ausbildung eines zunächst bindegewebigen Kallus charakterisiert, worauf eine osteonale Frakturheilung folgt.

\subsubsection{Frakturheilung und Osteoporose}

Die Heilung und Behandlung einer Osteoporose-induzierten Fraktur geht mit wesentlich größeren Herausforderungen einher, als die Wiederherstellung der Integrität eines grundsätzlich gesunden Knochens. Neben der verminderten Knochenqualität erschweren auch die Minderperfusion des Knochens und seines Weichteilmantels sowie die Fragilität der Knochenfragmente die Frakturversorgung [Bartl 2011]. Weiterhin können insuffiziente biomechanische Bedingungen der osteoporotischen Knochensubstanz ebenso wie systemische Entzündungen die Frakturheilung beeinträchtigen [Claes et al. 2012]. Es wurde gezeigt, dass die erste Phase der Knochenheilung bei Osteoporose zwar größtenteils mit dem Beginn des Heilungsprozesses im normalen Knochen übereinstimmt, der entstandene Kallus allerdings schlechter mineralisiert ist und mangelhafte biomechanische Eigenschaften aufweist [Augat et al. 2005]. Die BMD im Bereich des Kallus fällt bei ovarektomierten Ratten um 23\% geringer 
aus, als in der Kontrollgruppe [Namkung-Matthai et al. 2001]. Im experimentellen Versuch an ovarektomierten Schafen wurde nach der Osteotomie der Tibia eine Abnahme der Biegesteifigkeit am Kallus von 20\% nachgewiesen [Lill et al. 2003]. Weiterhin scheinen auch Alterationen in Bezug auf Wachstumsfaktoren die Heilung des osteoporotischen Knochens zu obstruieren. In der Umgebung der Trabekel am Frakturort wurde eine reduzierte Expression des Faktors TGF- $\beta$ (vgl. 1.2.1.2) verglichen mit dem gesunden Knochen festgestellt [Xu et al. 2004]. Die Unterschiede in der Frakturheilung können durch die signifikant veränderten Marker des Knochenumsatzes erklärt werden. Es fällt auf, dass sowohl osteokatabole Marker wie die 5-Tartrat-resistente saure Phosphatase (TRAP-5b), die eine Rolle in der OsteoklastenMigration spielt, als auch osteoanabole Marker, wie die knochenspezifische alkalische Phosphatase (BAP), bei Fraktur-Patienten mit niedriger BMD deutlich abweichen. Während der BAP-Spiegel bei Patienten mit geringerer Knochendichte konstant ansteigt, anstatt wie bei Knochen mit normaler Dichte stetig abzufallen, liegt der TRAP-5b-Wert signifikant unter dem der Patienten mit normaler BMD [Wölfl et al. 2014]. Aus dem offenbar verminderten resorptiven Prozess zu Beginn der Frakturheilung ist die erschwerte Wiederherstellung der Integrität osteoporotischer Knochen ableitbar

\subsubsection{Frakturheilung im metaphysären Osteotomie-Modell}

Die ovarektomierte Ratte ist ein weithin anerkanntes Osteopenie-Modell. Im Zuge dieser Arbeit wurde die Frakturheilung an der Metaphyse der Tibia überprüft, da sich bisherige Forschungen oft auf die diaphysäre Knochenheilung beschränkt haben [Stürmer et al. 2010a; 2010b]. Ein Großteil Osteoporose-induzierter Frakturen tritt allerdings im Bereich der Metaphysen der Röhrenknochen auf (vgl. 1.3.6). Darüber hinaus unterscheiden sich die osteoporotischen Veränderungen in Diaphyse und Metaphyse stark. Die Kortikalis im Bereich der Diaphyse wird zwar zunehmend dünner, doch eine Zunahme des Durchmessers erhält die Stabilität am Knochenschaft. Daher kann es dazu kommen, dass Messungen die Diaphyse betreffend verfälscht werden [Danielsen et al. 1993; Peng et al. 1994]. Im Zuge der vorgenommenen Osteotomie $7 \mathrm{~mm}$ unterhalb des Knies wurde ein Osteotomie-Spalt von etwa 0,5 $\mathrm{mm}$ erzeugt und die Frakturenden mit einer Titan-Platte stabilisiert. Um die Effektivität des im Laufe des Versuches applizierten Baicaleins untersuchen zu können, wurde der Frakturspalt als definierter Bereich für diese Evaluation gewählt. Außerdem kann an der Metaphyse mit einer geringeren periostalen Kallusbildung gerechnet werden, als in der Region der Diaphyse. Dieses Modell eignet sich daher zur Beobachtung der Auswirkung von Pharmazeutika auf die osteoporotische Frakturheilung besonders gut [Stürmer et al. 2010a; 2010b]. 


\section{Material und Methoden}

Die Durchführung der folgenden Versuche ist durch die Bezirksregierung Braunschweig nach $\S 8 \mathrm{a}$ des Tierschutzgesetzes genehmigt (AZ 33.9-42502-04-14/1530).

\subsection{Versuchsablauf}

Das im Folgenden beschriebene Projekt wurde durch Fördermittel der Elsbeth-BonhoffStiftung, Berlin (Projektnummer: 114) unterstützt.

Der Versuchszeitraum betrug 12 Wochen ab dem Tag des ersten operativen Eingriffes bis zum letzten Tag der Obduktion. Das Versuchskollektiv bestand aus 60 weiblichen Ratten des Stammes Sprague-Dawley im Alter von 3 Monaten bei Ovarektomie und wurde gleichermaßen in 5 Gruppen aufgeteilt (siehe Tabelle 1). Während die Kontrollgruppe (Gruppe 1) vorerst unbehandelt blieb, wurden die Gruppen 2-5 einer Ovarektomie unterzogen. Der folgende Östrogenmangel sollte bei den ovarektomierten Tieren eine manifeste Osteoporose induzieren. Es ist wissenschaftlich bewiesen, dass das Modell der ovarektomierten Ratte vergleichbar ist mit dem Östrogenmangelzustand bei postmenopausalen Frauen [Kalu 1991]. Statistisch signifikante Veränderungen der Knochenmasse können in der Metaphyse der Tibia bereits nach 14 Tagen nachgewiesen werden, während sie bei lumbalen Wirbelkörpern erst nach 60 Tagen nachweisbar sind [Lelovas et al. 2008]. Nach 8 Wochen, während derer kein Baicalein appliziert wurde, wurden alle Versuchstiere einer Osteotomie im Bereich der Metaphyse der Tibia und folgend einer Platten-Ostesynthese unterzogen. Die gruppenspezifische Behandlung mit DMSO bzw. Baicalein begann ab dem Tag nach der Osteotomie. Die Größe des Versuchskollektivs wurde auf Grund von Unverträglichkeiten der Narkose bei den operativen Eingriffen und dem folgenden Versterben der betroffenen Ratten auf 50 Tiere reduziert. Die Kontrollgruppe wurde aufgeteilt in 2 Gruppen $\mathrm{zu} 5$ Tiere, von der eine überhaupt keinen Wirkstoff erhielt und die andere das als Lösungsmittel verwendete DMSO. Es wirkt als Penetrationsverstärker für andere Arzneimittel und wurde wegen der optimierten Applizierbarkeit dem Wirkstoff Baicalein zugemischt. Da DMSO anti-inflammatorische Eigenschaften aufweist [Hollebeeck et al. 2011], sollte eine Verfälschung der Ergebnisse des Lipoxygenase-Inhibitors ausgeschlossen werden. Daher wurde die erwähnte Kontrollgruppe lediglich mit dem Lösungsmittel DMSO (s.c.) behandelt. Innerhalb des Kollektivs ovarektomierter Ratten blieben ebenfalls 5 Tiere unbehandelt, 5 weiteren wurde DMSO subkutan injiziert. Unter den restlichen Versuchstieren wurden 10 mit dem Wirkstoff Baicalein (gelöst in DMSO) in einer Konzentration von $1 \mathrm{mg} / \mathrm{kg}$ Körpergewicht, eine weitere Gruppe aus 10 Tieren mit Baicalein in der Konzentration $10 \mathrm{mg} / \mathrm{kg}$ Körpergewicht und die übrigen 10 
Ratten mit 100 mg Baicalein pro kg Körpergewicht (s.c.) behandelt. Die jeweilige Applikation der Wirkstoffe erfolgte täglich.

Da das Voranschreiten der Umbauvorgänge während der Frakturheilung im Zuge der Fluoreszenzmikroskopie untersucht werden sollte, wurden den Tieren nach dem Prinzip der polychromen Sequenzmarkierung zu spezifischen Zeitpunkten Fluorochrome subkutan gespritzt. Auf die bereits beschriebenen Maßnahmen folgte 4 Wochen nach Osteotomie die Obduktion der Versuchstiere (Abb. 1). Im weiteren Verlauf wurden die gründlich präparierten Tibiae biomechanischen und morphologischen Analysen unterzogen. In der folgenden Tabelle wurden die mit DMSO behandelten Tiere nicht von den unbehandelten abgegrenzt aufgelistet, da keine signifikanten Unterschiede feststellbar waren, dies gilt auch für die Präsentation im Ergebnisteil.

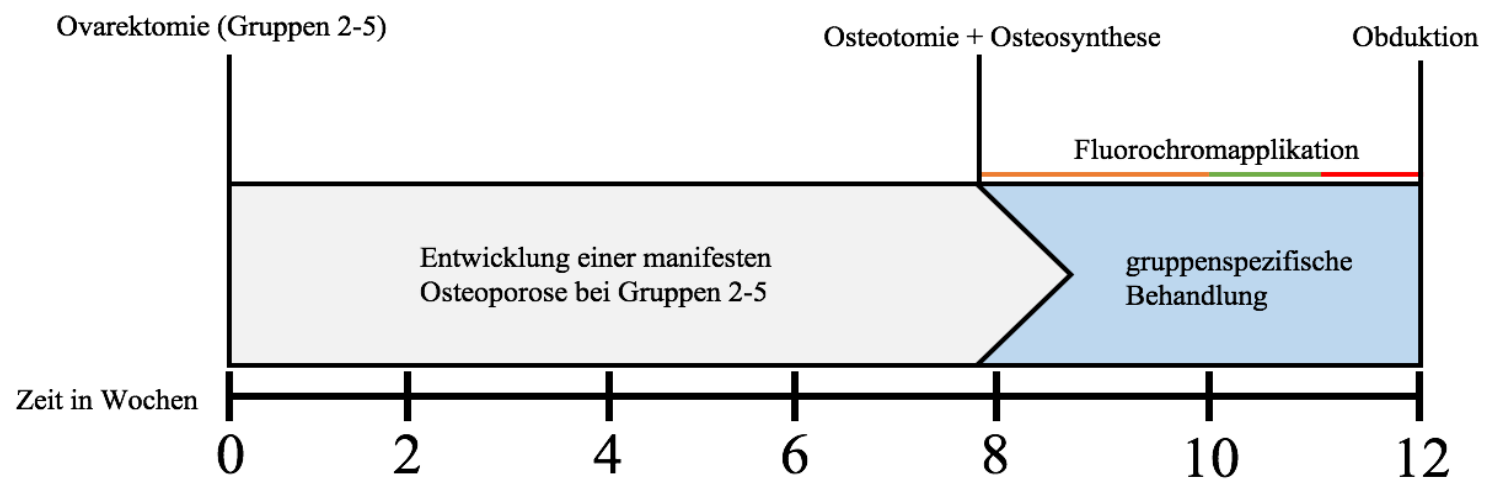

Abb. 1: Darstellung des Versuchsablaufes ab Zeitpunkt der Ovarektomie 
Tabelle 1: Darstellung der Gruppen und der Behandlung der Ratten, Anzahl der Versuchstiere bezieht sich auf den Zeitpunkt nach Versuchsende

\begin{tabular}{|c|c|c|c|}
\hline $\begin{array}{l}\text { Gruppen- } \\
\text { nummer }\end{array}$ & Gruppebezeichnung & Behandlung & $\begin{array}{l}\text { Anzahl der } \\
\text { Versuchstiere }\end{array}$ \\
\hline 1 & NON OVX & $\begin{array}{l}\text { a) Osteotomie } \\
\text { b) Osteotomie + DMSO ab } \\
\text { Osteotomie }\end{array}$ & $\begin{array}{l}5 \\
5\end{array}$ \\
\hline 2 & OVX & $\begin{array}{l}\text { 1) Ovarektomie + Osteotomie } \\
\text { 2) Ovarektomie + Osteotomie + } \\
\text { DMSO ab Osteotomie }\end{array}$ & $\begin{array}{l}5 \\
5\end{array}$ \\
\hline 3 & $\begin{array}{l}\mathrm{OVX}+ \\
1 \mathrm{mg} \text { Baicalein/ kg } \\
\text { Körpergewicht }\end{array}$ & $\begin{array}{l}\text { Ovarektomie }+ \text { Osteotomie }+ \\
\text { Baicaleininjektion (Konz. 1) ab } \\
\text { Osteotomie }\end{array}$ & 10 \\
\hline 4 & $\begin{array}{l}\text { OVX }+ \\
10 \mathrm{mg} \text { Baicalein/ kg } \\
\text { Körpergewicht }\end{array}$ & $\begin{array}{l}\text { Ovarektomie }+ \text { Osteotomie }+ \\
\text { Baicaleininjektion (Konz. 2) ab } \\
\text { Osteotomie }\end{array}$ & 10 \\
\hline 5 & $\begin{array}{l}\text { OVX }+ \\
100 \text { mg Baicalein/ kg } \\
\text { Körpergewicht }\end{array}$ & $\begin{array}{l}\text { Ovarektomie }+ \text { Osteotomie }+ \\
\text { Baicaleininjektion (Konz. 3) ab } \\
\text { Osteotomie }\end{array}$ & 10 \\
\hline
\end{tabular}

\subsection{Versuchstiere und Versuchstierhaltung}

Zur Durchführung der experimentellen Untersuchungen wurden 60 weibliche Ratten der Rasse Sprague-Dawley (Zuchtanstalt Fa. Winkelmann, Borken, Deutschland) im Alter von 3 Monaten in der Zentralen Tierexperimentellen Einrichtung im Universitätsklinikum Göttingen gehalten. Das Körpergewicht bei Versuchsbeginn betrug im Mittel 275,4 \pm 15 g. Gruppen von 3-5 Tieren wurden in Makrolon ${ }^{\circledR}$ - Käfigen vom Typ IV gehalten und professionell von Tierpflegern und Veterinärmedizinern versorgt. Das sojafreie Futter (ssniff SM R/M, 10 mm-Pellets; ssniff Spezialitäten $\mathrm{GmbH}$, Soest, Deutschland) wurde nach Bedarf bereitgestellt und dessen Verbrauch zweimaleinmal pro Woche ermittelt, indem das Restfutter gewogen und auf $1500 \mathrm{~g}$ wieder aufgefüllt wurde. Wasser stand ebenfalls zur freien Verfügung. Darüber hinaus wurde alle drei Tage einmal pro Woche eine Reinigung der Käfige veranlasst. Die Raumtemperatur 
lag bei $20{ }^{\circ} \mathrm{C}$, während die relative Luftfeuchtigkeit 55\% betrug. Die Beleuchtungszyklen alternierten im 12-Stunden-Takt angepasst an Tag- (beleuchtet) und Nachtverhältnisse (unbeleuchtet).

\subsection{Ovarektomie}

Die Ovarektomie wurde durchgeführt, um im Sinne einer Nachahmung des Hormonhaushaltes einer postklimakterischen Patientin eine Osteoporose zu erzeugen. Es ist gesichert, dass das Modell der ovarektomierten Ratte einen realistischen Ansatz zur Nachempfindung der postmenopausalen Stoffwechsellage bietet [Lelovas et al. 2008]. Zu diesem Zweck wurden die Ovarien von 50 Tieren operativ entfernt.

Während der OP-Vorbereitung wurden die Tiere mit $\mathrm{CO}_{2}$ sediert und mit einem KetaminMedetomidinhydrochlorid-Gemisch im Verhältnis 3:1 intraperitoneal narkotisiert. Sowohl 60 mg Ketamin (Hostaket ${ }^{2}$, Firma Hoechst, Bad Soden, Deutschland) als auch $10 \mathrm{mg}$ Medetomidinhydrochlorid (Domitor ${ }^{\circledR}$, Firma Orion Pharma, Espoo, Finnland) pro kg Körpergewicht wurden verabreicht. Daraufhin wurde das entsprechende Gebiet zu beiden Seiten für den operativen Eingriff vorbereitet. Das folgende Vorgehen wurde kontralateral in gleicher Weise wiederholt. Paravertebral erfolgte eine Inzisur in die zuvor rasierte und desinfizierte Haut. Nach tieferer Präparation bis zum Peritoneum erfolgte die Eröffnung der Bauchhöhle. Nach Darstellung des Ovars und anschließender Ligatur der Tuba uterina folgte die Ablösung des Ovars (Abb. 2 A). Mit Hilfe von 4.0 Vicrylfäden (Ethicon, Johnson \& Johnson, Norderstedt, Deutschland) wurden sowohl die Adaptierung des Peritoneums als auch das Aneinandernähen der Muskeln vorgenommen, wohingegen der Hautverschluss mit Hilfe von Klammern erfolgte (Michel woundbrackets 7,5 x 1,75 mm, Gebrüder Martin GmbH \&Co.KG, Tuttlingen, Deutschland). Weiterhin versah man die Ratten mit einem Transponder im subkutanen Fettgewebe der Nackenfalte (Uno Micro-Id-System, Iso-Transponder (12 mm), UNO Roestvaststaal BV, Zevenaar, Niederlande) mit dem Ziel der Qualitätssicherung und eindeutigen Identifikation eines jeden Versuchstieres. Nach subkutaner Injektion von $3 \mathrm{ml}$ isotoner Kochsalzlösung wurden die Tiere postoperativ zur weiteren Beobachtung in beheizte Käfige gelegt. 


\subsection{Osteotomie und Osteosynthese}

Die Osteotomie wurde nach Manifestierung der Osteoporose im Abstand von 8 Wochen zur vorangegangenen Ovarektomie durchgeführt [Stürmer et al. 2010a; 2010b]. Nach Einleitung der Narkose, die nach dem bereits in Kapitel 2.3 beschriebenen Procedere ausgeführt wurde, erfolgte die Vorbereitung des OP-Gebietes durch Rasur und Desinfektion der Hinterbeine. Auf der kontralateralen Seite wurde ebenso verfahren, wie folgend beschrieben. Im weiteren Verlauf setzte man einen etwa $3 \mathrm{~cm}$ messenden Hautschnitt auf der medio-ventralen Seite der Tibia. Die Muskulatur wurde durchtrennt und von der Margo anterior bis zur Tuberositas tibiae freipräpariert. Dabei wurde die Beugemuskulatur abgelöst, während das Periost geschont wurde. Der vorher festgelegte Ort der Osteotomie sollte sich $7 \mathrm{~mm}$ distal des Tibiaplateaus befinden. Dort wurde die Osteotomielinie unter Zuhilfenahme einer Schablone mit einem Skalpell markiert. Für die Osteosynthese kam eine 5-Loch-Leibinger-Platte aus Titan (5705140 XS-Titan-Fixationsplatte T-Form 90 , Stryker Trauma, Selzach, Schweiz) zum Einsatz. Diese wurde so auf den Knochen gelegt, dass die proximalen Plattenlöcher auf Höhe der Epiphysen zu Liegen kamen, und die Strecke von der Osteotomie-Linie sowohl zu den proximalen als auch zu den distalen Bohrlöchern die gleiche Entfernung hatte (Abb. 3). Um ein Verrutschen der Platte zu unterbinden, hat man zunächst vier Bohrungen unter Auslassung des Loches über der Osteotomielinie vorgenommen und ein proximales Plattenloch mit dem Bohrkanal verschraubt. Zur Durchführung der Osteotomie wurde die Leibinger-Platte vorübergehend aus dem Bereich der Osteotomielinie entfernt und die Tibia mittels gepulstem Ultraschall (OT 7 Piezosurgery ${ }^{\circledR}$, Mectron Medical Technology, Carasco, Italien) durchtrennt. Währenddessen blieben die Weichteile unverletzt. Es folgte die vollständige Fixierung der Osteosynthese-Platte, indem proximal zwei $7 \mathrm{~mm}$ lange und distal eine $4 \mathrm{~mm}$ sowie eine $5 \mathrm{~mm}$ messende Schraube (Stryker Trauma, Selzach, Schweiz) angebracht wurden (Abb. 2 B). Auf Grund der vorab determinierten Bohrkanäle wird bei dieser Methode gezielt ein Osteotomiespalt von $0,5 \mathrm{~mm}$ erzeugt, welcher mit der standardmäßigen Dicke des eingesetzten

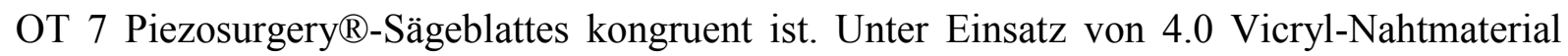
(Ethicon, Johnson \& Johnson, Norderstedt, Deutschland) wurde die Beugemuskulatur aneinandergenäht, während die Haut mittels Wundklammerung (Michel woundbrackets $7 \mathrm{x}$ 1,75 mm, Gebrüder Martin GmbH \& Co.KG, Tuttlingen, Deutschland) readaptiert wurde. Der Eingriff wurde mit einer Wunddesinfektion (Braunovidon ${ }^{\circledR}$, Bayer, Leverkusen) und dem Transport der Ratten in vorgewärmte Käfige beendet. Bis zum Erwachen aus der Allgemeinanästhesie standen die Tiere unter Beobachtung. 
Postoperativ wurde singulär Decentan (s.c.) (5 mg/kg KG, Merck, Darmstadt, Deutschland) und $3 \mathrm{ml}$ isotone Kochsalz-Lösung injiziert. Im Rahmen der Schmerzmedikation wurde am Tag der Osteotomie einmal und an den folgenden zwei postoperativen Tagen zweimal am Tag Rimadyl (4 mg/kg KG, Pfizer, Karlsruhe, Germany) subkutan appliziert.
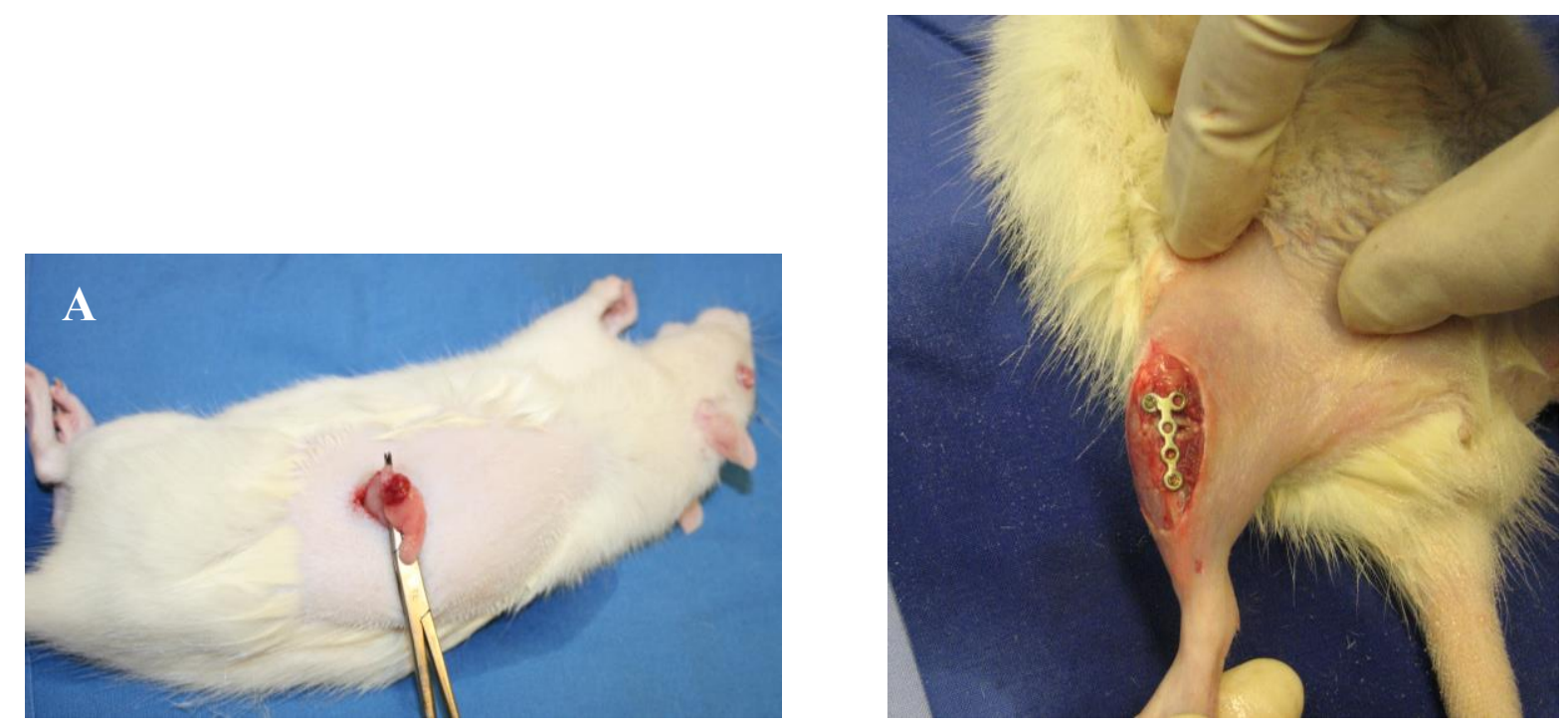

Abb. 2: Dokumentation der Ovarektomie und der Anbringung der Osteosyntheseplatte im Zuge der Osteotomie; A= Präpariertes Ovar wird abgeklemmt, B= Osteosyntheseplatte wird über der osteotomierten Tibia angebracht (Komrakova et al. 2010); zur Verfügung gestellt von Marc Zimmermann

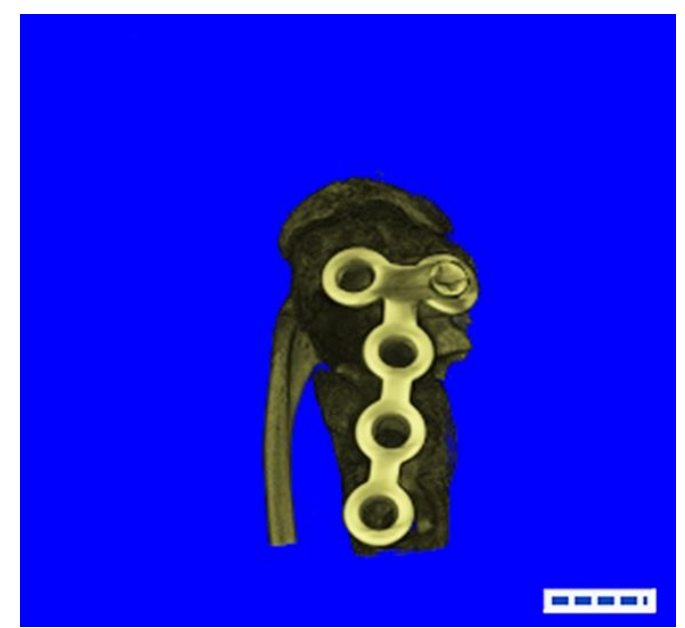

Abb. 3: Darstellung der Lage der Osteosyntheseplatte auf der Tibia im 3D-Bild des Micro-CT 


\subsection{Obduktion und Präparation}

12 Wochen nach Versuchsbeginn, beziehungsweise 4 Wochen nach der Osteotomie, wurde der Versuch im Zuge der Obduktion der Versuchstiere abgeschlossen. Vorerst wurde die Sedierung der Tiere mittels $\mathrm{CO}_{2}$ herbeigeführt, im Anschluss erfolgte die Dekapitation. Im Verlauf der Obduktion wurde eine der randomisiert ausgewählten Tibiae zusammen mit der assoziierten Fibula sorgfältig herauspräpariert. Dazu wurde sie im Knie- sowie im Sprunggelenk exartikuliert und nach Entfernung der Osteosynthesematerialien oberflächlich von ihrem Wichteilmantel befreit. Bei einigen Tibiae blieb die Osteosynthese-Platte bewusst bestehen, um ihre Position im Zuge des später durchgeführten Mikro-CT Verfahrens überprüfen zu können. Eine umfangreiche Präparation der Knochen erfolgte erst nach Beendigung des Eingriffes. Zum Zwecke der Erhaltung der mechanischen Eigenschaften der Tibiae wurden sie bei $-20{ }^{\circ} \mathrm{C}$ aufbewahrt. Unterdessen wurde die jeweils kontralaterale Tibia bei $-80{ }^{\circ} \mathrm{C}$ gelagert, um den Kallus im Zuge der molekularbiologischen Untersuchungen einer Genanalyse unterziehen zu können. Ferner wurden Teile der Muskulatur sowie der Lendenwirbelsäule und die Femora der Ratten herauspräpariert und im Verlauf anderer Arbeiten ausgewertet.

\subsection{Biomechanischer Test}

\subsubsection{Prinzip des biomechanischen Tests}

Mit Hilfe dieser durch Komrakova et al. (2015) druchgeführten Methode sollen die mechanischen Parameter der Kallushärtung und Knochenstabilität gemessen werden. Entscheidend sind dabei die Elastizität und Widerstandsfähigkeit des neu entstandenen Gewebes. Im Zuge dessen wird die Tibia $1 \mathrm{~mm}$ unterhalb der Osteotomielinie mit einer orthogonal zur Längsachse verlaufenden Kraft belastet. Diese Aufgabe übernimmt eine Werkstoffprüfmaschine (Typ 145660 Z020/TND Zwick/Roell, Ulm, Deutschland), welche mit Hilfe der entsprechenden Software "testXpert ${ }^{\circledR}$ “ $\square$ (Zwick/Roell, Ulm, Deutschland) ein Kraft/Weg-Diagramm für den jeweiligen Knochen aufzeichnet. Die Fibula wurde für diesen Versuch entfernt.

\subsubsection{Validierung}

Der Durchführung des eigentlichen Versuches vorangestellt wurde eine Überprüfung der fachgerechten Bedienung der Werkstoffprüfmaschine sowie der gewissenhaften Auswertung der Messparameter. Dies sollte die Validität des Tests sichern. Im Rahmen der Validierung erfolgte eine Einweisung in die Untersuchungsmethode anhand von 20 Knochen aus 10 ähnlich gewichtigen Ratten. Die Durchführung des Versuches erfolgte wie nachfolgend beschrieben, allerdings mit beiden Tibiae eines Versuchstieres. Unter den einzelnen Ratten sowie unter den 
Knochen eines Tieres durfte keine Deviation der Messwerte von mehr als 10\% bestehen. Dies wurde von einer qualifizierten Fachkraft der Arbeitsgruppe überprüft. Sobald diese Voraussetzung erfüllt war, wurde der Test mit den tatsächlich zu untersuchenden Knochen durchgeführt.

\subsubsection{Versuchsdurchführung}

Die Versuchsdurchführung erfolgte nach der Methodik von Komrakova et al. (2015).

Diese Methodik basiert auf der Befestigung der Tibia in einer speziellen Metallhalterung, welche ein Verrutschen verhindern und die Reproduzierbarkeit der Knochenposition gewährleisten soll. Der Knochen sollte sowohl am Ort der ehemaligen distalen Synostose zwischen Fibula und Tibia als auch auf den Kondylen auf dem Träger aufliegen. Die Kraftausübung erfolgte durch einen metallenen Stempel, an dessen Ende sich ein zylindrisches Metallstück befand, welches langsam über der Osteotomieline positioniert wurde (Abb. 4). Im Anschluss an diese Vorbereitungen wurde der Stempel der Werkstoffprüfmaschine mit 50 $\mathrm{mm} /$ Minute heruntergefahren. Es folgte der Start der Krafteinwirkung, die stetig zunahm, indem der Stempel konstant auf die Frakturstelle an der Tibia drückte. Die Kraft wurde von der Software in Newton registriert und jeweils nach einer Strecke von 0,1 mm im Kraft-/WegDiagramm dargestellt. Mit einer Aberration der Kurvenlinearität von über 2 mm oder einem Absinken der Kraft um mehr als $2 \mathrm{~N}$ erfolgte die sofortige Beendigung des Versuchs. In gleicher Weise wurde mit allen Tibiae verfahren.

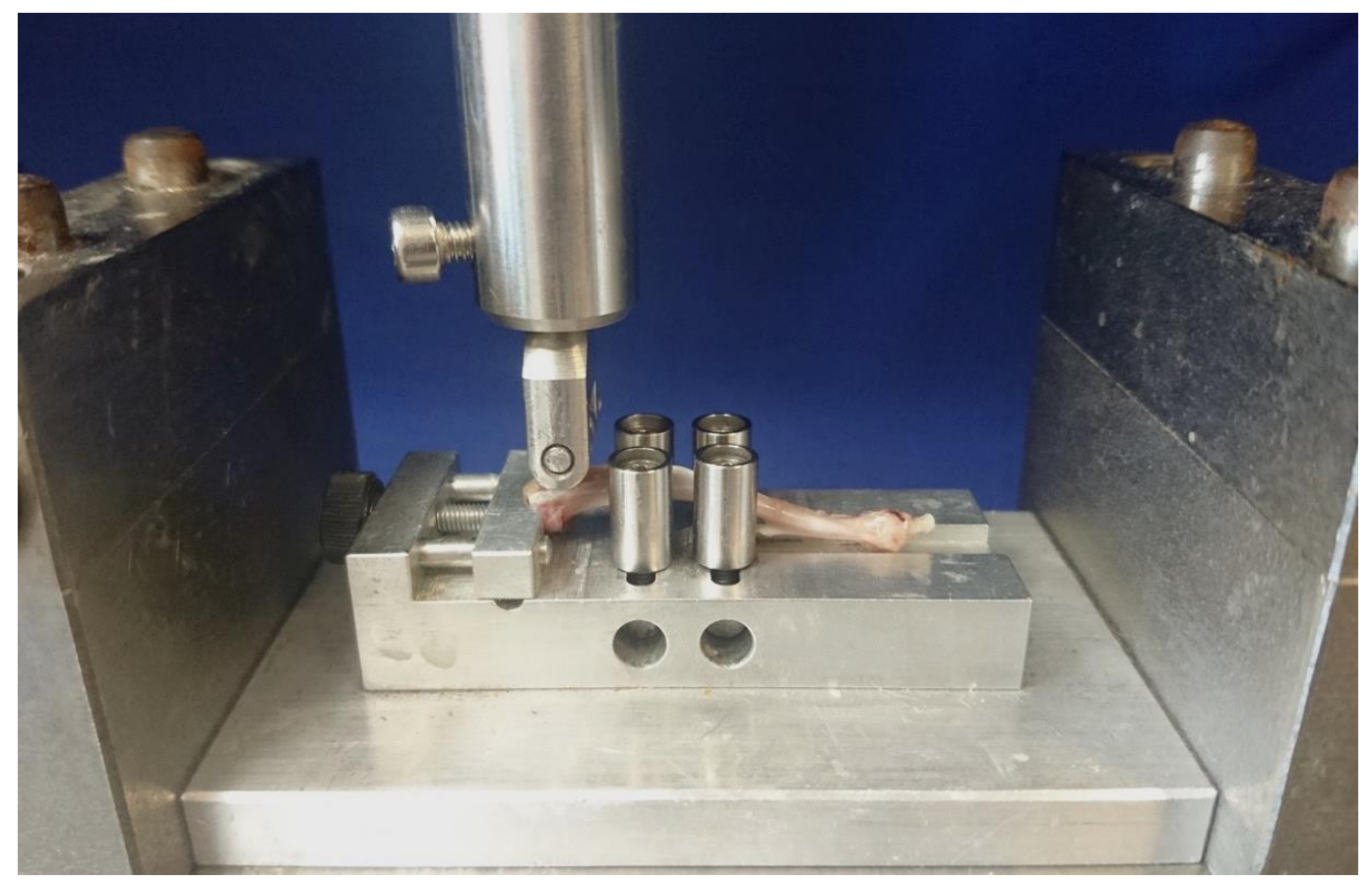

Abb. 4: Positionierung der Tibia auf der Trägerplatte in der Werkstoffprüfmaschine 


\subsubsection{Auswertung der Kraft-Weg-Diagramme}

Das während des biomechanischen Tests entstandene Diagramm ist in drei charakteristische Phasen differenzierbar, die bereits von Stürmer et al. im Jahr 2006 dargestellt wurden. Im Anfangsteil folgt die Kurve einem linearen Verlauf, was der elastischen, reversiblen Deformierung des Knochens entspricht. Während der zweiten Phase verringert sich die Steigung, bis $F_{\max }$ und damit der höchste Punkt des Graphen erreicht ist. Sobald diese Phase der plastischen Deformation endet, treten Mikrofrakturierungen im trabekulären Knochenanteil auf, sodass die Kurvenlinearität nicht mehr gegeben ist [Komrakova et al. 2014]. Der Bereich vor dem Maximum der Krafteinwirkung, in welchem die Mikrofrakturen auftreten, wird als yield load bezeichnet. Während der finalen Phase kommt es zu multiplen Frakturen, bis auch der kortikale Knochenanteil nachgibt [Komrakova et al. 2015; Stürmer et al. 2014]. In diesem Bereich fällt die Kurve, bis die Maschine den Test selbständig beendet, da eine vollständige Fraktur unerwünscht war.

\subsubsection{Messparameter}

\subsubsection{Elastizität}

Dieser Parameter ist während der Phase der elastischen Deformation im linearen Kurventeil messbar, indem der Quotient aus der Differenz zweier Werte auf der Kraftachse $\left(\mathrm{F}_{2}-\mathrm{F}_{1}\right)$ und der Differenz assoziierter Werte auf der Wegachse $\left(\mathrm{s}_{2}-\mathrm{s}_{1}\right)$ berechnet wird. Dieser Steigungswert wird in $\mathrm{N} / \mathrm{mm}$ angegeben.

\subsubsection{Streckgrenze (Yield Load)}

Dieser Messwert markiert die Grenze zwischen reversibler und irreversibler Verformung des Knochens. Dementsprechend befindet sich an dieser Stelle gleichsam der Übergang von elastischer zu plastischer Deformation. Die yield load steht am Ende des linearen Kurventeils und repräsentiert den maximalen Dehnungswert der Kollagenfasern. Kommt es zu einem Steigungsabfall um mehr als zwei Standardabweichungen, stellt der erreichte Wert die Streckgrenze dar, welche die Einheit N trägt. Die Standardabweichung wird anhand der Regressionsgeraden des linearen Kurvenabschnittes definiert [Stürmer et al. 2006].

\subsubsection{Maximalkraft $\left(F_{\max }\right)$}

$\mathrm{F}_{\max }$ ist am höchsten Punkt des Graphen erreicht und wird in N gemessen. Sie ist das Äquivalent der größten Belastung, bei welcher der Knochen bestehen kann, ohne eine Fraktur zu erleiden. Auf den Punkt der Maximalkraft folgt der Abfall der Kurve [Stürmer et al. 2006]. 


\subsection{Mikro-Computertomographie}

Im Zuge der computertomographischen Untersuchung wurde ein Low Dose In-Vivo-Mikro-CT des Herstellers Rigaku Micro CT Technology verwendet. Das verwendete Modell Quantum FX wird durch PerkinElmer Health Sciences Inc. vertrieben und benötigt nur geringe Strahlendosen von durchschnittlich 15 mGy pro Scan. Das Gerät arbeitet mit einem Bildverstärkersystem, welches auf der Verwendung einer Bildkette mit entsprechender Optik, Kamera und Monitor basiert. Dabei wird Röntgenstrahlung mittels einer Szintillatorschicht in sichtbares Licht umgewandelt und nach einer Verstärkung durch Elektronenoptik auf einem Monitor in Echtzeit mit Hilfe einer Digitalkamera abgebildet.

Die Untersuchung wurde mit jedem der Knochen anhand definierter Scanparameter (Tab. 2) durchgeführt und anschließend mit der dafür entwickelten Software 3D Osteoanalyze v 1.000.4 ausgewertet.

Tabelle 2: Scanparameter des Scanprotokolls

\begin{tabular}{|l|l|}
\hline Scanparameter & Wert + Einheit \\
\hline Röhrenspannung & $70 \mathrm{kVp}$ \\
\hline Röhrenstrom & $200 \mu \mathrm{A}$ \\
\hline Anzahl der Projektionen $\left(360^{\circ} \mathrm{Scan}\right)$ & 3600 \\
\hline Scanzeit & 2 Minuten \\
\hline Scanmode & Vollrotation $360^{\circ}$ \\
\hline FOV (Field of View) & $20 \times 20 \mathrm{~mm}^{2}$ \\
\hline Effektive „Voxel“- Größe & $40 \times 40 \times 40 \mu \mathrm{m}^{3}$ \\
\hline Detektor Frame Rate & $30 \mathrm{~Hz}$ \\
\hline Bildmatrix & $512 \times 512$ \\
\hline Datenrepräsentation & $16 \mathrm{bit}$ \\
\hline
\end{tabular}

\subsubsection{Durchführung des Scans}

Die Durchführung erfolgte in mehreren Arbeitsschritten.

Arbeitsschritt 1: Vorbereitung der Probe auf den Scan

Die Tibiae wurden mit Hilfe einer angepassten Schaumstoffvorrichtung auf einem Plastikeinsatz fixiert. Dies sollte ein Verrutschen und eine exakte, reproduzierbare Positionierung ermöglichen. Der Knochen wurde, wenn möglich, auf die Kondylen und die 
distale tibiofibulare Synostose aufgelegt. Vor die proximale Seite der Tibia wurde ein Kalibrierungsphantom platziert, welches 5 Hydroxylapatit-Einschlüsse verschiedener Dichte enthält. Anhand dieser normierten Dichte-Werte sollte die Übertragbarkeit der Grauwerte des angefertigten Scans in Bone Mineral Density $\left(\mathrm{g} / \mathrm{cm}^{3}\right)$ ermöglicht werden. Abschließend wurde der Plastikeinsatz so ausgerichtet, dass sowohl das Phantom als auch die metaphysale Tibia optimal dargestellt werden konnten. Dies wurde am Bildschirm überprüft.

\section{Arbeitsschritt 2: Scannen}

Während der Messung wird die Probe anders als im konventionellen Computertomographen nicht vorwärtsbewegt. Mit Hilfe der Längsausdrehung des Detektors kann die dritte Dimension dargestellt werden, sodass letztlich das gesamte Volumen in transversaler, sagittaler und frontaler Ebene aus Schnittbildern rekonstruiert werden kann. Während eines einzelnen Scans wurden 3600 Aufnahmen getätigt.

\section{Arbeitsschritt 3: Rekonstruktion}

Für die 3D Rekonstruktion wurde ein klassischer ,filtered back projection“(FBP)-Algorithmus eingesetzt, welcher in die zugehörige Software des Systems integriert ist.

Nach Erfassung der Grauwerte des Phantoms konnten die Tibiae im zwei- und dreidimensionalen Bild rekonstruiert werden.

\subsubsection{Auswertung}

Unter Verwendung der Software 3D Osteoanalyze v 1.000.4 konnten die Volumina der Bereiche Weichteil, Kallus, Kortikalis und des gesamten Knochengewebes erfasst werden. Darüber hinaus wurde die jeweilige Gewebedichte in BMD ermittelt. Außerdem war es möglich, die Positionierung einiger Osteosynthese-Platten im dreidimensionalen Bild darzustellen. Diese wurden zur Determinierung der Knochendichte allerdings vor dem erneuten Scan entfernt, da die Metall-Platten Bildartefakte hervorrufen.

\section{Arbeitsschritte der Auswertung}

Arbeitsschritt 1: Anpassung der Transparenz und des Kontrasts

Zuerst wurde der ausgewählte Knochen in zwei-, sowie in dreidimensionaler Ansicht abgebildet. Es folgte die Adjustierung der Bilddarstellung, um sicherzustellen, dass jeder Knochen mit dem gleichen Modus Operandi angezeigt und ausgewertet wird. Dazu wurde die so genannte opacity function (Abb. 7, Abb. 8) angewählt, um den optimalen Transparenzwert $\mathrm{zu}$ adaptieren. Dies sichert die homogene und vergleichbare Bilddarstellung der einzelnen 
Tibiae und folglich eine standardisierte Auswertung. Unterdessen wurde die Kontrastierung der zweidimensionalen Aufnahmen wie in Abbildung 5 und 6 beschrieben justiert, bis eine bestmögliche Visualisierung der Weichteile erreicht war.

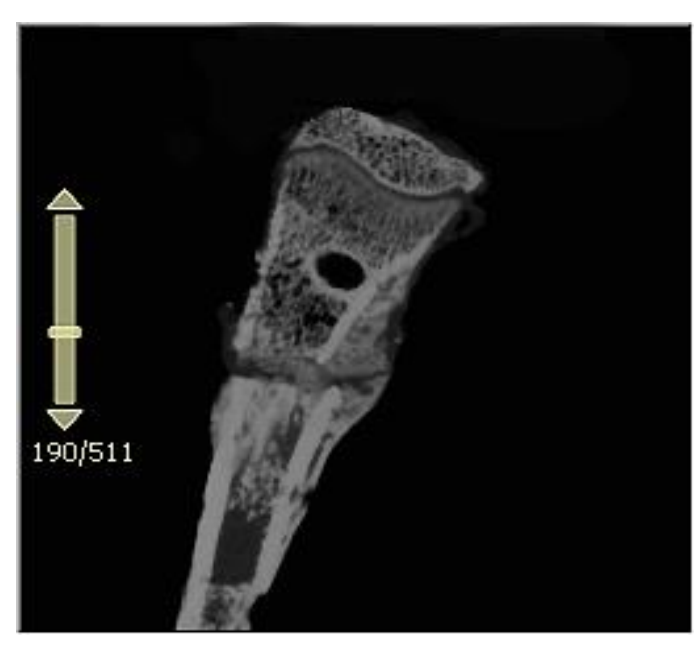

Abb. 5: optimal adaptierter Kontrast im

2D-Bild; Versuchsgruppe $1 \mathrm{mg}$ Baicalein

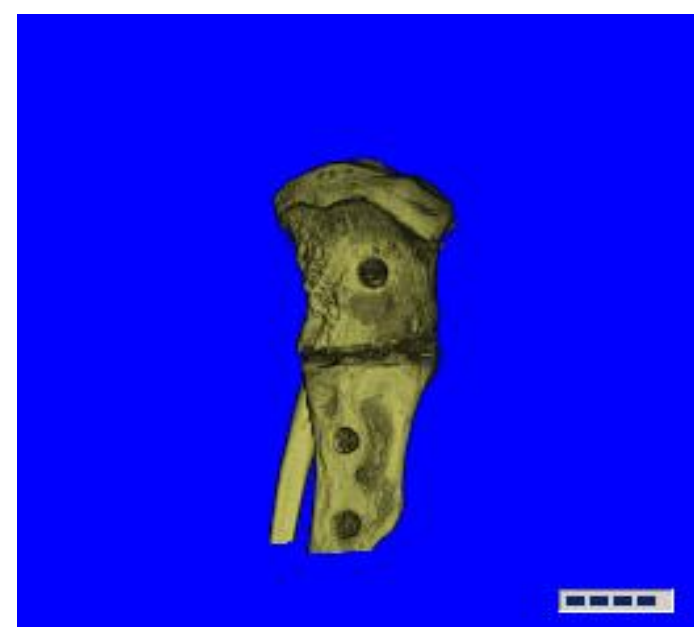

Abb. 7: optimal adaptierte Transparenz mittels Opacity Function im 3D-Bild; Versuchsgruppe $1 \mathrm{mg}$ Baicalein

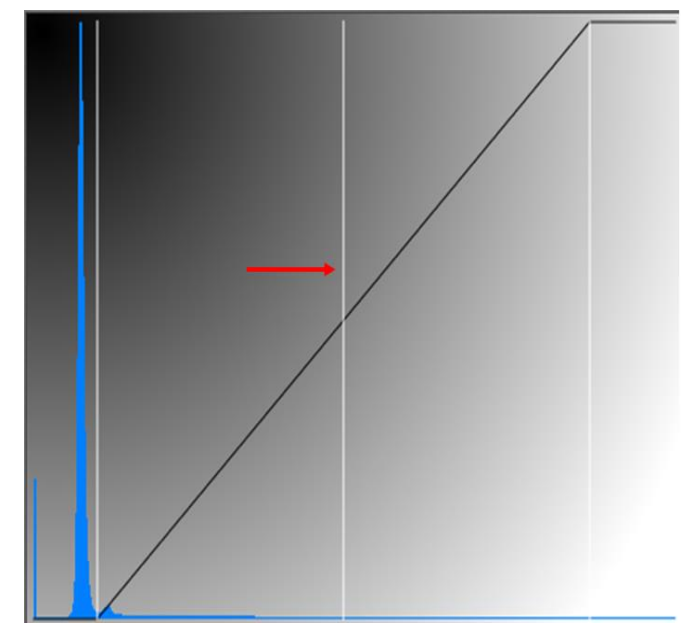

Abb. 6: entsprechendes Grauwerthistogramm mit optimal adaptiertem Kontrast: Pfeil markiert verschiebbare Linie; Versuchsgruppe $1 \mathrm{mg}$ Baicalein

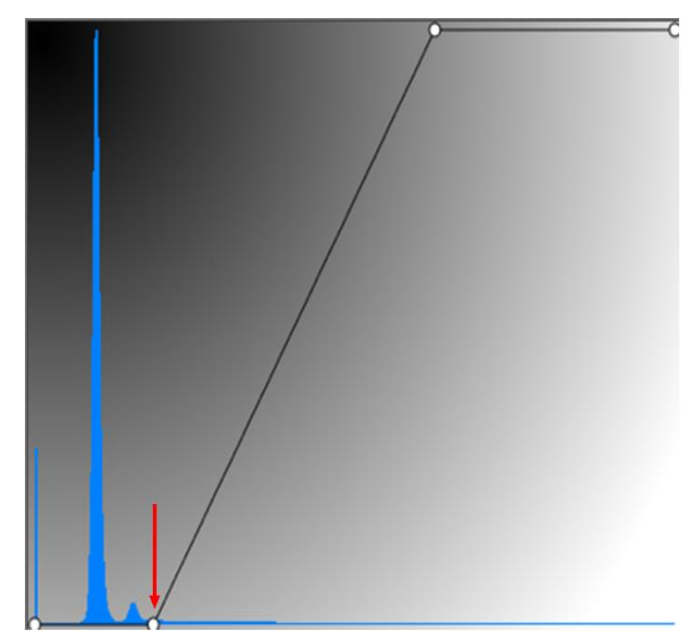

Abb. 8: entsprechendes Grauwerthistogramm mit optimal adaptierter Transparenz: Pfeil markiert verschiebbaren Punkt; Versuchsgruppe 1 mg Baicalein 
Arbeitsschritt 2: Auswertung des Phantoms

Das Registrieren der Phantom-Dichte ermöglicht die Erfassung der BMD der Tibiae. Vor der eigentlichen Knochenanalyse wurden die 5 Dichte-Werte des Phantoms in HounsfieldEinheiten umgerechnet. Zu diesem Zweck wurde die Funktion cut outside gewählt, um den Bereich außerhalb des Phantoms temporär zu entfernen. Nachfolgend konnten im Histogramm die Dichte-Werte der Phantom-Einschlüsse als 5 „Peaks“ angezeigt werden (Abb. 9 A). Anschließend erfolgte eine Kalibrierung, während derer die Hounsfield-Werte aus dem Histogramm abgelesen und in einer Tabelle eingetragen wurden. Mit Hilfe des sogenannten Density Mapping wurden die Grauwerte und analoge Hounsfield-Einheiten sowie die entsprechende BMD gespeichert (Abb. 9 B). Abschließend wurde das gesamte Bild wiederhergestellt und mit der Auswertung des Knochens begonnen.
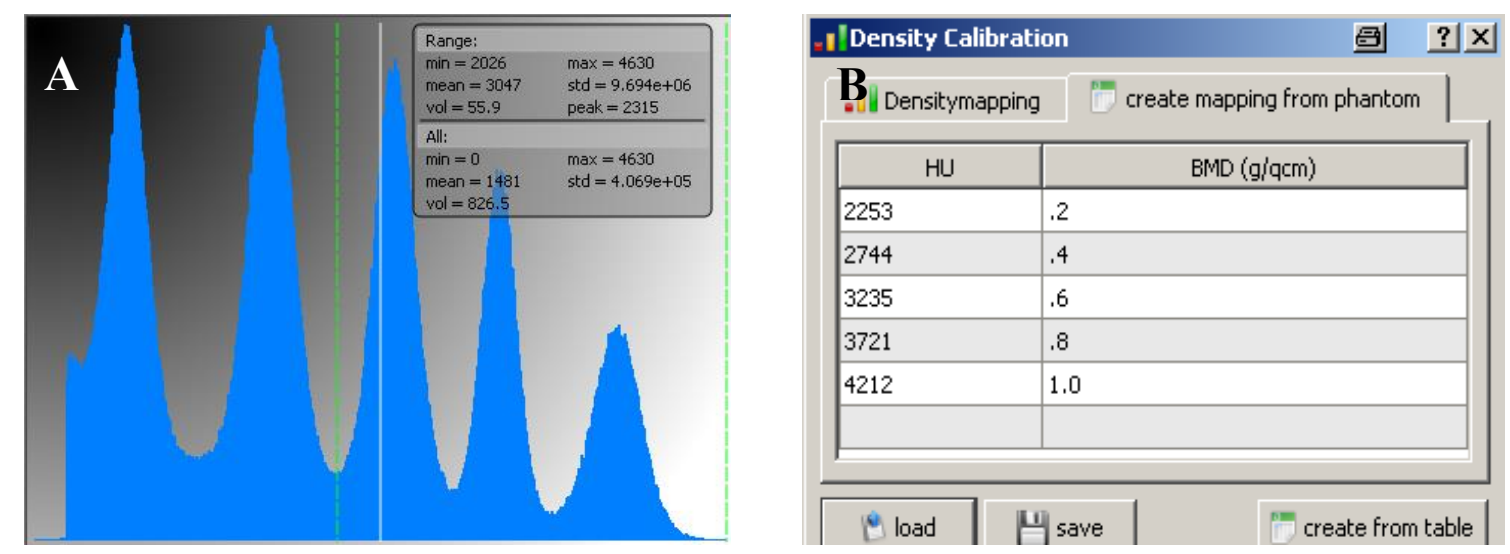

Abb. 9: Darstellung der Phantom-Dichtewerte im Grauwerthistogramm und Density Mapping; $\mathrm{A}=$ Phantom-Dichte dargestellt als 5 Peaks im Histogramm, $\mathrm{B}=$ Tabellarische Darstellung der Hounsfield-Einheiten (HU) mit entsprechender Knochendichte (BMD)

\section{Arbeitsschritt 3: Erstellung des Messrahmens}

Da im Zuge dieser Arbeit nur die Volumen- und Knochendichtebestimmungen im Bereich des Frakturspaltes der Tibiae von Interesse waren, wurde ein Messrahmen um das relevante Gebiet erstellt. Vorab wurden die Cursor innerhalb der zweidimensionalen Aufnahmen so positioniert, dass die Achsen unmittelbar durch den Frakturspalt verliefen. Der jeweils $3 \mathrm{~mm}$ oberhalb und unterhalb der Mittellinie und $10 \mathrm{~mm}$ in der Länge messende Quader wurde an die Position der Cursor dirigiert, um proximal und distal der Osteotomielinie das gleiche Volumen in die Messung einzubeziehen. Abschließend wurden die restlichen Knochenteile entfernt (Abb. 10). 


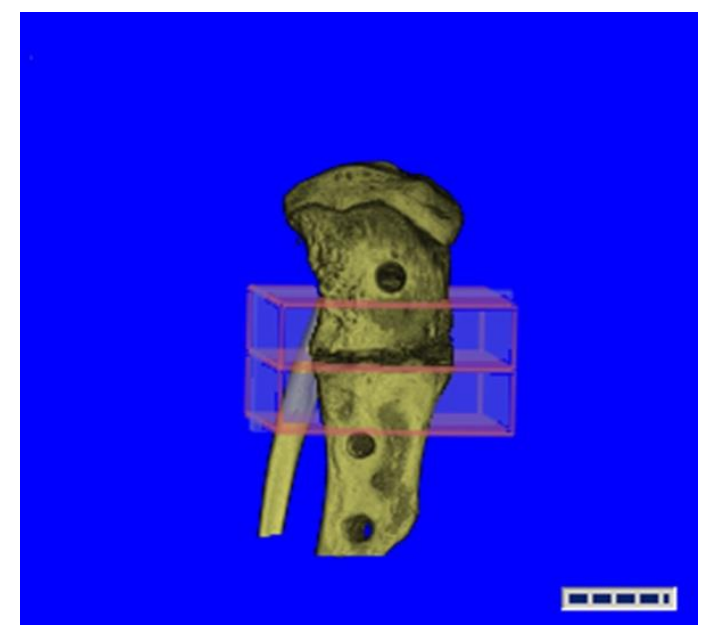

Abb. 10: Positionierung des Messrahmens über der Osteotomielinie; Versuchsgruppe $1 \mathrm{mg}$ Baicalein

\section{Arbeitsschritt 4: Erstellen eines Grauwerthistogramms}

Anders als die herkömmliche CT-Untersuchung zeigt der Mikro-CT Scan keine direkten Hounsfield-Werte an, sondern Grauwerte, welche keine unmittelbaren Rückschlüsse auf die Knochenqualität zulassen. Da Hounsfield-Einheiten allerdings ein standardisiertes Schema bieten, Röntgen-Schwächungswerte zu skalieren, ist es obligatorisch, die Grauwerte in Bezug zu den linearen Schwächungskoeffizienten der Phantom-Einschlüsse zu setzen. Das Grauwerthistogramm wurde selbständig durch 3D-Osteoanalyze v 1.000 .4 erstellt. Dieses Histogramm stellt die Häufigkeitsverteilung der Grauwerte eines Bildes und damit die Anzahl der Pixel, die den entsprechenden Grauwert tragen dar. Dabei werden die linearen Röntgenschwächungswerte und dementsprechend Helligkeitswerte auf der x-Achse gegen die Anzahl der Bildpunkte des zugehörigen Grauwertbereiches auf der y-Achse aufgetragen. Es ist eine lineare Beziehung erkennbar. $\mathrm{Zu}$ beachten ist, dass die Röntgenschwächungswerte nicht in direkten Bezug zur Massendichte eines Gewebes gesetzt werden können, da sie lediglich ein Maß für die relative Elektronendichte eines Materials darstellen. Doch durch die Bestimmung der Hounsfield-Einheiten für die bereits bekannte Dichte der Referenzmaterialien im Phantom (siehe 2.7.2, Arbeitschritt 2) konnte auf Grundlage eines Vergleiches mit den GValues des Knochens eine Messung der BMD erfolgen. Das Grauwerthistogramm stellte vier charakteristische Peaks für die jeweilige Dichte von Luft, Weichteil, Kallus und Kortikalis dar. Nach dem Ausschließen der Wertekurve für Luft konnte die Auswertung der restlichen Gewebeteile beginnen (Abb. 11). 


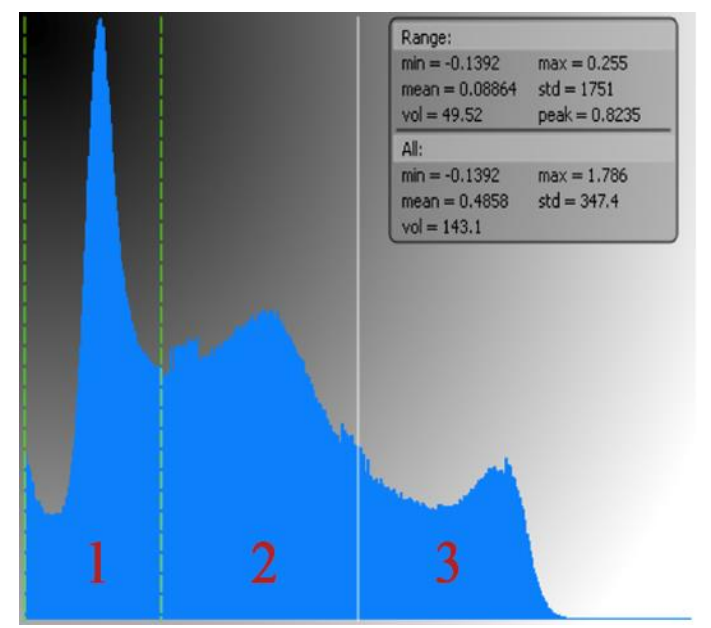

Abb. 11: Eingrenzung eines Grauwert-

bereiches am Beispiel des Weichteilbereiches;

$1=$ Weichteil, $2=$ Kallus, $3=$ Kortikalis;

Versuchsgruppe $1 \mathrm{mg}$ Baicalein

Arbeitsschritt 5: Auswertung der Knochenanteile

Die im Grauwerthistogramm angezeigten Peaks konnten den einzelnen Knochenanteilen zugeordnet und entsprechend eingegrenzt werden (siehe 2.7.2. Arbeitsschritt 4). Mit der Determinierung eines bestimmten Bereiches war es möglich, die Volumen- und Knochendichtegrößen zu speichern, und darüber hinaus in eine Excel-Tabelle zu transferieren. Im Rahmen dieser Methode wurde die maximale Dichte des Weichteils in Knochendichtewerten zugleich als Minimalwert für die Abgrenzung des Kallus verwendet (Abb. 13). Analog entsprach das Maximum der BMD des Kallus der unteren Begrenzung des Kortikalisbereiches. Die Datenkurve ergab letztlich Werte der mittleren Knochendichte und des Volumens der Weichteil-, Kallus- und Kortikalisregion, sowie für den gesamten Knochen und das vollständige Gewebe. Während der manuellen Festlegung der Schwellenwerte wurden die individuell ausfallenden Peaks der Knochenanteile als Orientierungshilfe genutzt und der entsprechende Bereich im zweidimensionalen Bild als grüne Markierung visualisiert (Abb. 12). Somit erfolgte für jeden Knochen eine spezifische Überprüfung der Schwellenwerte einer jeweils einzugrenzenden Region. 


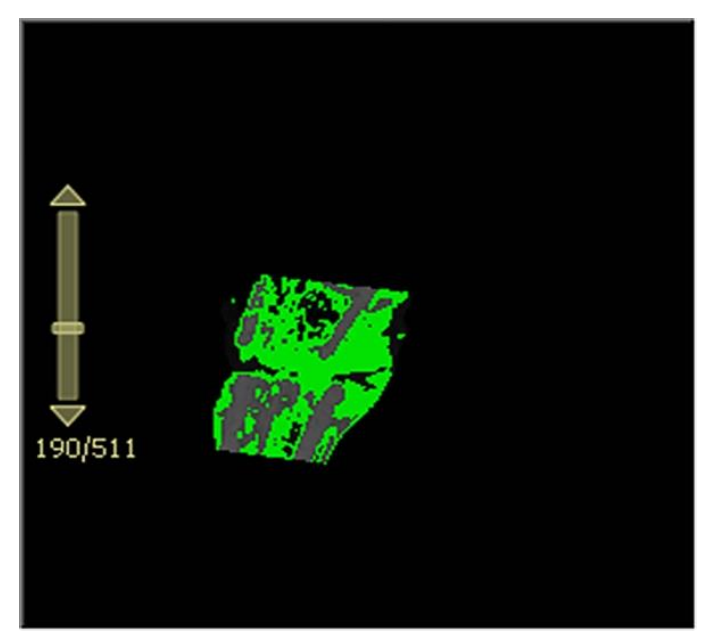

Abb. 12: Visualisierung des Kallusbereiches im 2D-Bild;

Versuchsgruppe $1 \mathrm{mg}$ Baicalein

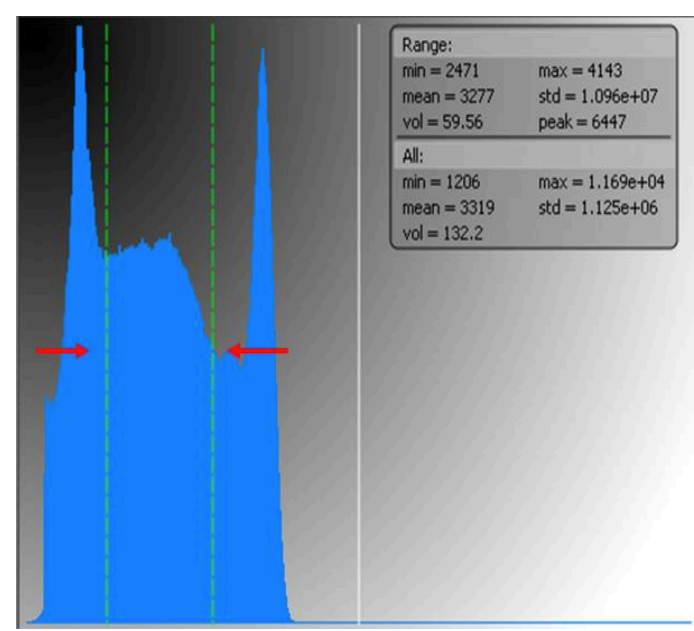

Abb. 13: Eingrenzung eines Grauwertbereiches am Beispiel des Kallusbereiches; linker Pfeil= minimaler Schwellenwert, rechter Pfeil= maximaler

Schwellenwert; Versuchsgruppe $1 \mathrm{mg}$ Baicalein

\subsubsection{Messparameter}

\section{Tabelle 3: Darstellung der Messparameter der Auswertung mit Einheit und Bedeutung}

\begin{tabular}{|c|c|c|}
\hline Messparameter & Einheit & Bedeutung \\
\hline Mittlere Kortikalisdichte & $\mathrm{g} / \mathrm{cm}^{3}$ & $\begin{array}{l}\text { Mittelwert der kalkulierten Dichtewerte im ermittelten } \\
\text { Kortikalisbereich }\end{array}$ \\
\hline Kortikalisvolumen & $\mathrm{mm}^{3}$ & Volumen im ermittelten Kortikalisbereich \\
\hline $\begin{array}{l}\text { Mittlere Dichte gesamter } \\
\text { Kallus }\end{array}$ & $\mathrm{g} / \mathrm{cm}^{3}$ & $\begin{array}{l}\text { Mittelwert der kalkulierten Dichtewerte ermittelten im } \\
\text { Kallusbereich }\end{array}$ \\
\hline Volumen gesamter Kallus & $\mathrm{mm}^{3}$ & Volumen im ermittelten Kallusbereich \\
\hline Mittlere Dichte total & $\mathrm{g} / \mathrm{cm}^{3}$ & $\begin{array}{l}\text { Mittelwert der kalkulierten Dichtewerte für alle } \\
\text { ermittelten Bereiche }\end{array}$ \\
\hline Volumen total & $\mathrm{mm}^{3}$ & Volumen aller ermittelten Bereiche \\
\hline
\end{tabular}




\subsection{Mikroradiographie}

\subsubsection{Anfertigung der histologischen Schnitte und der Mikroradiographien}

Nach der computertomographischen Analyse der Tibiae erfolgte die histologische Aufarbeitung und Herstellung der Gewebeschnitte. Vorerst wurden die Tibiae mit Hilfe einer aufsteigenden Alkoholreihe entwässert und entfettet. Darauf folgte die Einbettung in reinem Methylmethacrylat für weitere 3 Tage. In einem Gemisch aus $29 \mathrm{~g}$ Benzoylperoxid, $200 \mathrm{ml}$ Dibutylphtalat und $1000 \mathrm{ml}$ Methylmethacrylat wurden die Tibiae in einzelnen Gefäßen über 3 Wochen ausgehärtet. An die Aushärtungsphase schloss sich die Herstellung der $150 \mu \mathrm{m}$ dicken Gewebeschnitte an. Dabei diente die ehemalige Schraubenebene als Orientierungshilfe für die sagittalen Schnitte, welche aus der Mitte der Knochen gefertigt wurden. Die Bildgebung von je drei Schnitten pro Tibia wurde mit Hilfe eines Fraxitron Röntgengerätes (Modell-Nr. 43855A, Faxitron X-ray system, Hewlett-Packard, San Diego, USA) auf einem Kodak Professional Film festgehalten (INDUSTREX SR45 Film ISO 9002, Rochester, New York).

\subsubsection{Auswertung der Mikroradiographien}

\subsubsection{Software und Geräte}

Die morphometrische Beurteilung wurde nach der bereits durch Weidemann (2013) durchgeführten Methodik an einem Stereomakroskop (Leica MZ 7-5, Bensheim, Deutschland) vorgenommen. Unter Verwendung einer im Makroskop integrierten Kamera (Leica DFC 490; Bensheim; Deutschland) und der MetaMorph Basic Acquisition Software (Leica Mikrosysteme Vertrieb GmbH; Wetzlar; Deutschland) wurden die Bilder in Verbindung mit einem Computer (Intel Pentium 4, $2.6 \mathrm{GHz}$ ) digitalisiert und anschließend mittels eines standardisierten Algorithmus ausgewertet. Die Vergrößerung des Bildes wurde durch ein 1,0er Objektiv am Stereomakroskop erzielt. Die Lichtquelle des Makroskops (Kaltlichtquelle Leica KL 1500 LCD, Bensheim, Deutschland) konnte durch eine mechanische Blendeneinstellung so modifiziert werden, dass ein mäßiger Lichteinfall ermöglich wurde.

\subsubsection{Arbeitsschritte der histomorphometrischen Auswertung}

Arbeitsschritt I: Feststellung der Auswertbarkeit und Positionierung der Mikroradiographien Es wurde zunächst eine Selektion der Schnitte vorgenommen, da einige Knochen durch suboptimale Heilung sowie die Beschädigung durch den vorangegangenen biomechanischen Test morphologisch deutlich von anderen Tibiae abwichen, was zu einer Verzerrung der Ergebnisse geführt hätte. Die vorrangigen Kriterien waren hierbei die Abgrenzung der Kortikalis vom Kallus und den Trabekeln sowie ein nicht zu breiter Bruchspalt. 
Bei der Positionierung der drei Schnitte unter dem Makroskop sollten der proximale Teil oben, der distale Teil unten und die ventrale plattennahe Seite links, sowie die dorsale, Kallus reichere Tibiaseite rechts platziert werden (Abb. 12). Nach der korrekten Platzierung wurde eine Aufnahme des Bildes gemacht und am Bildschirm des Computers im Bearbeitungsprogramm der bereits erwähnten Software angezeigt. Die distale Osteotomielinie wurde dann auf eine angezeigte Linie verschoben, sodass der Bruchspalt im vorgesehenen Messrahmen von $4 \mathrm{~mm}$ (vertikal) mal $5 \mathrm{~mm}$ (horizontal) lag.

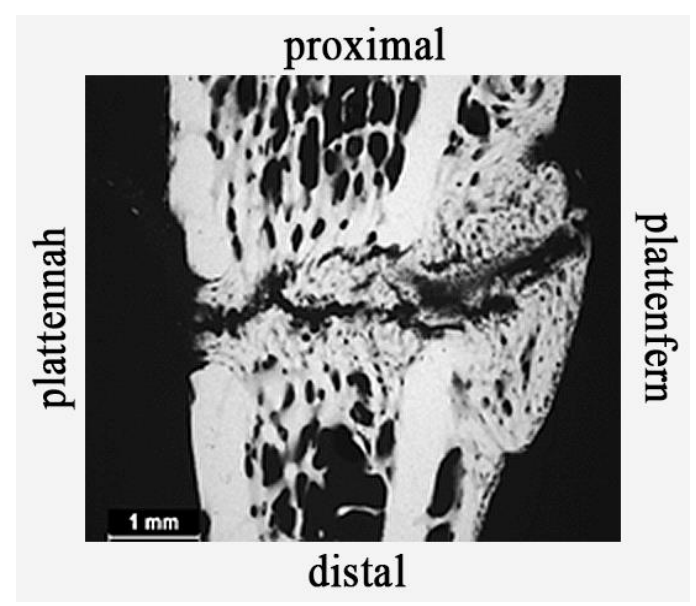

Abb. 14: Position des histologischen

Schnittes unter dem Mikroradioskop;

Versuchsgruppe NON OVX

Arbeitsschritt II: Graudetektion

Im nächsten Schritt erfolgte eine computergesteuerte Detektion, sodass die sichtbaren Knochenanteile durch die Software erfasst werden konnten. 
Arbeitsschritt III: Flächendefinition

Durch manuelles Umfahren der jeweiligen Flächen mit der Maus, konnten die entsprechenden Areale abgegrenzt werden. Die Flächen wurden in nachstehender Abfolge, der Methode von Weidemann (2013) entsprechend, definiert:

1) gesamter Knochen inklusive Kallus;

2) proximale, plattennahe Kortikalis;

3) proximale, plattenferne Kortikalis;

4) distale, plattennahe Kortikalis;

5) distale, plattenferne Kortikalis;

6) plattennaher Kallus;

7) plattenferner Kallus;

8) endostaler Kallus.

Arbeitsschritt IV: Definition der Kortikalis-, Knochen- und Kallusdicke

Dieser Arbeitsschritt beinhaltete die Festlegung von orthogonal zur Längsachse gelegenen Vektoren, welche etwas über die jeweilige Fläche hinausreichen sollten.

Die tatsächliche Kallus- bzw. Kortikalisdicke wurde dann durch die oben genannte Software berechnet. Die folgenden Parameter wurden auf diese Weise ermittelt:

1) distale, plattennahe Kortikalisdicke;

2) distale, plattenferne Kortikalisdicke;

3) proximale Knochendicke;

4) distale Knochendicke;

5) plattennahe Kallusdicke;

6) plattenferne Kallusdicke.

\subsubsection{Messparameter}

\subsubsection{Gesamter Knochen}

Tabelle 4: Messparameter gesamter Knochen, Einheit und Berechnung

\begin{tabular}{|c|c|c|}
\hline Messparameter & Einheit & Berechnung \\
\hline Knochendicke proximal & $\mathrm{mm}$ & $\begin{array}{l}\text { Arithmetisches Mittel der in Arbeitsschritt IV.3 } \\
\text { vorgenommenen Vektorenmessungen }\end{array}$ \\
\hline Knochendicke distal & $\mathrm{mm}$ & $\begin{array}{l}\text { Arithmetisches Mittel der in Arbeitsschritt IV.4 } \\
\text { vorgenommenen Vektorenmessungen }\end{array}$ \\
\hline
\end{tabular}




\subsubsection{Kortikalis}

Tabelle 5: Messparameter Kortikalis, Einheit und Berechnung

\begin{tabular}{|l|l|l|}
\hline $\begin{array}{l}\text { Messparameter } \\
\text { Kortikalisdicke distal } \\
\text { plattennah }\end{array}$ & Einheit & Berechnung \\
\hline $\begin{array}{l}\text { Kortikalisdicke distal } \\
\text { plattenfern }\end{array}$ & $\mathrm{mm}$ & $\begin{array}{l}\text { Arithmetisches Mittel der in Arbeitsschritt IV.1 } \\
\text { vorgenommenen 5 Vektorenmessungen }\end{array}$ \\
\hline $\begin{array}{l}\text { Kortikalisdichte distal } \\
\text { plattennah }\end{array}$ & $\%$ & $\begin{array}{l}\text { Prozentualer Anteil der in Schritt III.4 } \\
\text { vorgenommenen 5 Vektorenmessungen } \\
\text { festgelegten Fläche an mineralisierter } \\
\text { Knochenmatrix }\end{array}$ \\
\hline $\begin{array}{l}\text { Kortikalisdichte distal } \\
\text { plattenfern }\end{array}$ & $\%$ & $\begin{array}{l}\text { Prozentualer Anteil der in Schritt III.5 } \\
\text { festgelegten Fläche an mineralisierter } \\
\text { Knochenmatrix }\end{array}$ \\
\hline
\end{tabular}

\subsubsection{Kallus}

Tabelle 6: Messparameter Kallus, Einheit und Berechnung

\begin{tabular}{|c|c|c|}
\hline Messparameter & Einheit & Berechnung \\
\hline Kallusdicke plattennah & $\mathrm{mm}$ & $\begin{array}{l}\text { Arithmetisches Mittel der in Arbeitsschritt IV.5 } \\
\text { vorgenommenen Vektorenmessungen }\end{array}$ \\
\hline Kallusdicke plattenfern & $\mathrm{mm}$ & $\begin{array}{l}\text { Arithmetisches Mittel der in Arbeitsschritt IV.6 } \\
\text { vorgenommenen Vektorenmessungen }\end{array}$ \\
\hline Kallusdichte plattennah & $\%$ & $\begin{array}{l}\text { Prozentualer Anteil der in Schritt III.6 } \\
\text { festgelegten Fläche an mineralisierter } \\
\text { Knochenmatrix }\end{array}$ \\
\hline Kallusdichte plattenfern & $\%$ & $\begin{array}{l}\text { Prozentualer Anteil der in Schritt III.7 } \\
\text { festgelegten Fläche an mineralisierter } \\
\text { Knochenmatrix }\end{array}$ \\
\hline Kallusdichte endostal & $\%$ & $\begin{array}{l}\text { Prozentualer Anteil der in Schritt III.8 } \\
\text { festgelegten Fläche an mineralisierter } \\
\text { Knochenmatrix }\end{array}$ \\
\hline
\end{tabular}




\subsection{Prinzip der polychromen Sequenzmarkierung}

Die polychrome Sequenzmarkierung ist ein Verfahren zur Markierung des neu gelbildeten Knochengewebes, sodass eine Darstellung der dynamischen Veränderungen während der Frakturheilung erfolgt. Im Gegensatz zu den bisher beschriebenen Momentaufnahmen der bildgebenden Verfahren kann diese Methode das zeitliche und räumliche Ausmaß der Kallusbildung protokollieren. Vorab wurden den Tieren intravital drei Fluorochrome mit verschiedener Farbe appliziert. Dies erfolgte zu bestimmten, zuvor festgelegten Zeitpunkten. Die Substanzen werden in den Knochen inkorporiert und bilden Komplexe mit den Mineralsalzen des biologisch aktiven Knochens aus. Die Chelatkomplexe aus Kalzium und dem jeweiligen Fluorochrom lagern sich entlang der Mineralisationsfronten ein. So entsteht in der folgenden quantitativen fluoreszenzmikroskopischen Darstellung eine farbliche Kodierung des Mineralisationszeitraumes durch die entsprechend fluoreszierende Bande. Auffällig ist dabei die verstärkte Markierung des Frakturkallus, der durch eine signifikant höhere Umbauaktivität gekennzeichnet ist.

\subsubsection{Fluorochrome}

Die polychrome Sequenzmarkierung wurde unter Verwendung der Fluorochrome Xylenolorange-Tetranatriumsalz (XO), Calcein-Grün (CG) und Alizarinkomplexon (AK) (alle: Merck, Darmstadt, Deutschland), wie durch B. Rahn 1976 etabliert, nach der Methodik von Komrakova et al. (2010) durchgeführt. Die subkutane Injektion erfolgte, nach Lösung der Fluorochrome in destilliertem Wasser (Tab. 7). Zu beachten ist, dass einerseits lediglich die bis zum Injektionszeitpunkt vorangeschrittene Knochenmineralisation und andererseits nur die bisher durch andere Flourochrome ungefärbte Substanz markiert wird. Die farbliche Kodierung in der Blaufloureszenz ist in Tabelle 7 unter dem spezifischen Fluorochrom aufgeführt.

Tabelle 7: Darstellung der Applikationszeitpunkte, Anfärbungszeiträume und Dosierungen der verschiedenen Fluorochrome

\begin{tabular}{|l|l|l|l|l|}
\hline $\begin{array}{l}\text { Fluorochrom } \\
\text { und Farbe }\end{array}$ & $\begin{array}{l}\text { Applikations- } \\
\text { zeitpunkt } \\
\text { [Tag nach Osteotomie] }\end{array}$ & $\begin{array}{c}\text { Markierungszeit- } \\
\text { raum [Tag nach } \\
\text { Osteotomie] }\end{array}$ & $\begin{array}{l}\text { Dosierung in } \\
\text { mg/kg Körper- } \\
\text { gewicht }\end{array}$ & $\begin{array}{l}\text { Dosie- } \\
\text { rung in } \\
\text { ml }\end{array}$ \\
\hline XO; orange & 15 & $0-15$ & 90 & 0,5 \\
\hline CG; grün & 20 & $16-20$ & 10 & 0,3 \\
\hline AK; rot & 28 & $21-28$ & 30 & 0,5 \\
\hline
\end{tabular}




\subsubsection{Auswertung}

\subsubsection{Apparaturen und Software}

Die histologischen Schnitte wurden nach dem bereits unter 2.8.1 beschriebenen Prinzip angefertigt und zur Auswertung auf Objektträgern (52 x 76 mm) mit Eukitt ${ }^{\circledR}$ (Fa. Kindler, Freiburg, Deutschland) eingedeckt.

Durch das Auflicht-Fluoreszenz-Stereomakroskop (Leica Stereomakroskop MZ 7-5 mit FluoCombi III, Bensheim, Deutschland) erfolgte die Beurteilung der histologischen Präparate in Blaufluoreszenz. Unter Einsatz eines Anregungsfilters für den Wellenlängenbereich von 450-490 nm, wurde die durch blaues Licht erzeugte Fluorochromanregung erreicht. Die Lichtquelle des Makroskops bestand aus einer Quecksilberhöchstdrucklampe mit einer Leistung von 100 Watt. Durch die integrierte Kamera (Leica DC 300F, Bensheim, Deutschland) und die bereits für die Mikroradiographie verwendete Software (MetaMorph Basic Acquisition Software; Leica Mikrosysteme Vertrieb GmbH; Wetzlar; Deutschland) wurden die Bilder auf den Computer übertragen.

Die Untersuchungseinstellungen wurden entsprechend der optimierten Konfigurationen vorangegangener Versuche gewählt. Mit Hilfe eines 1,6er Objektivs am Makroskop wurde eine 16-fache Vergrößerung erzielt. Durch die Software konnte die Belichtungszeit auf 111 Sekunden festgelegt werden. Zur Verbesserung der Lichtverhältnisse wurde der Raum zusätzlich abgedunkelt.

\subsubsection{Arbeitsschritte}

Arbeitsschritt I: Feststellung der Auswertbarkeit und Positionierung der Präparate

Analog zur unter 2.8.2.2 (S.39, Arbeitsschritt I) erläuterten Vorgehensweise bei den Mikroradiographien wurde auch bei der Evaluierung und Positionierung der fluoreszenzmikroskopischen Schnitte verfahren.

\section{Arbeitsschritt II: Flächendefinition}

Auch die im Folgenden aufgeführten Flächen wurden nach dem unter 2.8.2.2 (S. 40, Arbeitsschritt III) angewendeten Prinzip festgelegt: 
1) gesamter Knochen inklusive Kallus;

2) proximale, plattennahe Kortikalis;

3) proximale, plattenferne Kortikalis;

4) distale, plattennahe Kortikalis;

5) distale, plattenferne Kortikalis;

6) plattennaher Kallus;

7) plattenferner Kallus;

8) endostaler Kallus.

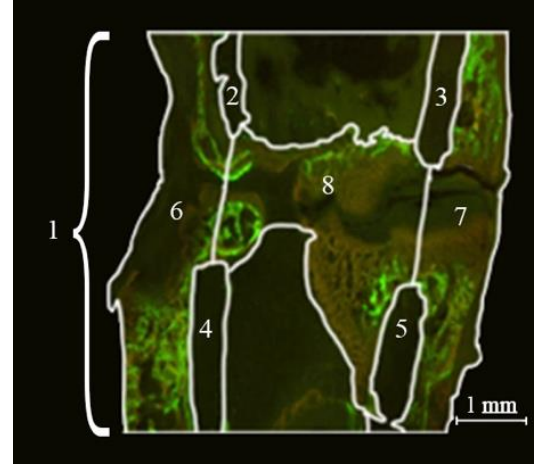

Abb. 15: Flächendefinition unter dem Fluoreszenzmikroskop; Versuchsgruppe $100 \mathrm{mg}$ Baicalein

Die Abbildung 15 verdeutlicht die obenstehenden Flächenabgrenzungen am Beispiel eines fluoreszenzmikroskopischen Bildes.

Arbeitsschritt III: Zuordnung der Knochenflächen und Fluorochrome

Unter Beachtung lediglich dreier der bereits genannten Flächen konnten die in gleicher Weise fluoreszierenden Areale umfahren und dem jeweiligen Fluorochrom zugeordnet werden. Nur die plattennahen, plattenfernen und endostalen Kallusbereiche wurden hierbei berücksichtigt.

\section{1) XO-Fläche:}

Diese Knochenflächen stellten sich orange dar. Da die durch das zuerst applizierte Xylenolorange-Tetranatriumsalz markierten Bereiche so klein waren, dass sie nur unter hoher Auflösung zu sehen waren, stellte sich ihre Abgrenzung als problematisch heraus. Daher erfolgte ihre Auswertung gemeinsam mit den umliegenden CG-Flächen.

\section{2) CG-Fläche:}

In unmittelbarer Umgebung der Trabekel war eine grüne Knochenfläche entsprechend der Calcein-Grün-Einfärbung zu erkennen.

\section{3) AK-Fläche:}

Die rot eingefärbte Alizarinkomplexon-Fläche konnte als ein dem Osteotomiespalt am nächsten liegender Bereich identifiziert werden. Da die Applikation dieses Fluorochroms zu einem späteren Zeitpunkt stattgefunden hatte, wurde das markierte Areal durch das früher verabreichte CG von den Trabekeln abgegrenzt. 


\subsubsection{Zeitpunkt der frühesten Überbrückung des Frakturspalts}

Im Rahmen der Frakturheilung wurde der zeitliche Verlauf der knöchernen Zusammenfügung der Osteotomieenden innerhalb der Versuchsgruppen untersucht und verglichen. Der früheste Zeitpunkt der Frakturüberbrückung konnte anhand von Markierungen der zu bestimmten Zeitpunkten applizierten Fluorochrome determiniert werden. Die Anreicherung der verschiedenen Farben sowie deren Lokalisation ermöglichte unter Betrachtung von 11 verschiedenen Schnitten eines Knochens die Beurteilung der zuerst entstandenen Kallusbrücke. Es fluoreszierte dabei immer der Gewebeteil in der entsprechenden Farbe, der sich bis zum Zeitpunkt der Applikation gebildet hatte. Die Fluorochrome reicherten sich allerdings nur in bisher nicht markierten Bereichen an. Unter Beurteilung der Farbe der Kallusbrücke (eine rote Brücke entspricht der Frakturüberbrückung im Zeitraum der AK-Anreicherung (Tag 21-28)) und deren Dicke (eine größere Fluorochrom Ausdehnung ist konform mit einer früheren Überbrückung, während eine schmale Brücke für eine spätere Frakturheilung spricht), wurden die Überbrückungszeitpunkte und deren Mittelwerte erhoben.

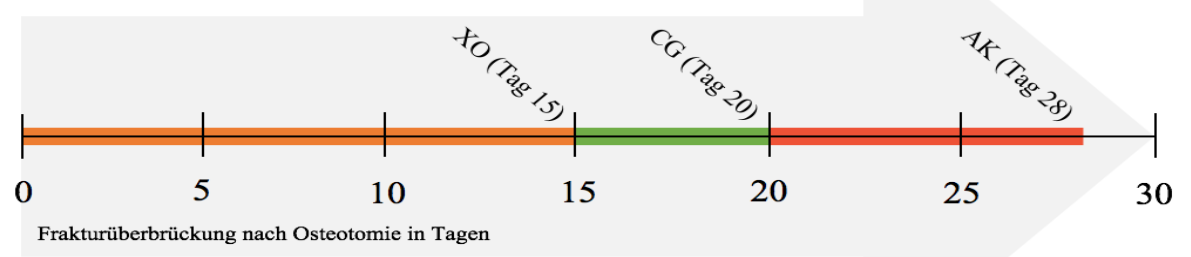

Abb. 16: Schematische Darstellung der Frakturüberbrückung durch die FluorochromMarkierung

\subsubsection{Messparameter}

\subsubsection{Kallus plattennah}

Tabelle 8: Messparameter Kallus plattennah, Einheit und Berechnung

\begin{tabular}{|l|l|l|}
\hline Kallusfläche plattennah & Einheit & Bedeutung \\
\hline $\begin{array}{l}\text { Gesamtfläche plattennaher } \\
\text { Kallus }\end{array}$ & $\mathrm{mm}^{2}$ & $\begin{array}{l}\text { absolute Fläche des gesamten } \\
\text { plattennahen Kallus }\end{array}$ \\
\hline CG- Fläche & $\mathrm{mm}^{2}$ & $\begin{array}{l}\text { absolute Fläche des CG-markierten } \\
\text { plattennahen Kallus }\end{array}$ \\
\hline AK- Fläche & $\mathrm{mm}^{2}$ & $\begin{array}{l}\text { absolute Fläche des AK-markierten } \\
\text { plattennahen Kallus }\end{array}$ \\
\hline
\end{tabular}




\subsubsection{Kallus plattenfern}

Tabelle 9: Messparameter Kallus plattenfern, Einheit und Berechnung

\begin{tabular}{|l|l|l|}
\hline Kallusfläche plattenfern & Einheit & Bedeutung \\
\hline $\begin{array}{l}\text { Gesamtfläche plattenferner } \\
\text { Kallus }\end{array}$ & $\mathrm{mm}^{2}$ & $\begin{array}{l}\text { absolute Fläche des gesamten } \\
\text { plattenfernen Kallus }\end{array}$ \\
\hline CG- Fläche & $\mathrm{mm}^{2}$ & $\begin{array}{l}\text { absolute Fläche des CG-markierten } \\
\text { plattenfernen Kallus }\end{array}$ \\
\hline AK- Fläche & $\mathrm{mm}^{2}$ & $\begin{array}{l}\text { absolute Fläche des AK-markierten } \\
\text { plattenfernen Kallus }\end{array}$ \\
\hline
\end{tabular}

\subsubsection{Kallus endostal}

Tabelle 10: Messparameter Kallus endostal, Einheit und Berechnung

\begin{tabular}{|l|l|l|}
\hline Kallus endostal & Einheit & Bedeutung \\
\hline $\begin{array}{l}\text { Gesamtfläche endostaler } \\
\text { Kallus }\end{array}$ & $\mathrm{mm}^{2}$ & $\begin{array}{l}\text { absolute Fläche des gesamten } \\
\text { endostalen Kallus }\end{array}$ \\
\hline CG- Fläche & $\mathrm{mm}^{2}$ & $\begin{array}{l}\text { absolute Fläche des CG-markierten } \\
\text { endostalen Kallus }\end{array}$ \\
\hline AK- Fläche & $\mathrm{mm}^{2}$ & $\begin{array}{l}\text { absolute Fläche des AK-markierten } \\
\text { endostalen Kallus }\end{array}$ \\
\hline
\end{tabular}

2.9.4.4 Kompletter Kallus

Tabelle 11: Messparameter Kallus komplett, Einheit und Berechnung

\begin{tabular}{|l|l|l|}
\hline Kompletter Kallus & Einheit & Bedeutung \\
\hline $\begin{array}{l}\text { Gesamtfläche kompletter } \\
\text { Kallus }\end{array}$ & $\mathrm{mm}^{2}$ & $\begin{array}{l}\text { Summe aus der Gesamtfläche des } \\
\text { plattennahen, plattenfernen und }\end{array}$ \\
& & \begin{tabular}{l} 
endostalen Kallus \\
\hline
\end{tabular} \\
\hline
\end{tabular}




\subsection{Statistik}

Für alle Versuchsgruppen und Methoden wurde die statistische Auswertung mit Hilfe des Programms GraphPad Prism (Version 5.0, GraphPad Software, San Diego, USA) vorgenommen. Unter Feststellung der Normalverteilung wurden im Rahmen der Ergebnisevaluation Mittelwert und Standardabweichung der jeweils erhobenen Daten ermittelt. Signifikante Unterschiede unter den Versuchstiergruppen konnten durch den gekoppelten Einsatz der Varianzanalyse one-way ANOVA und den Tukey-Kramer post-hoc-Test analysiert werden. Alle Ergebnisse $\mathrm{p}<0,05$ wurden als signifikant definiert. 


\section{Ergebnisse}

Die nachstehend präsentierten Resultate der Ermittlung von Körpergewicht und Futteraufnahme der Versuchstiere, des biomechanischen Tests, der MikroComputertomographie, sowie der Mikroradiographie und der polychromen Sequenzmarkierung werden nach einem identischen Schema veranschaulicht. Die Ergebnisse werden zunächst mit Hilfe von Diagrammen graphisch visualisiert und nach schriftlicher Darlegung tabellarisch zusammengefasst. Dabei erfolgt eine Darstellung der jeweiligen Mittelwerte mit zugehöriger Standardabweichung und Signifikanzen. Während das Signifikanzniveau auf $\mathrm{p}<0,05$ festgelegt ist, werden bei der Ergebnispräsentation $\mathrm{p}<0,05$ als signifikant, $\mathrm{p}<0,01$ als hoch signifikant und $\mathrm{p}<$ 0,001 als höchst signifikant definiert. Die Signifikanzen werden mit Hilfe dieser Symbole gekennzeichnet:

$*=\mathrm{p}<0,05$

$* *=\mathrm{p}<0,01$

$* * *=\mathrm{p}<0,001$

$\alpha=$ signifikant zu allen anderen Gruppen

$\beta=$ signifikant zu NON OVX

$\gamma=$ signifikant zu OVX

$\delta=$ signifikant zu $1 \mathrm{mg}$ Baicalein / kg Körpergewicht

$\varepsilon=$ signifikant zu $10 \mathrm{mg}$ Baicalein $/ \mathrm{kg}$ Körpergewicht

$\lambda=$ signifikant zu $100 \mathrm{mg}$ Baicalein / $\mathrm{kg}$ Körpergewicht 


\subsection{Körpergewicht der Tiere im Verlauf}

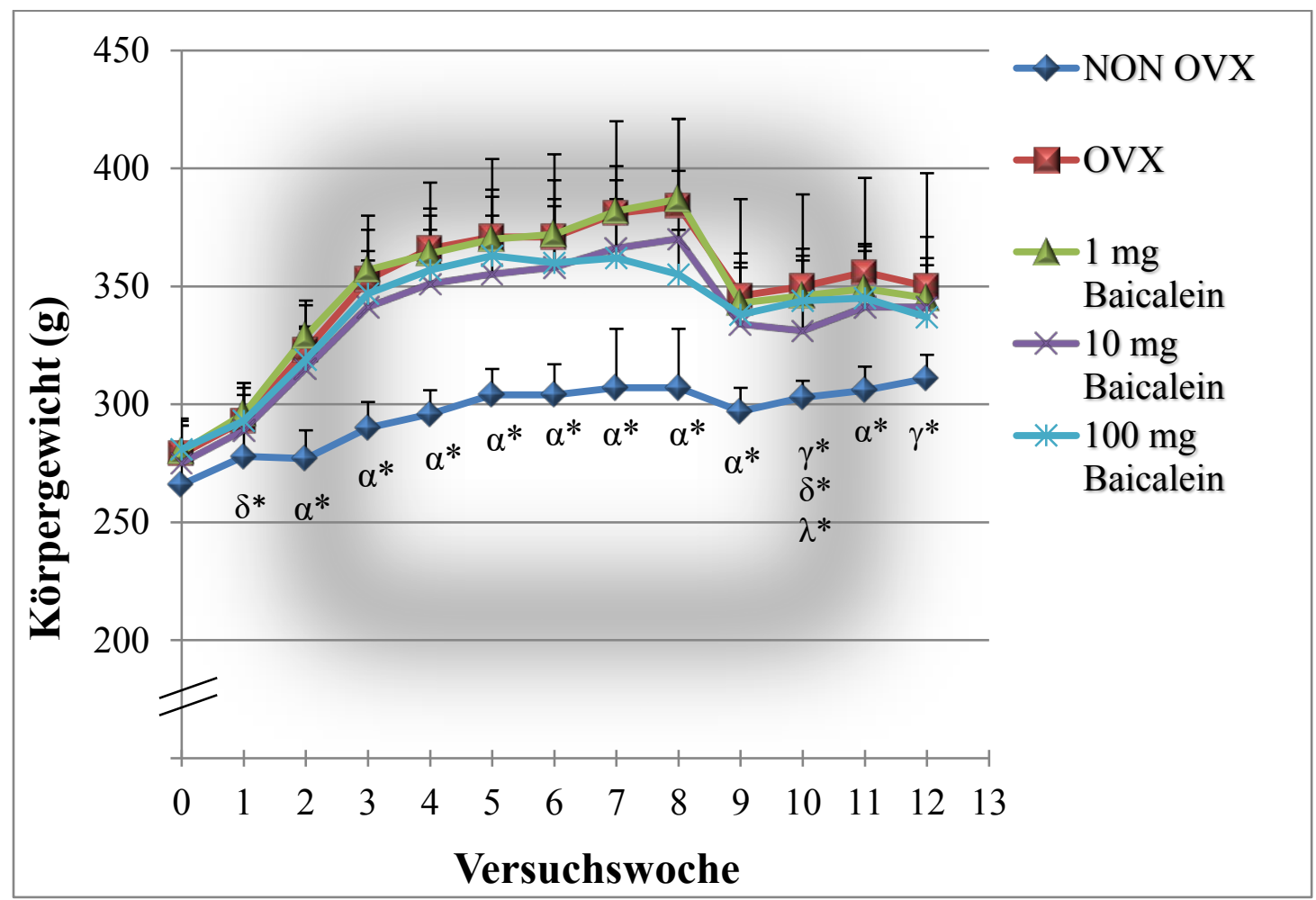

Abb. 17: Darstellung des mittleren Körpergewichts der Tiere jeder Gruppe pro Versuchswoche vom Beginn (Versuchswoche 0) bis zum Ende (Versuchswoche 12) des Versuchs; $\alpha=$ signifikant zu allen anderen Gruppen, $\gamma=$ signifikant zu OVX, $\delta=$ signifikant zu $1 \mathrm{mg}$ Baicalein, $\lambda=$ signifikant zu $100 \mathrm{mg}$ Baicalein, $*=\mathrm{p}<0,05$

(Analyse durch One-way ANOVA und Tukey-Kramer post-hoc-Test)

Zunächst ist bei der Auswertung der Körpergewichte augenscheinlich, dass sich die Ausgangsgewichte in den Gruppen nur unwesentlich unterscheiden. Weiterhin ist auffällig, dass das gesamte Versuchskollektiv über den Versuchszeitraum eine kontinuierliche Gewichtszunahme aufweist (Abb. 17). Dabei ist zu beachten, dass das Körpergewicht der ovarektomierten Ratten signifikant schneller steigt, als das Gewicht nicht operierter Tiere. Diese Differenz blieb bis zum Versuchsende bestehen. Während alle ovarektomierten Gruppen auch in der Woche der Osteotomie (Woche 8) signifikant mehr wogen als die Gruppe NON OVX, nahm das Gewicht in der folgenden Woche bei den mit Baicalein behandelten Tieren ab. Die starke Gewichtszunahme blieb nur in der ovarektomierten, nicht mit Baicalein behandelten Versuchsgruppe bestehen. In der letzten Versuchswoche waren die Körpergewichte innerhalb des ovarektomierten 
Kollektivs teilweise sogar rückläufig, so dass lediglich die ovarektomierten Tiere, bei denen kein Baicalein appliziert wurde, ein signifikant höheres Gewicht aufwiesen, als die nicht ovarektomierte Gruppe.

\subsection{Uterusgewicht}

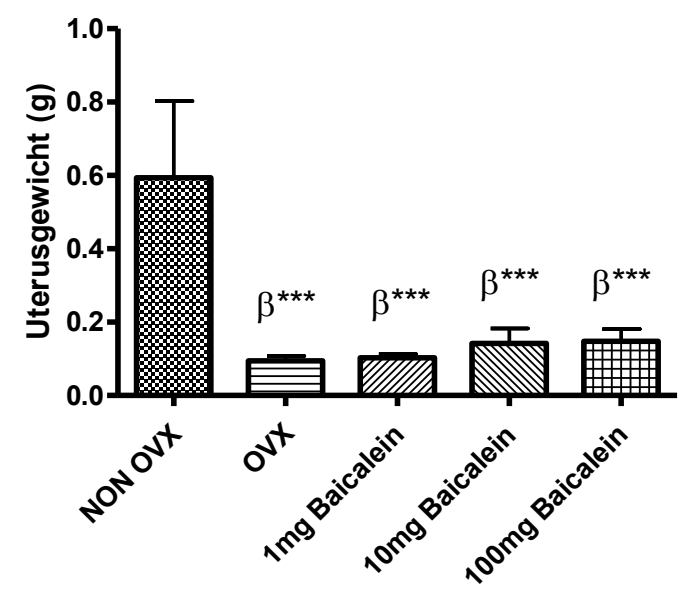

Abb. 18: Darstellung des mittleren Uterusgewichtes der Tiere jeder Versuchsgruppe am Tag der Obduktion; $\beta=$ signifikant zu NON OVX, $* * *=p<0,001$

(Analyse durch One-way ANOVA und Tukey-Kramer post-hoc Test)

Alle Tiere, die einer Ovarektomie unterzogen wurden, weisen mit höchster Signifikanz geringere Uterusgewichte auf, als die nicht ovarektomierten Ratten (Abb. 18).

\subsection{Ergebnisse des biomechanischen Tests}

\subsubsection{Elastizität}

Trotz einer deutlichen Tendenz der Knochen in der nicht ovarektomierten Kontrollgruppe $\mathrm{zu}$ höherer Elastizität war kein signifikanter Unterschied zu den anderen Versuchsgruppen nachweisbar (Abb. 19). Ebenfalls ohne Signifikanz zeigt sich eine gesteigerte Elastizität der Knochen der mit 100 mg Baicalein pro Kilogramm Körpergewicht behandelten Tiere gegenüber dem restlichen ovarektomierten Kollektiv. 


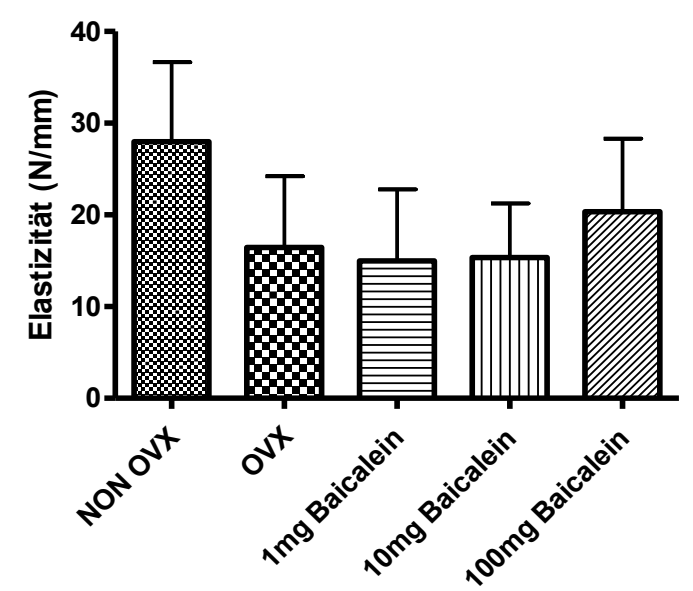

Abb. 19: Darstellung der Ergebnisse der Messgröße Elastizität

\subsubsection{Streckgrenze und Maximalkraft}

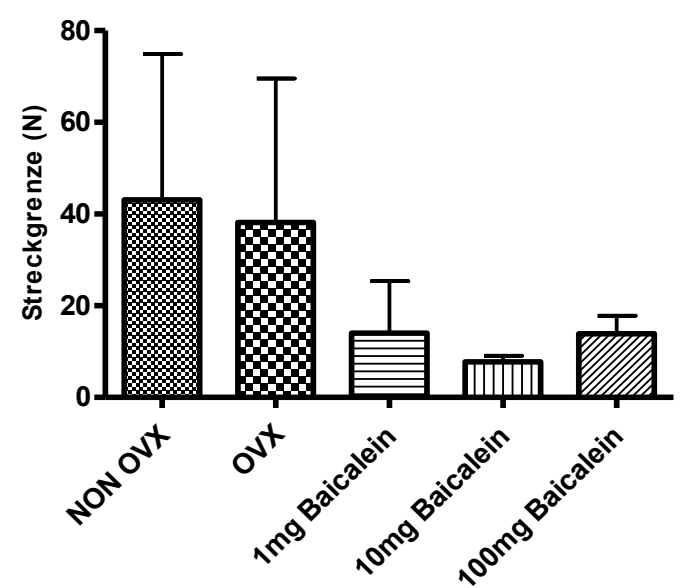

Abb. 20: Darstellung der Ergebnisse der Messgröße Streckgrenze

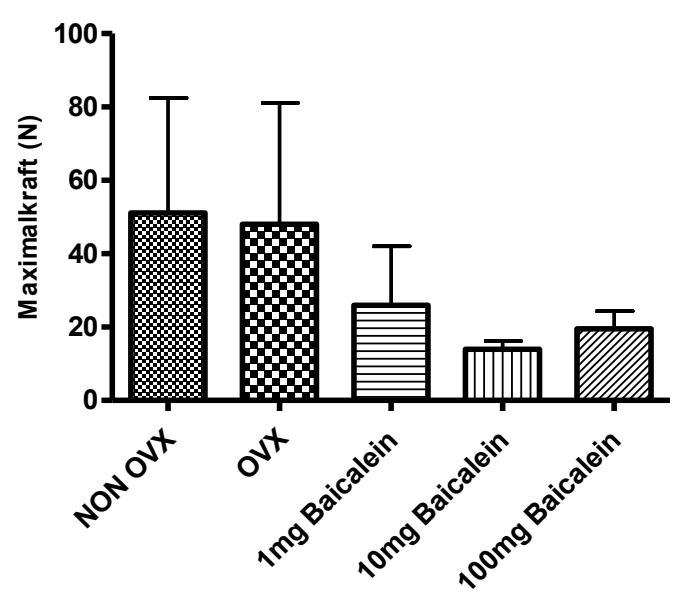

Abb. 21: Darstellung der Ergebnisse der Messgröße Maximalkraft

Sowohl die Messung der Streckgrenze (Yield Load) als auch der Maximalkraft zeigten in keiner Gruppe eine signifikante Differenz (Abb. 20 und 21). Vor allem in den Gruppen NON OVX und OVX ist allerdings auf die hohen Standardabweichungen bei beiden Parametern zu verweisen. Auffällig ist eine nicht signifikante Erhöhung der Streckgrenze sowie Maximalkraft bei den nicht mit Baicalein behandelten Tieren (NON OVX, OVX), verglichen mit den behandelten Gruppen. 


\subsection{Ergebnisse der Mikrocomputertomographie}

Nachfolgend werden die Ergebnisse der Mikro-Computertomographie-Untersuchung zunächst graphisch und anschließend tabellarisch zusammengefasst dargestellt. Die Erörterung erfolgt getrennt für die gemessenen Parameter (Knochen-)dichte und Volumen für die Bereiche Weichteil, Kortikalis, Kallus, gesamter Knochen und das gesamte Gewebe. Darüber hinaus wird die Messung des Knochenvolumens (Bone Volume) im Verhältnis zum Gewebevolumen (Tissue Volume) präsentiert und erläutert.

\subsubsection{Weichteilparameter}

\subsubsection{Weichteil-Dichte}

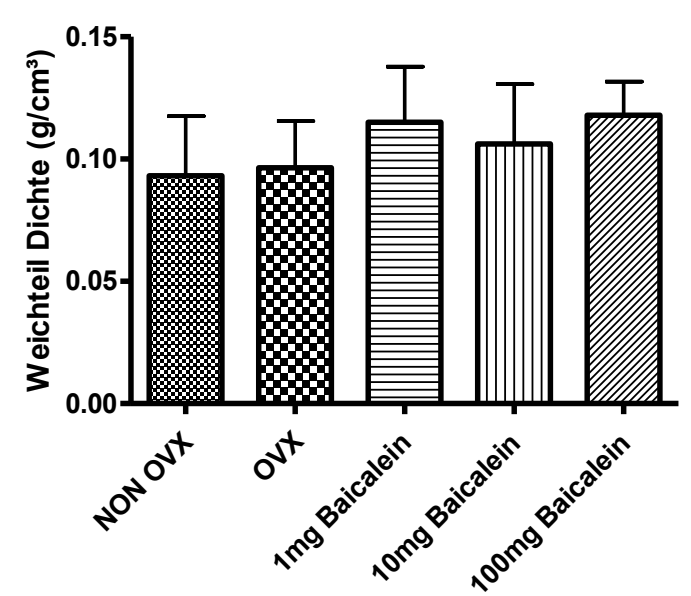

Abb. 22: Darstellung der Ergebnisse des Messparameters Weichteil-Dichte

In Bezug auf die Weichteildichte zeigten sich bei der Untersuchung keine signifikanten Differenzen unter den Versuchsgruppen (Abb. 22). Es bleibt darauf hinzuweisen, dass die mit Baicalein behandelten Tiere eine Tendenz zu höherer Weichteil-Dichte zeigen. 


\subsubsection{Weichteil-Volumen}

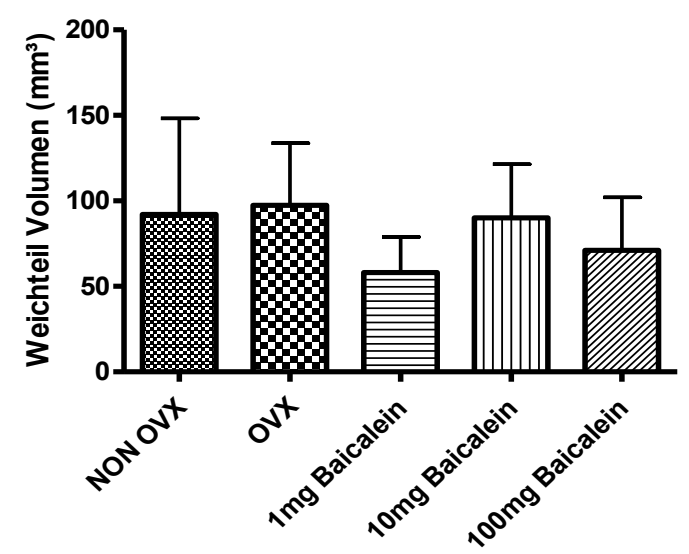

Abb. 23: Darstellung der Ergebnisse des Messparameters Weichteil-Volumen

Auch das Weichteil-Volumen unterscheidet sich nicht signifikant im GruppenVergleich. $\mathrm{Zu}$ beachten sind bei dieser Messung die hohen Standardabweichungen (Abb. 23).

\subsubsection{Kortikalisparameter}

\subsubsection{Kortikalis-BMD}

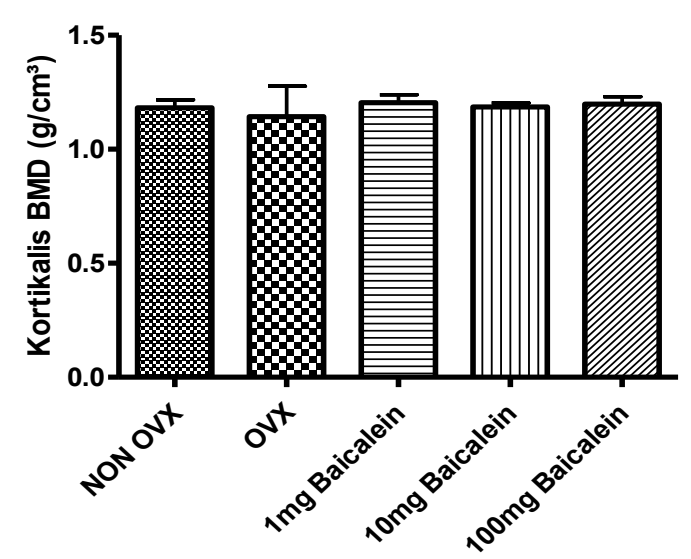

Abb. 24: Darstellung der Ergebnisse des Messparameters Kortikalis-BMD

Die Bone Mineral Density der Kortikalis ist innerhalb des gesamten Versuchskollektivs vergleichbar und weist keine signifikanten Differenzen auf (Abb. 24). 


\subsubsection{Kortikalis-Volumen}

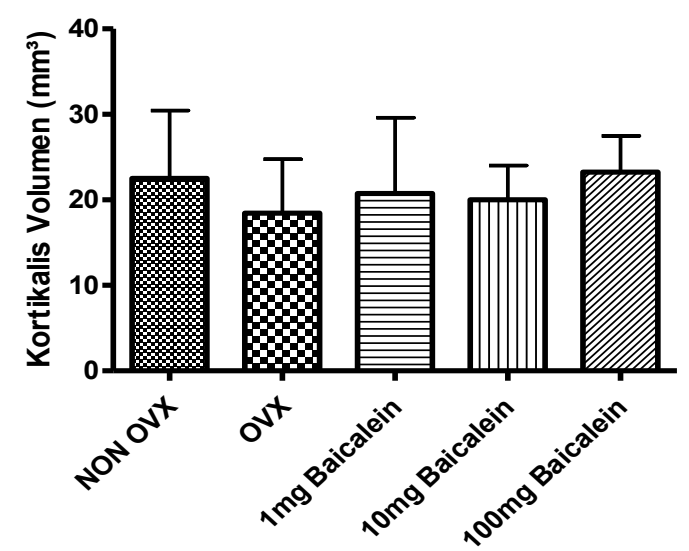

Abb. 25: Darstellung der Ergebnisse des Messparameters Kortikalis-Volumen

Das Kortikalis-Volumen weicht unter den Versuchsgruppen leicht voneinander ab. Eine Signifikanz ist dennoch nicht erkennbar (Abb. 25). Unter den ovarektomierten Ratten zeigt sich ein höheres Kortikalisvolumen der Baicalein-Behandlungsgruppe, gegenüber den unbehandelten Tieren.

\subsubsection{Kallusparameter}

\subsubsection{Kallus-BMD}

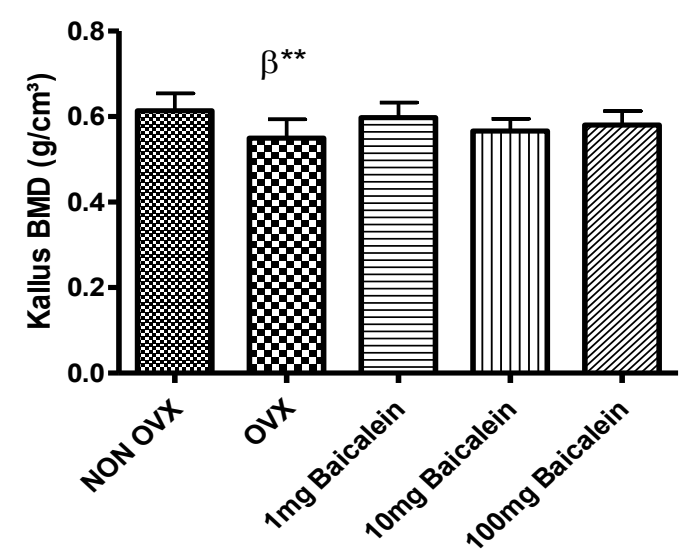

Abb. 26: Darstellung der Ergebnisse des Messparameters Kallus-BMD; $\beta=$ signifikant zu NON OVX, $* *=p<0,01$

(Analyse durch One-way ANOVA und Tukey-Kramer post-hoc-Test) 
Bezüglich der Kallus-Dichte ist auf eine hoch signifkante Verminderung bei den ovarektomierten, nicht mit Baicalein behandelten Tieren, verglichen mit der Gruppe NON OVX hinzuweisen (Abb. 26). Währenddessen sind die Dichtewerte der anderen Gruppen vergleichbar und weisen keine signifikanten Abweichungen auf.

\subsubsection{Kallus-Volumen}

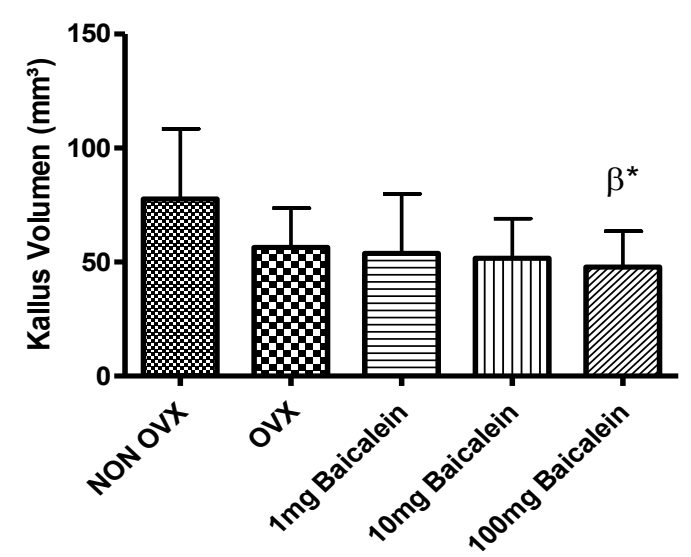

Abb. 27: Darstellung der Ergebnisse des Messparameters Kallus-Volumen; $\beta=$ signifikant zu NON OVX, $*=p<0,05$

(Analyse durch One-way ANOVA und Tukey-Kramer post-hoc-Test)

Hinsichtlich des Parameters Kallus-Volumen fällt eine signifikante Volumenverminderung bei den Tieren auf, bei denen die höchste Konzentration Baicalein appliziert wurde, verglichen mit dem nicht ovarektomierten Versuchskollektiv (Abb. 27). Darüber hinaus ist ein Trend der Gruppe NON OVX zu mehr Kallusvolumen bei Gegenüberstellung mit anderen Gruppen erkennbar. Dieser bleibt allerdings ohne Signifikanz. 


\subsubsection{Parameter, die den gesamten Knochen betreffen}

\subsubsection{Knochen-BMD}

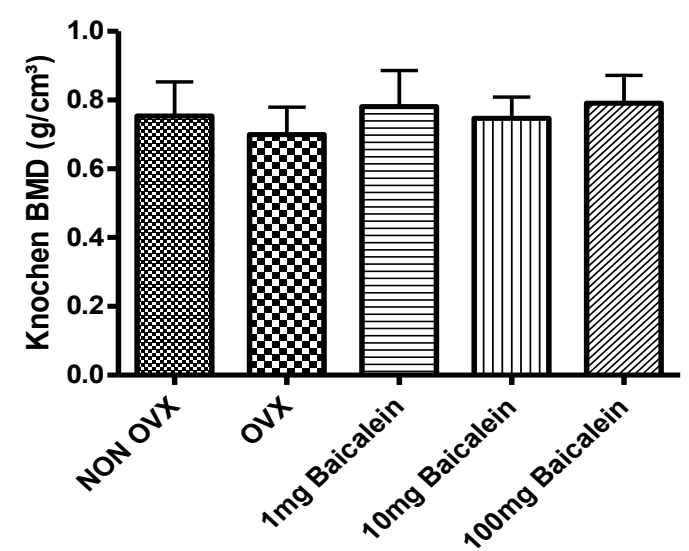

\section{Abb. 28: Darstellung der Ergebnisse des Messparameters Knochen-BMD}

Betreffend der Bone Mineral Density konnte kein signifikanter Unterschied unter den Versuchsgruppen ermittelt werden (Abb. 28).

\subsubsection{Knochen-Volumen}

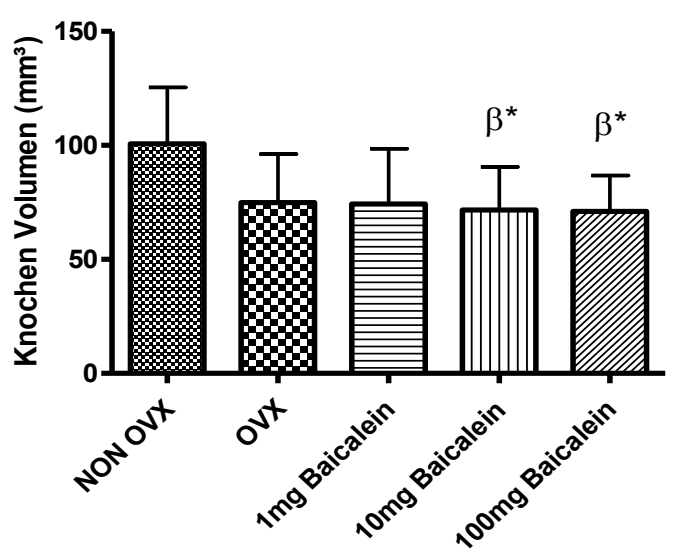

Abb. 29: Darstellung der Ergebnisse des Messparameters Knochen-Volumen; $\beta=$ signifikant zu NON OVX, $*=p<0,05$

(Analyse durch One-way ANOVA und Tukey-Kramer post-hoc-Test)

Im Hinblick auf das Knochen-Volumen stellen sich signifikante Unterschiede im Kollektiv der Baicalein-Behandlungsgruppe zu den nicht ovarektomierten Tieren dar (Abb. 29). Sowohl die mit $10 \mathrm{mg}$ als auch die mit $100 \mathrm{mg}$ Baicalein pro Kilogramm Körpergewicht behandelten Tiere weisen ein niedrigeres Knochenvolumen auf. 
Wiederum ist ein Trend der Gruppe NON OVX zu mehr Volumen erkennbar. Dieser ist weist indessen keine Signifikanz auf.

\subsubsection{Parameter, die das gesamte Gewebe betreffen}

\subsubsection{Gesamtes Gewebe Dichte}

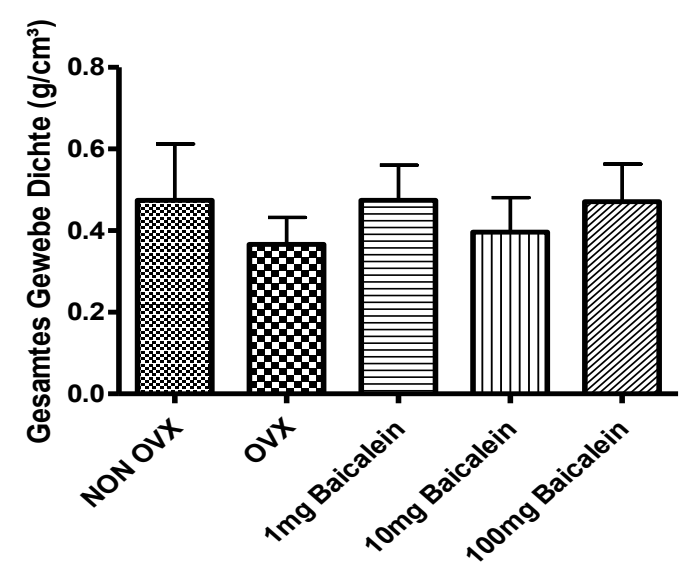

Abb. 30: Darstellung der Ergebnisse des Messparameters gesamtes Gewebe Dichte

Die Dichte des gesamten Gewebes variiert zwischen allen Gruppen, unterscheidet sich dennoch in keinem Fall signifikant (Abb. 30).

\subsubsection{Gesamtes Gewebe Volumen}

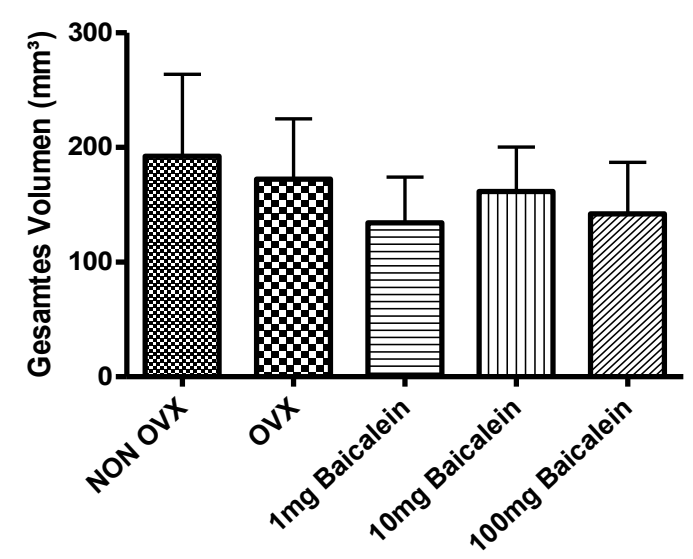

Abb. 31: Darstellung der Ergebnisse des Messparameters gesamtes Gewebe Volumen

Bezüglich des gesamten Volumens sind keine Signifikanzen erkennbar (Abb. 31). Lediglich eine geringe Tendenz der nicht ovarektomierten Gruppe zu einem höheren Gesamtvolumen deutet sich an. 


\subsubsection{BV/TV}

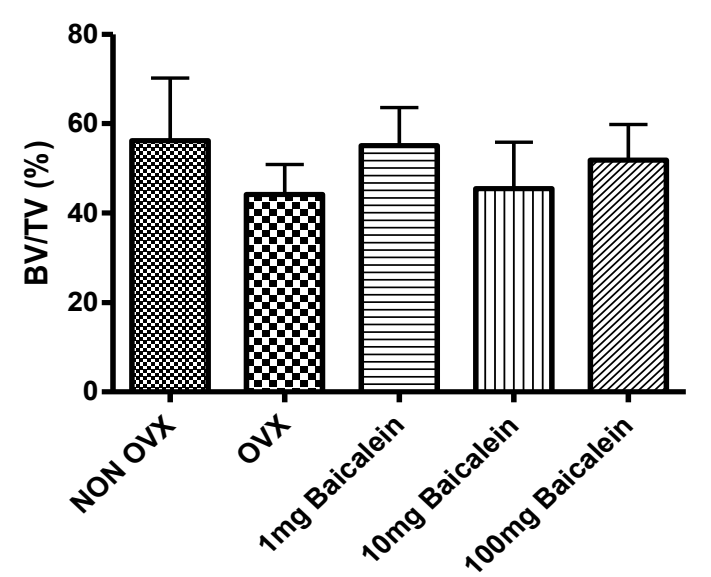

Abb. 32: Darstellung der Ergebnisse des Messparameters Bone Volume/ Tissue Volume

Hinsichtlich der Messgrößen des Knochenvolumens (BV) im Verhältnis zum Gewebevolumen (TV) zeigten sich keine signifikanten Unterschiede unter den Versuchsgruppen (Abb. 32).

\subsection{Ergebnisse der Mikroradiographie}

In den Abbildungen 33 bis 37 werden zunächst repräsentative mikroradiographische Aufnahmen jeder Versuchsgruppe dargestellt und im Folgenden die jeweiligen Ergebnisse, zunächst in Form von Diagrammen und abschließend in einer tabellarischen Übersicht, dargestellt.

Während der näheren Begutachtung der Mikroradiographien war allgemein erkennbar, dass bei einem überwiegenden Teil jeder Testgruppe eine deutliche Kallusbildung stattgefunden hatte. Ein augenscheinlicher Unterschied zwischen den einzelnen Gruppen war nicht auszumachen, da es in jeder Gruppe Tiere gab, bei denen deutliche Kortikalisdefekte sowie ein übermäßiges oder gar fehlendes Kalluswachstum vorlagen. Allerdings fiel bei jeder Versuchsgruppe auf, dass es am hinteren plattenfernen Bereich der Tibiae zu offensichtlich ausgeprägterem Kalluswachstum kam als an der ventralen Lokalisation der Osteosynthese Platte. In der Gruppe NON OVX war der endostale Kallus im Vergleich zu den behandelten Tieren vermehrt ausgebildet (Abb. 33). Eine vollständige Überbrückung des Frakturspalts lag dennoch in keiner Gruppe bei allen Tieren vor. 


\subsubsection{Repräsentative Mikroradiographien}

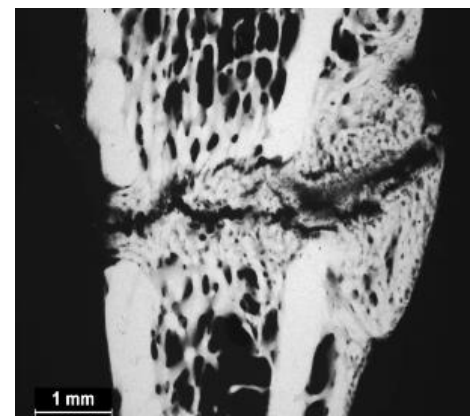

Abb. 33: NON OVX; repräsentative

Mikroradiographie

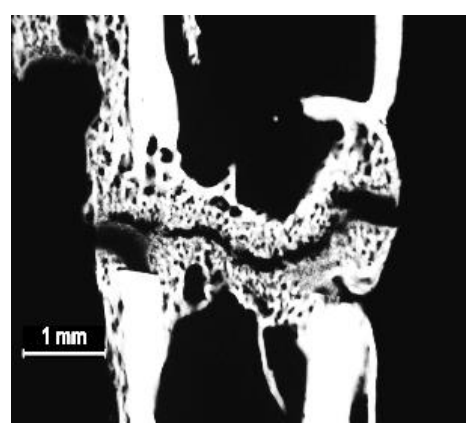

Abb. 36: $10 \quad \mathrm{mg}$

Baicalein; repräsentative

Mikroradiographie

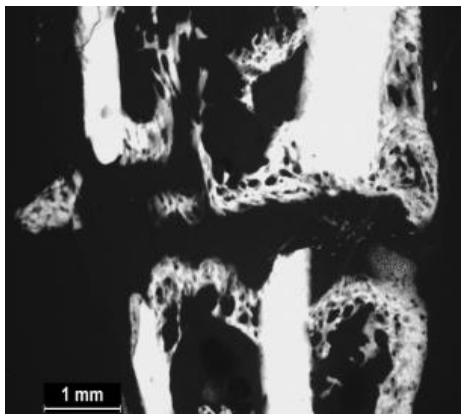

34: OVX;

repräsentative

Mikroradiographie

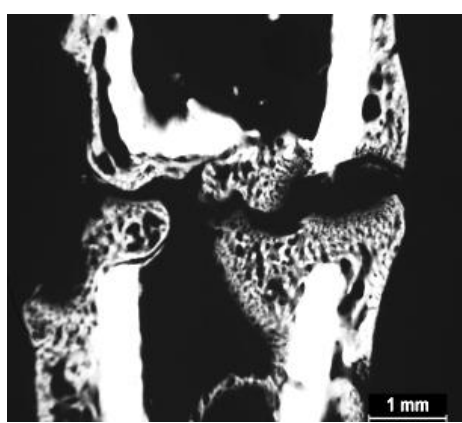

Abb. 37: $100 \quad$ mg

Baicalein; repräsentative

Mikroradiographie

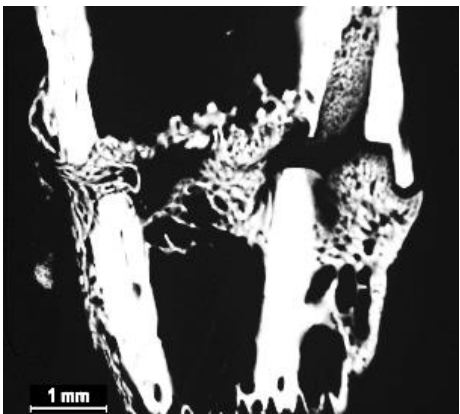

Abb. 35: $1 \mathrm{mg}$ Baicalein;

repräsentative

Mikroradiographie 


\subsubsection{Kortikalis}

\subsubsection{Kortikalis-Dicke distal plattennah}

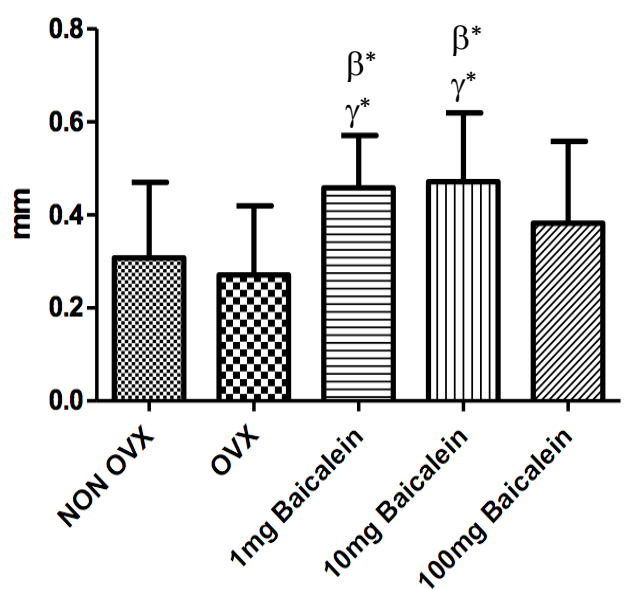

Abb. 38: Darstellung der Ergebnisse des Messparameters Kortikalis-Dicke distal plattennah; $\beta=$ signifikant zu NON OVX, $\gamma=$ signifikant zu OVX, $*=p<0,05$ (Analyse durch One-way ANOVA und Tukey-Kramer post-hoc-Test)

Die plattennahe Korikalis-Dicke erwies sich bei den nicht ovarektomierten Tieren als signifikant geringer gegenüber den mit $1 \mathrm{mg}$ und $10 \mathrm{mg}$ Baicalein behandelten Ratten (Abb. 38). Ebenso konnte auch für die Gruppe OVX eine signifikant geringere Kortikalis-Dicke im Vergleich zu den oben genannten mit Baicalein behandelten Versuchstieren gemessen werden. Die mit $100 \mathrm{mg}$ Baicalein behandelte Fraktion dagegen weißt keine Signifikanzen in Relation zum restlichen Versuchskollektiv auf.

\subsubsection{Kortikalis-Dicke distal plattenfern}

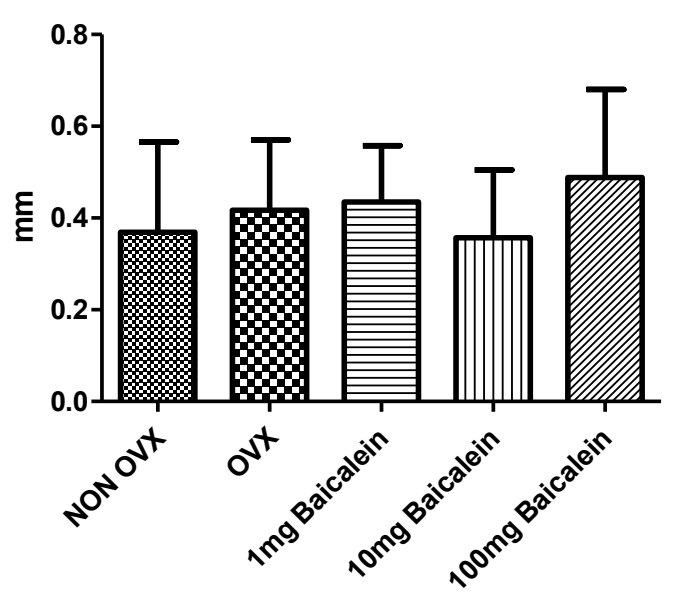

Abb. 39: Darstellung der Ergebnisse des Messparameters Kortikalis-Dicke distal plattenfern 
Die Kortikalis-Dicke auf der gegenüberliegenden Seite der Osteotomieplatte unterschied sich unter keiner der Gruppen signifikant voneinander. Zwar wurden für die geringste und die höchste Konzentration Baicalein die größte Dicke gemessen, doch die Werte weichen nur leicht von den anderen ab (Abb. 39). Allgemein liegen die Messergebnisse aller Gruppen in einem ähnlichen Bereich.

\subsubsection{Kortikalis-Dichte distal plattennah}

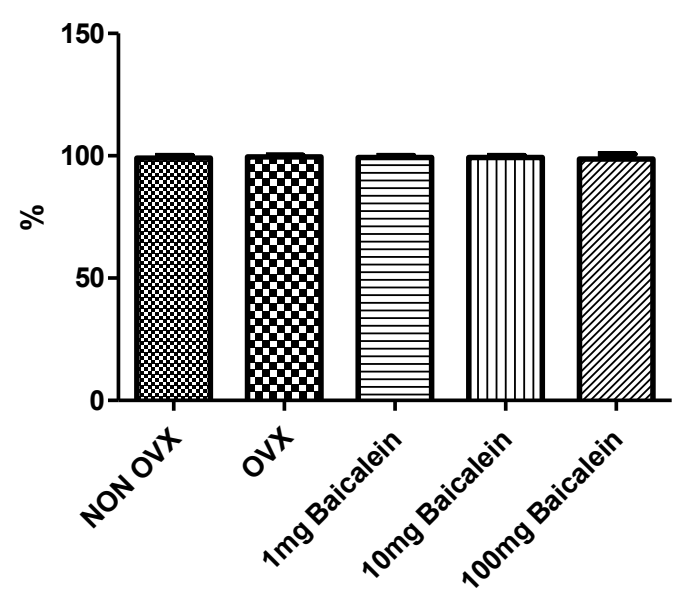

Abb. 40: Darstellung der Ergebnisse des Messparameters Kortikalis-Dichte distal plattennah

Die Dichte der Kortikalis unterschied sich unter den jeweiligen Versuchstieren nur minimal und beläuft sich in jeder Behandlungsgruppe auf fast $100 \%$ (Abb. 40).

\subsubsection{Kortikalis-Dichte distal plattenfern}

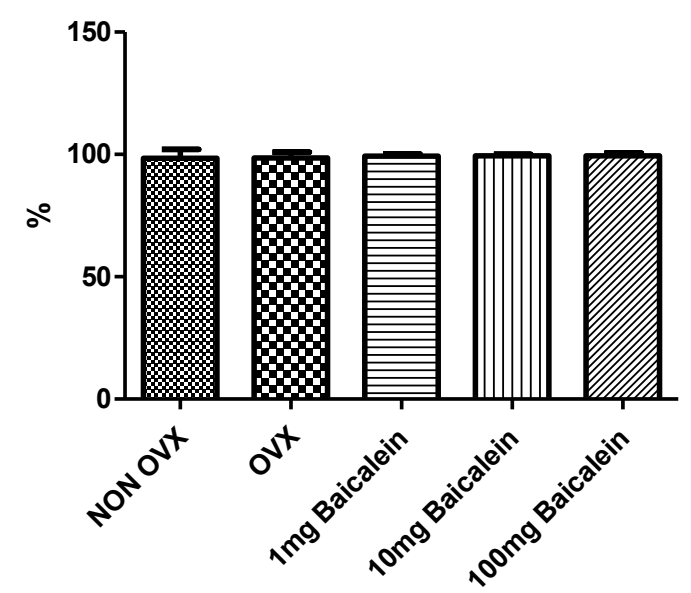

Abb. 41: Darstellung der Ergebnisse des Messparameters Kortikalis-Dichte distal plattenfern 
Die Ergebnisse bezüglich der plattenfernen Kortikalis-d

Dichte befinden sich auf einem annähernd identischen Niveau wie die Resultate der plattennahen Kortikalis-Dichte (Abb. 41) (vgl. 3.5.2.3).

\subsubsection{Kallus}

\subsubsection{Kallus-Dicke plattennah}

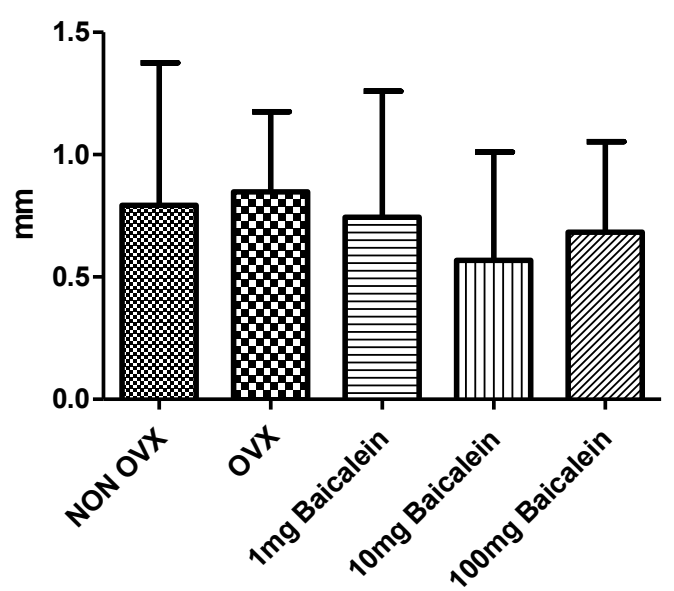

Abb. 42: Darstellung der Ergebnisse des Messparameters Kallus-Dicke plattennah

Die Werte in Bezug auf die plattennahe Kallus-Dicke zeigen keine signifikanten Unterschiede. Die nicht mit Baicalein behandelten Gruppen NON OVX und OVX weisen mit 0,79 mm und 0,85 mm die größte Kallusdicke auf (Abb. 42).

\subsubsection{Kallus-Dicke plattenfern}

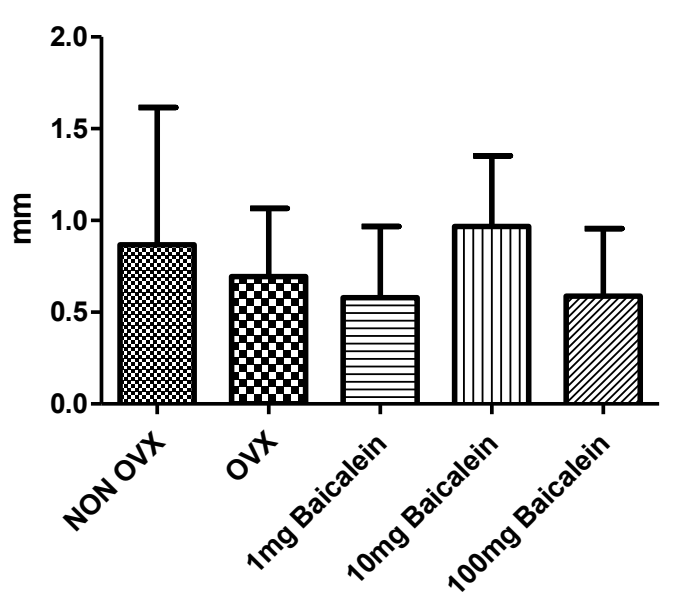

Abb. 43: Darstellung der Ergebnisse des Messparameters Kallus-Dicke plattenfern 
Die Dicke des plattenfern gelegenen Kallusanteils weicht bei keinem Kollektiv signifikant von den anderen Versuchsgruppen ab (Abb. 43). Die größte Kallus-Dicke von $0,97 \mathrm{~mm}$ konnte allerdings bei den mit $10 \mathrm{mg}$ behandelten Tieren ermittelt werden.

\subsubsection{Kallus-Dichte plattennah}

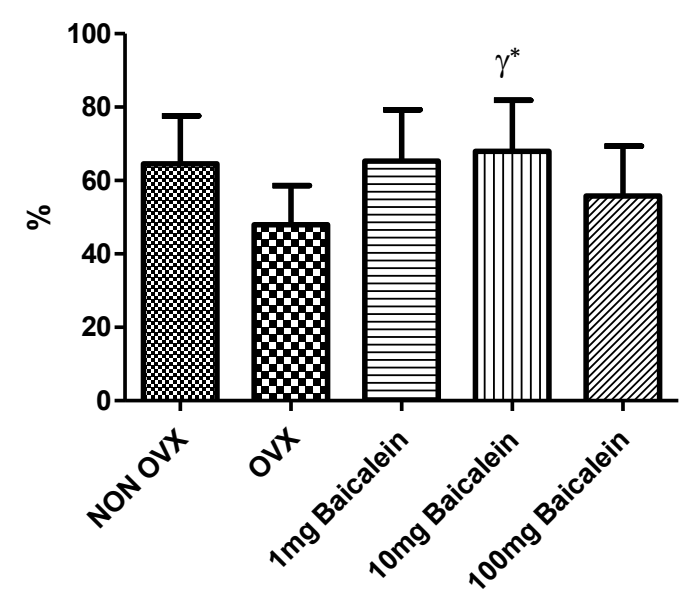

Abb. 44: Darstellung der Ergebnisse des Messparameters Kallus-Dichte plattennah; $\gamma=$ signifikant zu OVX, $*=p<0,05$

(Analyse durch One-way ANOVA und Tukey-Kramer post-hoc-Test)

Die Dichte des plattennahen Kallus betreffend konnte ein signifikanter Unterschied zwischen den ovarektomierten, unbehandelten Tieren und der 10-mg-Baicalein-Gruppe festgestellt werden. Die Kallus-Dichte der mit $10 \mathrm{mg}$ Baicalein behandelten Tiere lag im Mittel bei $68 \%$, während sie in der Gruppe OVX nur $48 \%$ betrug (Abb. 44). Die anderen Messwerte unterschieden sich nicht signifikant. 


\subsubsection{Kallus-Dichte plattenfern}

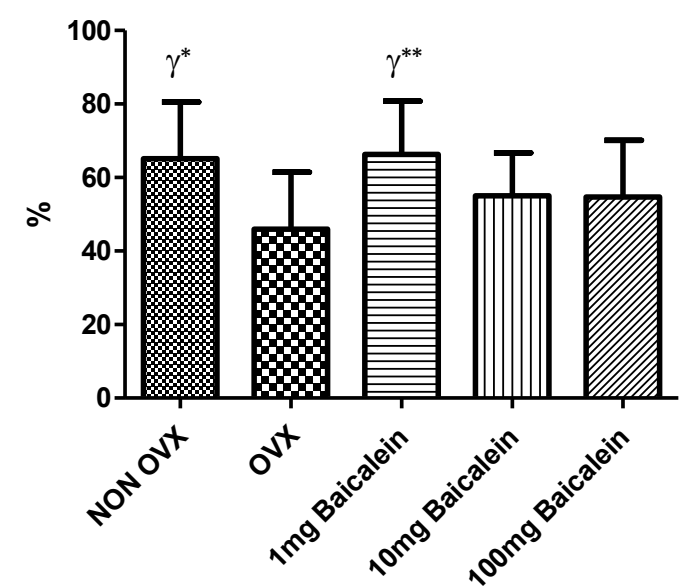

Abb. 45: Darstellung der Ergebnisse des Messparameters Kallus-Dichte plattenfern; $\gamma=$ signifikant zu OVX, $*=\mathrm{p}<0,05, * *=\mathrm{p}<0,01$

(Analyse durch One-way ANOVA und Tukey-Kramer post-hoc-Test)

Ein hoch signifikanter Unterschied der plattenfernen Kallus-Dichte konnte für die Gruppen OVX und $1 \mathrm{mg}$ Baicalein nachgewiesen werden. Die mit Baicalein behandelte Versuchsgruppe zeigte eine im Mittel 20 \% höhere Kallus-Dichte als die lediglich ovarektomierten Tiere (Abb. 45). Auch die nicht ovarektomierten Ratten wiesen eine signifikant höhere Kallus-Dichte auf als die OVX Gruppe.

\subsubsection{Kallus-Dichte endostal}

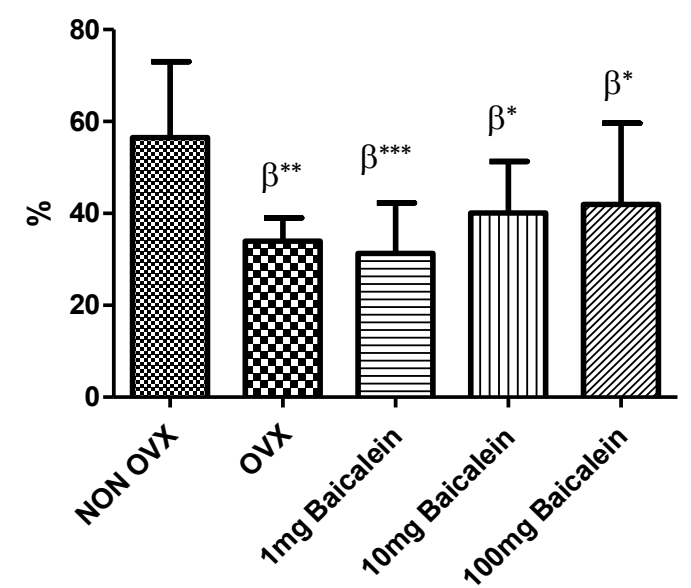

Abb. 46: Darstellung der Ergebnisse des Messparameters Kallus-Dichte endostal; $\beta=$ signifikant zu NON OVX, ${ }^{*}=\mathrm{p}<0,05, * *=\mathrm{p}<0,01, * * *=\mathrm{p}<0,001$

(Analyse durch One-way ANOVA und Tukey-Kramer post-hoc-Test) 
Hinsichtlich der Dichte des endostalen Kallus fielen signifikante Unterschiede jeder Gruppe im Vergleich zum nicht ovarektomierten Versuchskollektiv auf, welches die höchste Kallus-Dichte aufwies (Abb. 46). Während die ovarektomierten Ratten eine hoch signifikant geringere Kallus-Dichte zeigten, wich die Dichte der mit $1 \mathrm{mg}$ Baicalein behandelten Tiere sogar höchst signifikant von der NON OVX Gruppe ab. Die Versuchstiere, denen höhere Baicalein Konzentrationen verbreicht wurden, hatten jeweils eine signifikant geringere Kallus-Dichte.

\subsection{Ergebnisse der polychromen Sequenzmarkierung}

Vorerst werden die ermittelten Zeitpunkte der Überbrückung des Frakturspalts tabellarisch veranschaulicht. Folgend werden repräsentativ fluoreszenzmikroskopische Bilder der jeweiligen Versuchsgruppe dargestellt. Nachstehend erfolgt die statistische Ergebnispräsentation in Form von Säulendiagrammen und als tabellarische Übersicht.

\subsubsection{Zeitpunkt der frühesten Überbrückung des Frakturspalts}

Tabelle 12: Darstellung der Zeitpunkte der frühesten Frakturüberbrückung in Tagen; $\varnothing=$ es hat keine Frakturüberbrückung stattgefunden

\begin{tabular}{|l|l|l|l|l|l|}
\hline Ratte & NON OVX & OVX & $\begin{array}{l}\mathbf{1} \text { mg } \\
\text { Baicalein }\end{array}$ & $\begin{array}{l}\mathbf{1 0} \text { mg } \\
\text { Baicalein }\end{array}$ & $\begin{array}{l}\mathbf{1 0 0} \text { mg } \\
\text { Baicalein }\end{array}$ \\
\hline 1 & 28 & $\varnothing$ & $\varnothing$ & 28 & $\varnothing$ \\
\hline 2 & 20 & $\varnothing$ & 29 & 27 & $\varnothing$ \\
\hline 3 & $\varnothing$ & $\varnothing$ & 28 & 25 & $\varnothing$ \\
\hline 4 & $\varnothing$ & 26 & $\varnothing$ & 20 & 26 \\
\hline 5 & 10 & 29 & 19 & $\varnothing$ & 28 \\
\hline 6 & $\varnothing$ & $\varnothing$ & $\varnothing$ & 28 & 19 \\
\hline 7 & 26 & 29 & 23 & 28 & $\varnothing$ \\
\hline 8 & 21 & $\varnothing$ & & & 26 \\
\hline 9 & 20 & 27 & & & $\varnothing$ \\
\hline 10 & & & & & $\varnothing$ \\
\hline & Mittelwert & Mittelwert & Mittelwert & Mittelwert & Mittelwert \\
& NON OVX & OVX & $\mathbf{1}$ mg & $\mathbf{1 0}$ mg & $\mathbf{1 0 0}$ mg \\
Baicalein
\end{tabular}


Die Überbrückung des Frakturspalts fand bei den nicht ovarektomierten Ratten im Mittel 21 Tage nach der Osteotomie und dementsprechend mindestens 4 Tage vor den mit Baicalein behandelten Tieren statt (Tab. 12). Allerdings erfolgte die Frakturüberbrückung in der Versuchsgruppe OVX im Mittel erst an Tag 28 der Frakturheilung und damit mindestens 2 Tage verspätet in Relation zu den Gruppen, denen Baicalein gespritzt wurde. Außerdem kam es bei einigen Tieren zu keiner Frakturüberbrückung. In der Gruppe der nicht ovarektomierten Ratten wurde der Frakturspalt in $67 \%$ der Fälle überbrückt. Bezüglich der OVX Tiere fand lediglich bei 44\% eine Überbrückung statt. Dagegen erfolgte die Frakturüberbrückung bei 57\% der mit $1 \mathrm{mg}$ Baicalein behandelten Versuchstiere, bei 86\% der 10-mg-Baicalein-Gruppe, sowie bei $60 \%$ der Ratten, denen 100 mg Baicalein appliziert wurden.

\subsubsection{Repräsentative Bilder der polychromen Sequenzmarkierung}

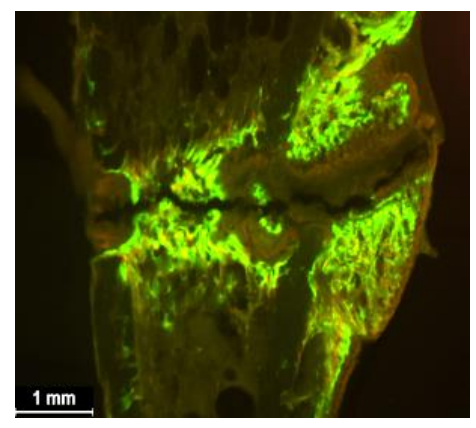

Abb. 47: NON OVX; repräsentative polychrome Sequenzmarkierung

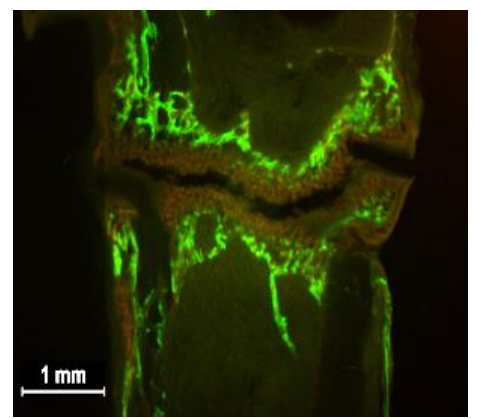

Abb. 50: 10 mg Baicalein; repräsentative polychrome Sequenzmarkierung

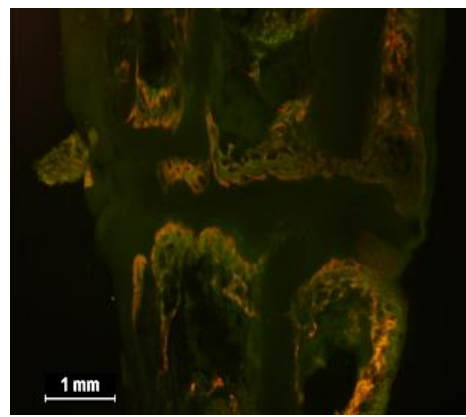

Abb. 48: OVX; repräsentative polychrome Sequenzmarkierung

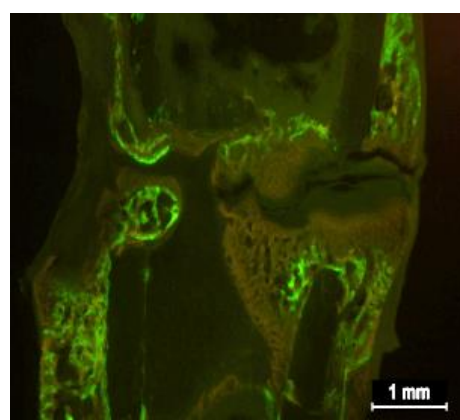

Abb. 51: 100 mg Baicalein; repräsentative polychrome Sequenzmarkierung

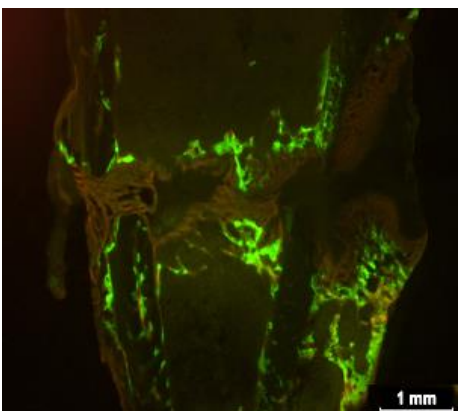

Abb. 49: 1 mg Baicalein; repräsentative polychrome Sequenzmarkierung 
Die repräsentativen Darstellungen der polychromen Sequenzmarkierung untermauern die ausgewerteten Daten. Die Gruppe NON OVX zeigte fluoreszenzmikroskopisch sowohl eine deutlich vorangeschrittenere Überbrückung des Frakturspaltes, als auch eine vermehrte Calcein-Grün Anreicherung im endostalen Kallusbereich (Abb. 47). Auffällig ist auch die offensichtlich schwächere Fluorochrommarkierung der Tibia aus der Gruppe OVX, sowie die weiter auseinanderstehenden Frakturenden (Abb. 48).

\subsubsection{Kallus plattennah}

\subsubsection{Gesamtfläche Kallus plattennah}

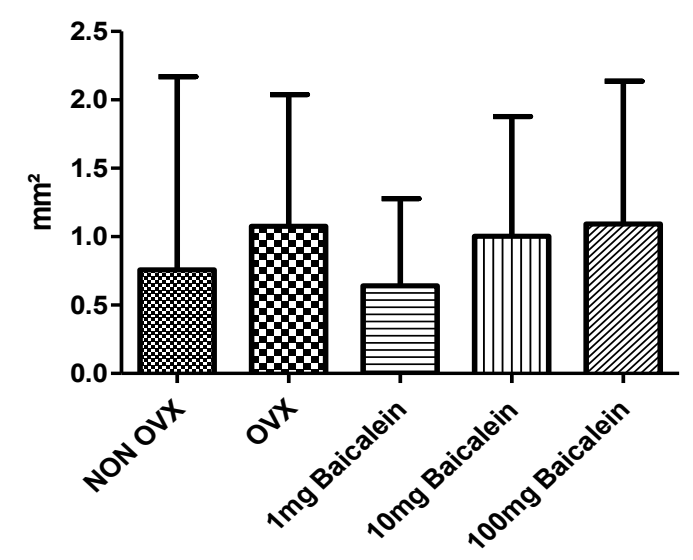

Abb. 52: Darstellung der Ergebnisse der Messgröße Gesamtfläche Kallus plattennah

Die gesamte plattennahe Kallus-Fläche unterschied sich hinsichtlich keiner der Gruppen signifikant (Abb. 52). Es fiel lediglich auf, dass die Versuchstiere der 1-mgBaicalein-Gruppe die geringste Fläche aufwiesen, während die Ratten der höchsten Baicalein-Konzentration die größte Gesamtkallus-Fläche zeigten. 


\subsubsection{CG-Fläche}

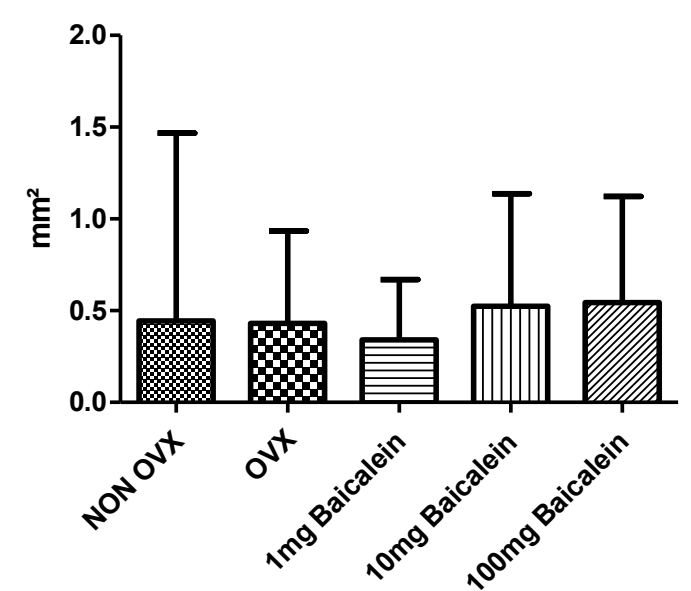

Abb. 53: Darstellung der Ergebnisse der Messgröße CG-Kallus-Fläche plattennah

In Bezug auf die CG-markierte Fläche des plattennahen Kallusanteils wichen die Ergebnisse der Versuchsgruppen nicht signifikant voneinander ab (Abb. 53). Die größte Kallus-Fläche wurde für die Tiere ermittelt, denen die höchste Baicalein-Konzentration appliziert worden war. Auffällig waren dahingegen hohe Standardabweichungen.

\subsubsection{AK-Fläche}

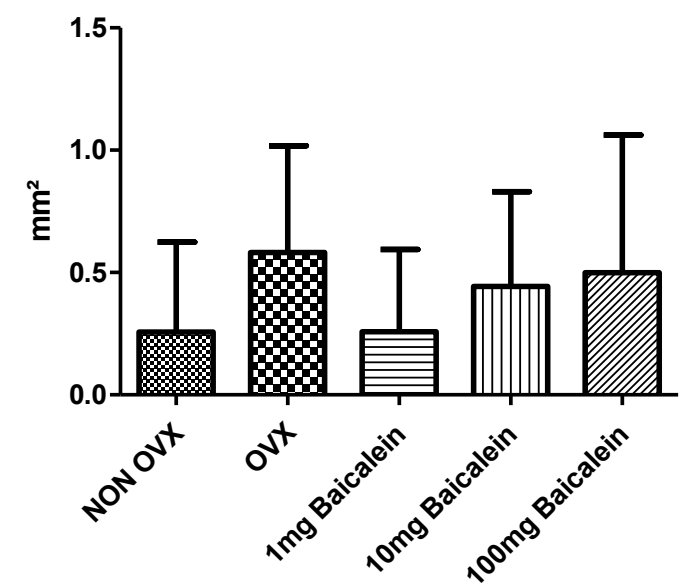

Abb. 54: Darstellung der Ergebnisse der Messgröße AK-Kallusfläche plattennah

Bezüglich der plattennahen AK-Kallus-Fläche konnten keine signifikanten Unterschiede ermittelt werden (Abb. 54). 


\subsubsection{Kallus plattenfern}

\subsubsection{Gesamtfläche Kallus plattenfern}

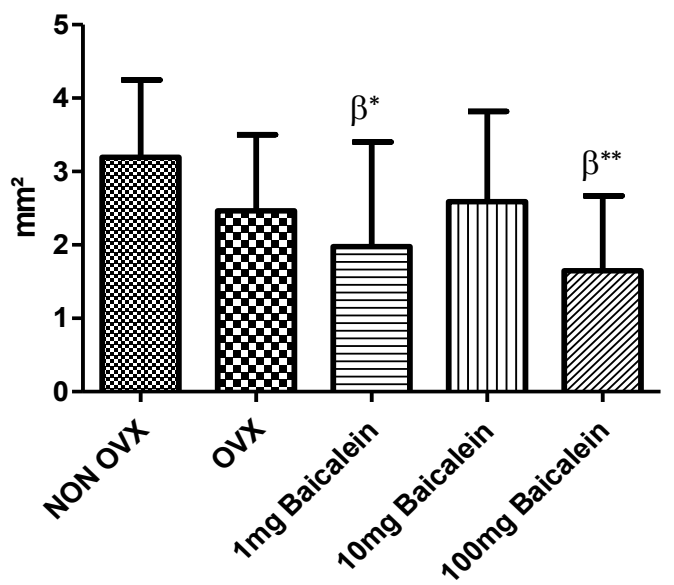

Abb. 55: Darstellung der Ergebnisse der Messgröße Gesamt-Kallus-Fläche plattenfern; $\beta=$ signifikant zu NON OVX, ${ }^{*}=\mathrm{p}<0,05, * *=\mathrm{p}<0,01$

(Analyse durch One-way ANOVA und Tukey-Kramer post-hoc-Test)

Für die Versuchsgruppe NON OVX konnten signifikant höhere Werte im Vergleich zur Gruppe $1 \mathrm{mg}$ Baicalein, sowie eine hoch signifikant größere Kallus-Fläche als bei der Gruppe 100 mg Baicalein festgestellt werden (Abb. 55).

\subsubsection{CG-Fläche}

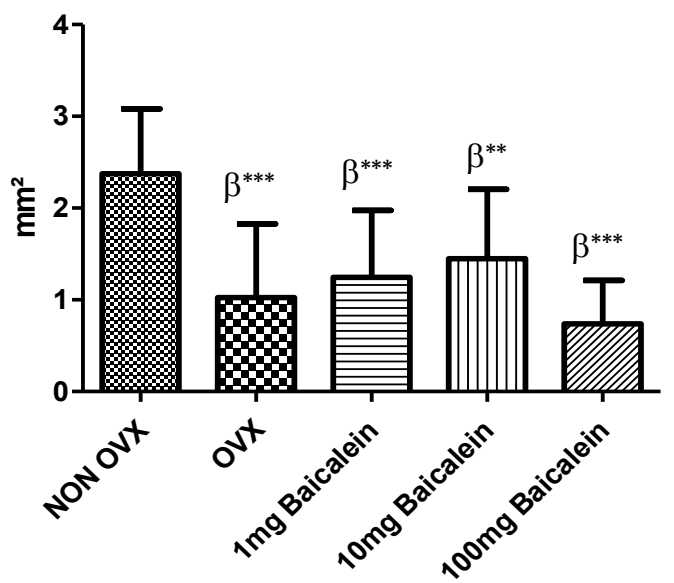

Abb. 56: Darstellung der Ergebnisse der Messgröße CG-Kallus-Fläche plattenfern; $\beta=$ signifikant zu NON OVX, ${ }^{*}=\mathrm{p}<0,05, * *=\mathrm{p}<0,01, * * *=\mathrm{p}<0,001$

(Analyse durch One-way ANOVA und Tukey-Kramer post-hoc-Test) 
Auch hinsichtlich der CG-markierten plattenfernen Kallus-Fläche konnten signifikant größere Flächen der nicht ovarektomierten Tiere erhoben werden (Abb. 56). In Bezug auf die Versuchsgruppen OVX, $1 \mathrm{mg}$ und $100 \mathrm{mg}$ Baicalein wurde eine höchst signifikant und im Vergleich mit der $10 \mathrm{mg}$ Baicalein eine hoch signifikant größere Kallus-Fläche erfasst.

\subsubsection{AK-Fläche}

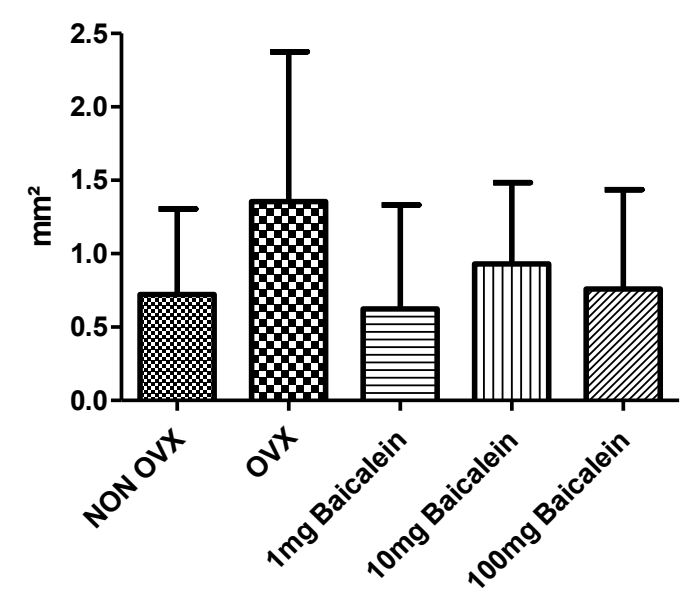

Abb. 57: Darstellung der Ergebnisse der Messgröße AK-Kallus-Fläche plattenfern

Im Hinblick auf den durch AK markierten plattenfernen Kallusanteil wurden keine Signifikanzen ermittelt (Abb. 57). 


\subsubsection{Kallus endostal}

\subsubsection{Gesamtfläche Kallus endostal}

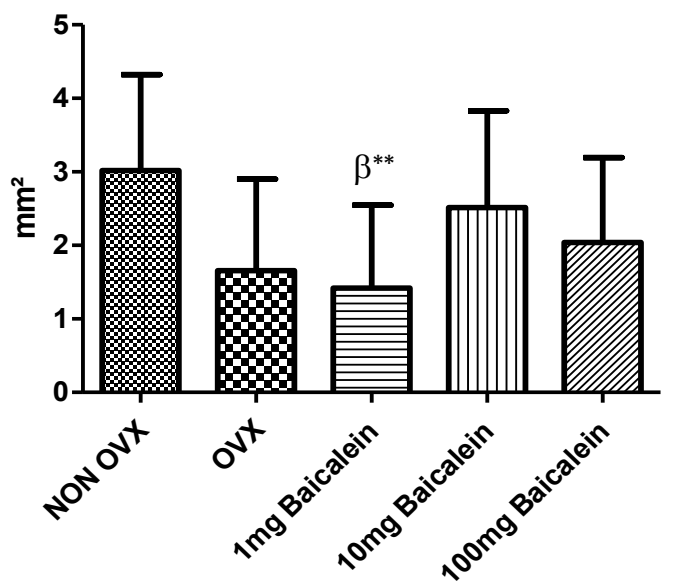

Abb. 58: Darstellung der Ergebnisse der Messgröße Gesamtfläche Kallus endostal; $\beta=$ signifikant zu NON OVX, $* *=p<0,01$

(Analyse durch One-way ANOVA und Tukey-Kramer post-hoc-Test)

Bei Auswertung der gesamten endostalen Kallus-Fläche konnte in Relation zur nicht ovarektomierten Gruppe eine hoch signifikant geringere Kallus-Fläche für die mit $1 \mathrm{mg}$ Baicalein beahndelten Tiere festgestellt werden (Abb. 58).

\subsubsection{CG-Fläche}

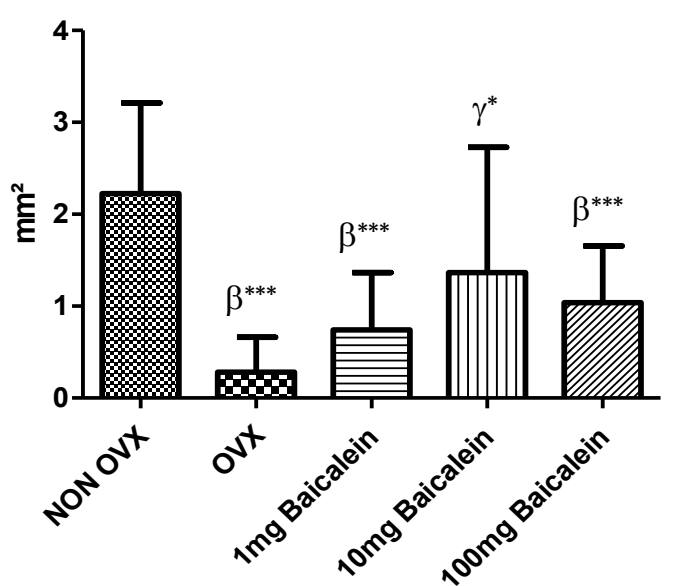

Abb. 59: Darstellung der Ergebnisse der Messgröße CG-Kallus-Fläche endostal; $\beta=$ signifikant zu NON OVX, $\gamma=$ signifikant zu OVX, $*=p<0,05, * * *=p<0,001$ 
Bezüglich der durch CG markierten endostalen Kallus-Fläche fielen höchst signifikant geringere Werte der Versuchsgruppen OVX, $1 \mathrm{mg}$ und $100 \mathrm{mg}$ Baicalein im Vergleich zum nicht ovarektomierten Versuchskollektiv auf (Abb. 59). Allerdings konnte für die mit 10 mg Baicalein behandelten Tiere eine signifikant größere Fläche in Bezug auf die Gruppe OVX ermittelt werden.

\subsubsection{AK-Fläche}

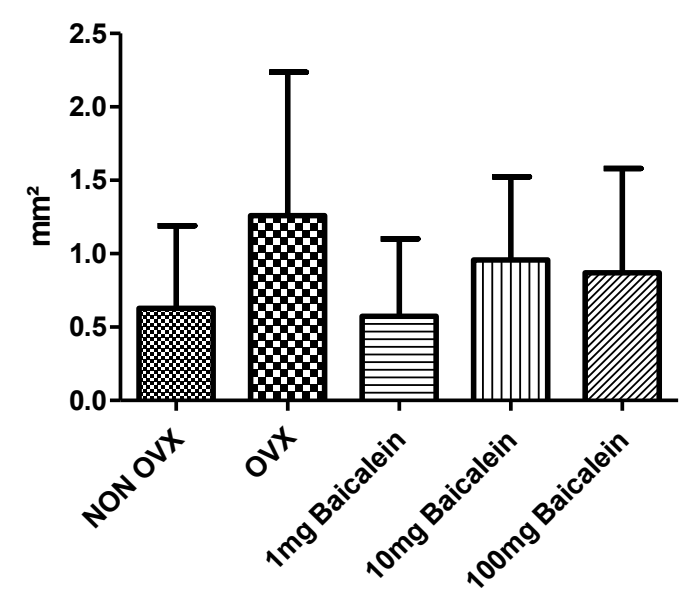

Abb. 60: Darstellung der Ergebnisse der Messgröße AK-Kallus-Fläche endostal

Für die AK-markierte endostale Kallus-Fläche konnten keine signifikanten Unterschiede gefunden werden (Abb. 60).

\subsubsection{Gesamtfläche kompletter Kallus}

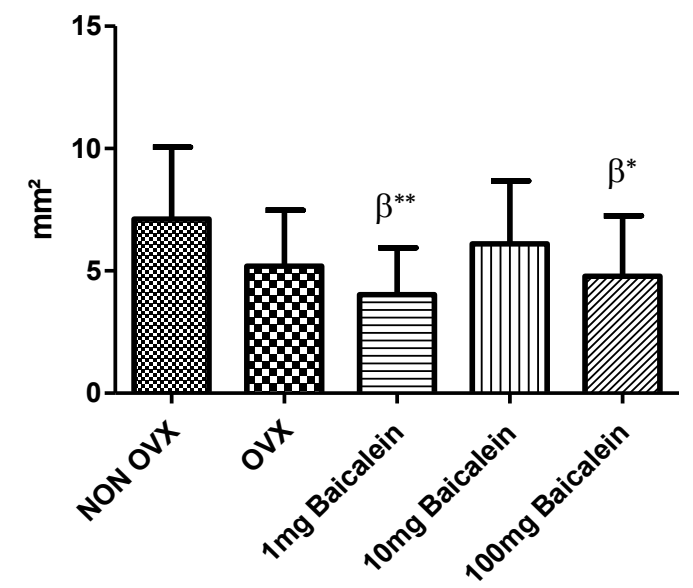

Abb. 61: Darstellung der Ergebnisse der Messgröße Gesamtfläche kompletter Kallus; $\beta=$ signifikant zu NON OVX, $*=p<0,05, * *=p<0,01$ 
Auch für den kompletten Kallus zeigte sich die größte Gesamtfläche in der Versuchsgruppe NON OVX (Abb. 61). Unterdessen wiesen sowohl die Ratten der 1mg-Baicalein-Gruppe eine hoch signifikant als auch die Tiere der 100-mg-BaicaleinGruppe eine signifikant geringere Gesamtkallus-Fläche auf. 


\section{Diskussion}

Im Zentrum dieser wissenschaftlichen Arbeit steht die Verbesserung der verminderten Knochenqualität osteoporotischer Knochen durch die pflanzliche Substanz Baicalein vor dem Hintergrund der problematischen Heilung Osteoporose-induzierter Frakturen. Grundlage der unverkennbar erschwerten Frakturheilung sind die signifikant verschlechterten Parameter der Knocheneigenschaften [Tarantino et al. 2013]. So ist ein osteoporotischer Knochen minderperfundiert und der bei einer Fraktur gebildete Kallus weist eine mangelhafte Mineralisation auf [Augat et al. 2005]. Darüber hinaus stellt sich der Knochenumsatz nach einer Fraktur als deutlich eingeschränkt dar, sodass der initial verringerte resorptive Prozess zu einer erschwerten Wiederherstellung der Integrität eines osteoporotisch veränderten Knochens führt [Wölf et al. 2014]. Es resultieren Schwierigkeiten in der medizinischen Versorgung, da es sich oft um Splitterbrüche handelt und übliche Implantate auf Grund der geringen Stabilität nicht in den Knochen eingebracht werden können [Kammerlander et al. 2013]. Die beschriebene Problematik bildet den Ansatzpunkt für das im Rahmen dieser Arbeit verwendete Präparat Baicalein. Das Flavonoid des Baikal-Helmkrautes (Scutellaria baicalensis), welches seit geraumer Zeit in der traditionellen asiatischen Medizin eingesetzt wird, hat bereits einige biologische Effekte gezeigt. Berichtet wurde sowohl von seiner anti-viralen, anti-inflammatorischen und anti-hepatotoxischen als auch von seiner anti-kanzerogenen Wirkung [Wang et al. 2015; Jang et al. 2014]. Baicalein ist ein selektiver Inhibitor verschiedener Lipoxygenasen, die im Zuge einer Entzündungsreaktion vermehrt exprimiert werden [Deschamps et al. 2006] und mittels Osteoklasten-Stimulation zu einem katabolen Knochestoffwechsel führen [Lee et al. 2012]. Folglich wurde die Hypothese aufgestellt, dass Baicalein durch einen osteoanabolen Effekt, welcher bereits an intakten Mäuseknochen gezeigt werden konnte [Kim et al. 2008], zu einer verbesserten Frakturheilung führen würde. Ungeklärt sind bisher die Auswirkungen von Baicalein auf den Knochenstoffwechsel und die Frakturheilung bei manifester Osteoporose, so dass diese Fragestellung im Rahmen dieser Studie untersucht wurde. 


\subsection{Die ovarektomierte Ratte als Osteoporosemodell und das metaphysäre Frakturmodell}

Das dieser Arbeit zu Grunde liegende Osteoporosemodell der ovarektomierten Ratte war bereits Gegenstand einer großen Anzahl wissenschaftlicher Studien, so dass sowohl der Effekt des Lebensalters als auch der Nahrung auf den Knochenstoffwechsel der Tiere hinlänglich dokumentiert sind [Thorndike und Turner 1998]. Überdies reagieren Rattenknochen auf mechanische Einflüsse, Hormone und Medikamente analog zur menschlichen Knochenstruktur [Frost und Jee 1992]. Die Ovarektomie der Ratten hat innerhalb von 8 bis 10 Wochen einen signifikanten Rückgang der spongiösen Knochenmasse zur Folge [Miller und Wronski 1993]. Unterdessen ist die Knochenmineraldichte der Tibia schon nach 14 Tagen nachweislich beeinträchtigt [Lelovas et al. 2008]. Zwar zeigte sich der Kalzium-Verlust ovarektomierter Ratten geringer, als der Kalzium-Verlust postmenopausaler Frauen [Kalu 1991], und der basale multizelluläre Knochenumbau scheint im Fall von Rattenknochen limitiert zu sein [Thorndike und Turner 1998], doch stimmen wesentliche Charakteristika, wie der initial erhöhte Knochenstoffwechsel, der stärkere Verlust von spongiösem gegenüber kortikalem Knochen und die Reaktion auf verschiedene Therapieformen überein [Kalu 1991]. So können die zentralen Aspekte des Knochenmasseverlustes postmenopausaler Frauen durch das Rattenmodell reproduziert werden.

Die erfolgreiche Ovarektomie wurde in diesem Versuch durch die Entwicklung der Körper- und Uterusgewichte der Versuchstiere untermauert. Bereits in der zweiten postoperativen Woche kam es zu einem signifikanten Anstieg des Körpergewichts aller ovarektomierten Ratten im Vergleich zur NON OVX-Gruppe (vgl. 3.1, S. 51). Darüber hinaus sprachen auch, entsprechend dem abfallenden Östrogenspiegel und Uterusgewicht in der Postmenopause, die höchst signifikant geringeren Uterusgewichte aller ovarektomierten Tiere (vgl. 3.2, S.52) für verringerte Östrogenwerte.

Ein Großteil der Osteoporose-induzierten Frakturen tritt im Bereich der Metaphysen der Röhrenknochen auf, was durch die deutliche Reduktion der spongiösen Knochendichte begründet ist, die sich im Bereich der proximalen Tibia auf bis zu 50\% innerhalb von 3 Monaten belaufen kann [Jee und Yao 2001]. Ungeachtet dieser Erkenntnisse behandelt eine Vielzahl von Studien lediglich die Frakturheilung der Diaphyse [Cao et al. 2002; Hatano et al. 2004; Kubo et al. 1999; Li et al 2001; Nakajima et al. 2002]. Doch osteoporotische Veränderungen treten in deutlich geringerem Maße 
am diaphysären Knochen auf, und biomechanische Eigenschaften divergieren vom eigentlichen Grad der Osteoporose, da durch die Zunahme des Durchmessers der Knochenmarkshöhle die Stabilität trotz dünnerer Kortikalis aufrechterhalten werden kann [Aerssens et al. 1996; Peng et al. 1994]. Diese Verzerrung wurde im Zuge dieser Arbeit durch die Wahl des etablierten metaphysären Frakturmodells nach Stürmer et al. [2010a; 2010b] vermieden.

\subsection{Biomechanischer Kompressionstest}

Um Unterschiede bezüglich der mechanischen Eigenschaften wie der Stärke des Frakturkallus und der Elastizität der Tibiae zu dokumentieren, wurde ein von Stürmer et al. [2006] entwickelter Drei-Punkt-Biegetest durchgeführt. Diese Methode hat sich bereits in einigen anderen Studien bewährt [Ibrahim et al. 2014; Chen et al. 2014; Kaczmarczyk-Sedlak 2013; Komrakova et al. 2013] und wurde daher zur Revision der Frakturheilung eingesetzt. Bekannt ist bereits, dass sich die osteoporotischen Veränderungen im biomechanischen Test im Bereich der Metaphyse als verminderte Elastizität und reduzierte maximale Belastung niederschlagen, während keine statistisch signifikanten Abweichungen an der diaphysalen Tibia nachweisbar sind [Chen et al. 2008]. Tatsächlich beeinflusst Osteoporose unverkennbar vor allem die frühe Phase der Frakturheilung, was in deutlich verminderter Kallus- und Knochenstabilität resultiert und sich sowohl durch die reduzierte BMD, als auch die begrenzte Ausbildung reifen Knochengewebes ausdrückt [Namkung-Matthai et al. 2001]. Weiterhin wird auch die späte Phase der Frakturheilung beeinflusst, verursacht durch eine prolongierte Kalzifikation des endochondralen Knochens, gesteigerte Osteoklasteaktivität und irreguläres sowie verstreutes Trabekelwachstum [Xu et al. 2004, Wang et al. 2005].

Unbekannt war bisher allerdings der Effekt von Lipoxygenasehemmern wie Baicalein auf die biomechanischen Eigenschaften und die Frakturheilung osteoporotischer Knochen. Für diverse Phytohormone konnte bereits ein positiver Effekt auf die Kallusqualität und die trabekuläre Knochenformation nachgewiesen werden [Kolios et al. 2010; Sehmisch et al. 2010]. Im Kontrast dazu können die Ergebnisse des biomechanischen Tests dieser Arbeit keine Verbesserung der Kallusfestigkeit und -elastizität für die mit Baicalein behandelten Gruppen erkennen lassen. Die Knochen der mit 100 mg Baicalein pro Kilogramm Körpergewicht behandelten Tiere zeigen lediglich eine nicht signifikant gesteigerte Elastizität gegenüber dem restlichen 
ovarektomierten Kollektiv. Dennoch wäre eine Verbesserung der Knochenstabilität durch die optimierte Verteilung des Lipoxygenasehemmers im Gewebe in Folge der Darreichung mit dem Futter denkbar. Die Möglichkeit der oralen Metabolisierung des Lipoxygenaseinhibitors wurde bereits im Rattenmodell untersucht und bestätigt [Akao et al. 2013]. Der schnellere Entzündungsrückgang und die verbesserte Defektheilung könnten so in einem stabileren Frakturkallus resultieren.

\subsection{Mikro-Computertomographie}

Entwicklungen im Bereich der Mikro-Computertomographie lassen mittlerweile eine In-vivo-Bildgebung bei Kleintiermodellen mit hoher räumlicher Auflösung zu, so dass eine Beurteilung der quantitativen und qualitativen Knochenarchitektur ohne Schädigung des Tieres erfolgen kann [Waarsing et al. 2004]. Darüber hinaus kann eine Quantifizierung des subchondralen Knochengewebes im Zeitverlauf an demselben Tier erfolgen und innerhalb eines longitudinalen Studiendesigns analysiert werden [Boyd et al. 2006; Perilli et al. 2010]. Das in dieser Studie verwendete Quantum GX microCT der Firma PerkinElmer ${ }^{\circledR}$ ist ein jüngst entwickeltes System, das mit Hilfe einer großen Anzahl an Schnittbildern eine 3D-Rekonstruktion von Geweben oder gesamten Organismen erlaubt. Die dreidimensionale Darstellung ist der zweidimensionalen Histomorphometrie von Dünnschnitten insofern überlegen, als dass topologische Parameter wie die Vernetzung der Knochenstruktur evaluiert werden können [Engelke et al. 1999]. Zwar wurden in dieser Arbeit keine lebenden Tiere, sondern lediglich die entnommenen Tibiae einer Bildgebung unterzogen, doch kamen hier das hohe Auflösungsvermögen (4,5 $\mu \mathrm{m}$ Voxel Größe) sowie die niedrige Strahlendosis (durchschnittlich $15 \mathrm{mGy}$ pro Scan) während einer äußerst kurzen Scan-Zeit (längste Scan-Zeit: 2 Minuten) zum Tragen. Damit wurden ein zentraler Nachteil der bisherigen Mikro-CT Technologien, die langen Scan-Zeiten von bis zu mehreren Stunden, behoben [Engelke et al. 1999; Yajima 2007]. Essenziell ist bei dieser neu etablierten Methode, dass die niedrige Strahlendosis die Gefahr der Schädigung der osteoporotischen Rattenknochen minimiert, welche bei früheren In-vivo-Mikro-CT Analysen zu einer Reduktion des Trabekelvolumens geführt hat [Klinck et al. 2008]. Die hohe räumliche Auflösung ermöglichte eine genaue Evaluierung der kortikalen Mikrostruktur, welche als fundamental für die Interpretation der biomechanischen Eigenschaften eines osteoporotischen Knochens gilt [Genant et al. 2007; Ito 2011]. 
Die Annahme, dass Baicalein, welches durch Inhibiton von Lipoxygenasen [Deschamps et al. 2006], die durch Osteoklasten-Stimulation einen katabolen Knochenstoffwechsel bedingen [Lee et al. 2012], einen osteoanabolen Effekt haben könnte, wurde durch diesen Versuch nicht vollständig bestätigt. Trotz des bereits nachgewiesenen osteoanabolen Effektes bei intakten Mäuseknochen [Kim et al. 2008], konnten weder beim Kortikalisvolumen, noch der BMD der Kortikalis signifikante Differenzen nachgewiesen werden. Das Kortikalisvolumen der mit Baicalein behandelten Gruppen lag allerdings leicht über dem der ovarektomierten,

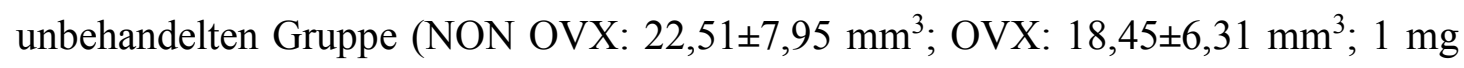

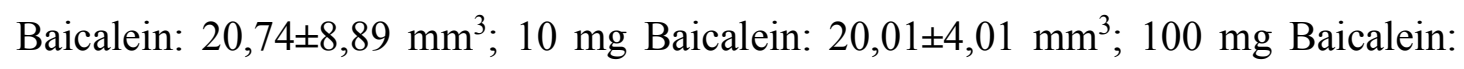
23,26 $\pm 4,23 \mathrm{~mm}^{3}$ ). In Bezug auf die Kallusdichte ist eine hoch signifkante Verminderung bei den ovarektomierten, nicht mit Baicalein behandelten Tieren, verglichen mit der Gruppe NON OVX zu verzeichnen, während die Werte aller anderen Versuchsgruppen auf nahezu gleichem Niveau sind. Dies spricht zumindest für eine Annäherung der Kallusdichte der mit Baicalein behandelten Gruppen an die nicht ovarektomierten und damit nicht von Osteoporose betroffenen Tiere. Dem gegenüber steht allerdings, dass das Kallusvolumen der Ratten, bei denen die höchste Konzentration Baicalein appliziert wurde (100 mg pro Kilogramm Körpergewicht), signifikant unter dem der Gruppe NON OVX liegt. Dieses Ergebnis ist womöglich auf die Osteoklasten-Inhibition durch Baicalein zurückzuführen. Osteoklasten stellen jedoch einen obligaten Faktor bezüglich der Kallusresorption und nicht zuletzt der Knochenheilung dar [Marsell et al. 2011]. Hinsichtlich des Knochenvolumens stellen sich signifikante Unterschiede im Kollektiv der Baicalein-Behandlungsgruppe gegenüber den nicht ovarektomierten Tieren dar. Sowohl die mit $10 \mathrm{mg}$, als auch die mit $100 \mathrm{mg}$ Baicalein behandelten Tiere wiesen ein signifikant niedrigeres Knochenvolumen auf. 


\subsection{Mikroradiographie}

Im Rahmen einer mikroradiographischen Untersuchung werden die Knochenbinnenstrukturen durch Erfassung der Unterschiede im Mineralgehalt der Gewebeanteile mit Hilfe von Röntgenstrahlung als zweidimensionales Bild dargestellt. Dieser Ansatz unterscheidet sich von der Mikro-Computertomographie insofern, als die dreidimensionale Visualisierung und Registrierung der Knochenvernetzung nicht möglich ist. Die Mikroradiographie ist dennoch eine lange etablierte und oft genutzte Methode, um Veränderungen der Knochenmineralisierung und Gewebeumbau feststellen zu können [Jowsey und Riggs 1972; Engström et al. 1955; Clemmons 1955]. Im Zuge der mikroradiographischen Analyse konnten bezüglich der distalen plattennahen Kortikalisdicke für die mit $1 \mathrm{mg}$ und $10 \mathrm{mg}$ Baicalein behandelten Versuchstiere signifikant größere Werte im Vergleich zu den Gruppen NON OVX und OVX ermittelt werden. Plattenfern wurden allerdings keine signifikante Abweichung der Kortikalis gefunden (vgl. Abb. 38 und 39, S. 55; Anh. Tab. 9, S. 86). Dieser Divergenz zwischen plattennaher und plattenferner Kortikalisdicke bedingt unter Umständen das Ergebnis der Mikro-Computertomographie. Hier konnten in Bezug auf die Knochenmineraldichte und das Volumen der Kortikalis keine signifikanten Unterschiede festgestellt werden (vgl. Abb. 24 und 25, S. 48/49; Anh. Tab. 5, S. 84). Die gute Korrelation zwischen den Methoden der zweidimensionalen und dreidimensionalen Bildgebung, welche durch Guggenbuhl et al. (2006) proklamiert wurde, ist daher aus diesen Ergebnissen nicht eindeutig ableitbar. Der alleinige Einsatz der Mikroradiographie könnte defizitär sein. Es scheint vielmehr zu einer Verbesserung der Validität zu kommen, wenn beide Untersuchungsmethoden kombiniert und kritisch gegeneinander abgewogen werden. $\mathrm{Zu}$ diesem Resultat kommen auch Gielkens et al. (2008) in ihrer Studie zum Vergleich der Mikro-CT, Mikroradiographie und Histomorphometrie, da hier sogar eine Überschätzung des Knochenaufbaus durch die Mikroradiographie detektiert werden konnte. Vor allem jedoch die Möglichkeit der BMD-Messung begründet in der Osteoporoseforschung die Überlegenheit der MikroComputertomographie, da die Knochenmineraldichte schon seit Jahren als starker Prädiktor für das Frakturrisiko postmenopausaler Frauen gilt [Garnero und Delmas 2004]. Die BMD- Ermittlung ist also ein entscheidender Schritt in der Übertragung dieser Studienergebnisse auf den klinischen Alltag. Gleichwohl kann die individuelle Differenzierung zwischen den plattennahen, plattenfernen und endostalen 
Kallusanteilen wiederum als deutlicher Vorteil der mikroradiographischen Auswertung betrachtet werden. Diese ermöglicht unter anderem, den Stellenwert der mechanischen Einflüsse durch die Osteosyntheseplatte auf die Kallusbildung einzuschätzen.

Hinsichtlich der Kallusparameter konnte mikroradiographisch eine signifikant verstärkte endostale Kallusbildung der nicht ovarektomierten Ratten festgestellt werden

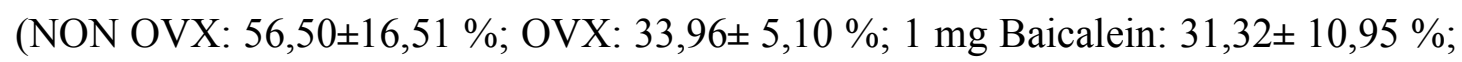

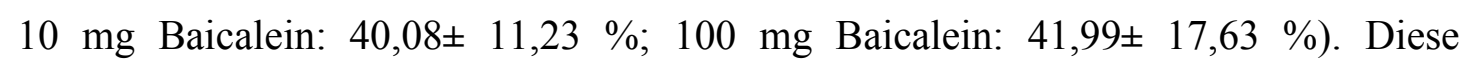
Ergebnisse decken sich mit der Mikro-CT Analyse, welche eine hoch signifikant höhere Kallus-BMD für NON OVX im Vergleich zu OVX sowie ein signifikant größeres Kallusvolumen des NON OVX-Kollektivs in Relation zur 100-mg-Baicalein-Gruppe ergab (vgl. Abb. 26 und 27, S. 49/50; Anh. Tab. 6, S. 84). Diese Resultate demonstrieren die überlegene Frakturheilung der nicht osteoporotischen Knochen, welche offenbar nur ansatzweise durch den Lipoxygenaseinhibitor Baicalein auszugleichen ist. Diese Ergebnisse stehen nicht vollständig im Einklang mit denen vergangener Studien, welche die deutliche osteoanabole und antiosteoporotische Wirkung des Baicaleins untermauern [Kim et al. 2008; Li et al. 2015]. Dies könnte in Zusammenhang mit dem Fazit von Somjen et al. (2008) stehen, welches Lipoxygenasemetabolite als Mediatoren des Parathormon-abhängigen Osteoblastenwachstums propagiert. PTH wird trotz seiner osteokatabolen Wirkung bei kontinuierlicher Gabe wiederum als eine Perspektive für die Osteoporosetherapie gesehen, da es bei intermittierender Applikation einen gegenteiligen Effekt erzielt [Esbrit und Alcaraz 2013; Morley et al. 2001]. Zu überprüfen wäre demnach, ob Lipoxygenaseinhibitoren möglicherweise vielmehr die Osteoblastenformation behindern als sie zu unterstützen. Auch die unter 4.3 erwähnte Behinderung des Osteoklastenwachstums durch Baicalein stellt ein Hindernis in der Frakturheilung dar. Die Osteoklastenhemmung, wenngleich sie sich positiv auf den gesunden Knochen auswirkt, ist bei der Knochenneuformation ein Nachteil.

Die in der Mikroradiographie signifikant niedrigere plattenferne Kallusdichte der ovarektomierten unbehandelten Ratten im Vergleich zu NON OVX und der niedrigsten Baicalein-Konzentration (vgl. Abb. 45, S. 59; Anh. Tab. 10, S. 87) lassen allerdings die gelungene Ovarektomie und nachfolgende Osteoporose sowie eine annähernde Heilungsverbessung durch die Baicalein-Applikation erkennen. Im Hinblick auf die Kallusdicke konnten jedoch keine signifikanten Unterschiede ermittelt werden (vgl. Abb. 42 und 43, S. 57; Anh. Tab. 10, S. 87). Dies könnte wiederum mit der 
Osteoklasten-Inhibition durch Baicalein zusammenhängen, da von diesen Zellen die Formation des harten Kallus abhängt [Schindeler et al. 2008].

\subsection{Polychrome Sequenzmarkierung}

Die Ergebnisse der polychromen Sequenzmarkierung weisen deutlich darauf hin, dass die Frakturheilung der nicht ovarektomierten Versuchstiere derjenigen der restlichen Gruppen überlegen ist. Im Hinblick auf den plattenfernen Kallusbereich konnte eine signifikant größere Fläche der NON OVX-Tiere im Vergleich zur 1-mg-BaicaleinGruppe und eine hoch signifikant größere Fläche in Bezug auf die 100-mg-BaicaleinGruppe ermittelt werden (vgl. Abb. 55, S. 64; Anh. Tab. 12, S. 88). Dieses mithilfe der Calcein-Grün-Markierung visualisierte Endergebnis, hatte sich bereits bis Tag 20 des Versuches herauskristallisiert. Zu diesem Zeitpunkt konnten für NON OVX schon hoch signifikant größere Werte als bei der $10 \mathrm{mg}$ Baicalein Gruppe und eine höchst signifikant größere Fläche im Vergleich zu den restlichen Tieren gemessen werden (vgl. Abb. 56, S. 64; Anh. Tab. 12, S. 88).

Des Weiteren verdeutlicht die Analyse der frühesten Überbrückung des Frakturspalts, dass im Falle der nicht osteoporotischen Tibiae der NON OVX-Ratten eine schnellere Wiederangliederung der Frakturenden stattfand. Bemerkenswert ist diesbezüglich gleichwohl die zwei bis drei Tage frühere Überbrückung der Frakturenden bei allen Baicalein-Gruppen im Vergleich zu den ovarektomierten, unbehandelten Tieren. Hier könnte die den Flavonoiden, also auch Baicalein, inhärente Wirkung als Phytoöstrogen eine Rolle spielen [Choi et al. 2013]. Es wurde jedoch gezeigt, dass Baicalein die Osteoblasten-Differenzierung weniger durch seine Östrogen-ähnliche Wirkung, sondern über den Wnt-Signalweg initiiert [Guo et al. 2011]. Letzterer führt über Aktivierung des Strukturproteins beta-Catenin zur Transkription von OsteogeneseGenen und schließlich auch zu einer verbesserten Knochenmineralisierung. Dieser osteoanabole Effekt hat sich womöglich positiv auf die Frakturüberbrückung ausgewirkt.

Die schlechteren Resultate der ovarektomierten Ratten sind höchstwahrscheinlich auch auf die durch Osteoporose beeinträchtigte Angiogenese und Differenzierung mesenchymaler Zellen zurückführbar [Cheung et al. 2016; Chen et al. 2016; Pang et al. 2015].

Bezüglich des plattennahen Kallus konnten allerdings für keinen Versuchszeitraum signifikante Unterschiede festgestellt werden (vgl. Abb. 52, S. 62; Anh. Tab. 11, S. 87). 
Auffällig ist unterdessen die in der Fluoreszenzmikroskopie gemessene endostale Kallusgesamtfläche in Relation zur in der Mikroradiographie erfassten endostalen Kallusdichte. Die Auswertung beider Parameter in der Versuchsgruppe NON OVX ergab, verglichen mit den anderen Versuchsgruppen, sowohl eine signifikant größere Fläche als auch eine deutlich höhere Dichte. Der endostale Kallus ist besonders wichtig für die Stabilisierung der Fraktur, während der periostal gebildete Spindel- oder Kugelkallus dabei eine untergeordnete Rolle spielt. Bereits innerhalb der ersten 20 Tage der Frakturheilung zeichnete sich ein deutlich gesteigertes endostales Kalluswachstum der nicht ovarektomierten Tiere ab (NON OVX höchst signifikant zu OVX, $1 \mathrm{mg}$ Baicalein und $100 \mathrm{mg}$ Baicalein). Von Tag 21 bis 29 ist diese Entwicklung allerdings rückläufig und es kam bei den Gruppen OVX, 10 mg Baicalein und $100 \mathrm{mg}$ Baicalein zu einer größeren Kallusentwicklung als bei den unbehandelten NON OVX-Tieren (vgl. Abb. 58 und 59, S. 66; Anh. Tab. 13, S. 88). Dieser Trend wird auch im Falle des plattenfernen Kalluswachstums deutlich. Während in der späten Phase der Frakturheilung bei NON OVX nur 30\% des vorher manifestierten Kallus entstanden, bildeten sich bei OVX $133 \%$, bei $1 \mathrm{mg}$ Baicalein $50 \%$, bei $10 \mathrm{mg}$ Baicalein $64 \%$ und bei 100 mg Baicalein 103 \% der zuvor entwickelten Kallusfläche (vgl. Abb. 55 und 56, S. 64; Anh. Tab. 12, S. 88).

Die negative Auswirkung der Osteoporose auf die frühe Periode der Frakturheilung ist bereits seit einigen Jahren bekannt [Xu et al. 2003]. Es wird mittlerweile angenommen, dass die protrahierte Kallusbildung der Ovarektomie-induzierten osteoporotischen Fraktur in Zusammenhang mit der verzögerten Expression der Östrogenrezeptoren alpha und beta steht [Chow et al. 2014]. Dies würde den Rückstand der Kallusentwicklung während der primären Heilungsphase erklären. Zweifelsohne stieg die Rate des Kalluswachstums später im Vergleich zu NON OVX, da in letzterer Gruppe bereits die Kallushärtung und die Entstehung von Geflechtknochen und somit kein Kalluswachstum mehr erfolgte. Dem gegenüber stehen jedoch Studien, welche größere Unterschiede der Frakturheilung zwischen ovarektomierten und nicht ovarektomierten Ratten nach 4 bis 6 Wochen beziehungsweise in der mittleren und späten Heilungsphase sehen [Oliver et al. 2013; Hao et al. 2007]. Auf Grund der frühzeitigen Beendigung des Versuches vor dem Hintergrund der ausgeprägten Nebenwirkungen des Baicaleins konnte der Heilungsverlauf leider nicht über eine Dauer von 4 Wochen hinaus beobachtet werden. Es bleibt also fraglich, wie das Kalluswachstum und die Kalllushärtung bezüglich der ovarektomierten Tiere verlaufen 
wäre. Tatsächlich konnten diese das Kalluswachstum der nicht ovarektomierten Ratten weder bezüglich der endostalen noch der plattenfernen Gesamtkallusfläche einholen. Somit ist auch die absolute Gesamtfläche des kompletten Kallus bei NON OVX signifikant größer als bei den mit Baicalein behandelten Versuchstieren (vgl. Abb. 61, S. 67; Anh. Tab. 14, S. 89). Dennoch scheint die mittlere Konzentration des Baicaleins einen vorteilhaften Einfluss auf die Kallusentwicklung gehabt zu haben. Die Tiere bildeten innerhalb der ersten 20 Tage eine signifikant größere endostale Kallusfläche im Verlgeich zu OVX sowie eine größere Gesamtfläche des kompletten Kallus aus (vgl. Abb. 59, S. 66; Anh. Tab. 13, S. 88). Es ist demnach denkbar, dass die niedrigere Dosis Baicalein im subtherapeutischen Bereich lag, während die höchste Konzentration zu einer übermäßigen subkutanen Baicalein-Ausfällung geführt und damit die Entzündungsreaktion provoziert hat. Auch während des durch Li et al. (2015) durchgeführten Versuches, der die Induktion der Osteoblasten-Differenzierung durch Baicalein nachwies, wurde eine tägliche Dosierung von $10 \mathrm{mg} / \mathrm{kg}$ Körpergewicht gewählt. Hervorzuheben ist, dass der Heilungsmechanismus metaphysaler Knochen von dem der Diaphysen abweicht. Der schnellere Heilungsprozess, welcher vermutlich mit der großen Anzahl mesenchymaler Stammzellen im metaphysalen Knochenmark zusammenhängt, und die Entstehung des endostalen Kallus während der Trabekelheilung unterscheiden sich von der langsameren Regeneration diaphysaler Frakturen. Diese heilen unter Ausbildung eines externen periostalen Kallus mit Knorpelenstehung [Sandberg et al. 2016]. Baicalein könnte also die Fähigkeit besitzen, genau diesen Mechanismus der endostalen Kallusbildung und Frakturstabilisierung zu fördern.

\subsection{Schlussfolgerungen}

Ein positiver Einfluss des Lipoxygenasehemmers Baicalein auf die metaphysäre Frakturheilung osteoporotischer Knochen konnte vor allem für die endostale Kallusbildung, sowie die Frakturüberbrückung gezeigt werden.

Aus den Ergebnissen des biomechanischen Belastungstests ließ sich jedoch keine Verbesserung der Kallusfestigkeit und -elastizität ableiten.

Auch das mit Hilfe der Mikro-Computertomographie ermittelte Kortikalisvolumen und deren BMD wiesen keine signifikanten Unterschiede auf. Dennoch hat sich während dieser Untersuchung herauskristallisiert, dass die ovarektomierten unbehandelten Tiere eine signifikant geringere Kallusdichte gegenüber den nicht ovarektomierten Ratten 
aufwiesen, während für die Baicalein-Gruppen und NON OVX ähnliche Werte ermittelt wurden. Das Kallusvolumen der mit der höchsten Baicalein-Konzentration behandelten Tiere lag allerdings signifikant unter dem der nichtovarektomierten. Dieses Resultat könnte für eine bessere Wirksamkeit der niedrigeren BaicaleinKonzentrationen sprechen.

Die Annahme deckt sich mit der mikroradiographischen Analyse, die bezüglich der distalen plattennahen Kortikalisdicke für die mit $1 \mathrm{mg}$ und $10 \mathrm{mg}$ Baicalein behandelten Versuchstiere signifikant größere Werte im Vergleich zu den Gruppen NON OVX und OVX demonstrierte. Obwohl die Frakturheilung der nicht osteoporotischen Knochen überlegen war, kann eine Heilungsverbesserung durch Baicalein gegenüber einer unbehandelten osteoporotischen Fraktur angenommen werden.

Auch die im Zuge der polychromen Sequenzmarkierung untersuchte Überbrückung des Frakturspalts fand bei den mit Bacalein behandelten Versuchstieren zwei bis drei Tage früher statt als bei der unbehandelten ovarektomierten Gruppe. Dennoch wurden im Hinblick auf die nicht ovarektomierten Ratten in der frühen Phase der Frakturheilung ein signifikant größere plattenferne Kallusfläche und letztlich eine größere Gesamtfläche des endostalen Kallus ermittelt. Da die mit 10 mg Baicalein behandelten Ratten indessen innerhalb der ersten 20 Tage eine signifikant größere endostale Kallusfläche im Vergleich zu OVX ausbildeten, manifestiert sich in dieser Untersuchung erneut der Vorteil der Applikation der mittleren Baicalein-Konzentration in Relation zum lediglich ovarektomierten Kollektiv.

Unter Berücksichtigung, dass besonders der endostale Kallus zur Frakturstabilisierung beiträgt, könnte hier ein Ansatzpunkt für weitergehende Forschungsprojekte bestehen. Dabei wäre die Wahl einer veränderten Applikationsform des Baicaleins sinnvoll, um Spritzabszesse zu vermeiden und eine bessere Wirkstoffverteilung zu erzielen. 


\section{Zusammenfassung}

Die systemische Skeletterkrankung Osteoporose zeichnet sich durch eine reduzierte Knochenmineraldichte und eine Schädigung der Mikroarchitektur des Knochengewebes aus. Die globale Rolle der Osteoporose bedingt ihre Einstufung durch die WHO als eine der 10 wichtigsten Volkskrankheiten [Bartl 2011]. Auch die Heilung der osteoporotischen Fraktur ist vor allem in der frühen Phase durch Minderperfusion sowie reduzierte Kallusformation und -qualität erschwert [Xu et al. 2003]. Die Therapie der metaphysären Fraktur des osteoporitschen Knochens durch Lipoxygenase-Hemmer stellt einen neuen Ansatz in der Osteoporose Behandlung dar. Schon länger wird, wegen der Auswirkung der 5-Lipoxygenasen auf die Frakturheilung, ein osteoanaboler Einfluss der Lipoxygenase-Inhibitoren angenommen [Lee et al 2012]. Der Effekt des selektiven 12/15-Lipoxygenase-Inhibitors Baicalein auf die manifeste Osteoporose wurde jedoch kaum untersucht. Für das Flavonoid des Baikal-Helmkrautes (Scrutellaria baicalensis) wurde bereits eine antiinflammatorische sowie eine anti-kanzerogene Wirkung nachgewiesen [Chen et al 2013].

60 weibliche Sprague-Dawley-Ratten (drei Monate alt, im Durchschnitt 275,4 \pm 15 g schwer) wurden randomisiert zu gleichen Teilen in 5 Gruppen zu jeweils 12 Tieren aufgeteilt. Die Gruppe NON OVX blieb ohne jegliche Behandlung, während die anderen Tiere einer Ovarektomie unterzogen wurden. Bis zur 8 Wochen später vorgenommenen bilateralen Osteotomie der Tibiae hatten die ovarektomierten Ratten eine manifeste Osteoporose entwickelt. Dabei wurde an jeder Tibia-Metaphyse ein transversaler Frakturspalt von 0,5 cm erzeugt und durch eine 5-Loch-Leibinger-Platte aus Titan und je vier Schrauben osteosynthetisch versorgt. Die Baicalein-Applikation erfolgte ab dem Tag nach der Osteotomie bei dreien der ovarektomierten Gruppen in den Konzentrationen $1 \mathrm{mg} / \mathrm{kg}$ Körpergewicht, 10 mg/kg Körpergewicht und 100 mg/kg Körpergewicht. An Tag 15, 20 und 28 nach Osteotomie wurden allen Tieren subkutan drei Fluorochrome gespritzt, um die Ergebnisse im Zuge der polychromen Sequenzmarkierung evaluieren zu können. Der Versuch wurde 4 Wochen nach Osteotomie mit der Obduktion der Ratten beendet. Die Tibiae wurden einem biomechanischen Belastungstest, einer Mikro-Computertomographie-Analyse sowie 
einer mikroradiographischen und fluoreszenzmikroskopischen Untersuchung unterzogen. Die Ergebnisse wurden durch den gekoppelten Einsatz der Varianzanalyse one-way ANOVA und den Tukey-Kramer post-hoc-Test analysiert und das Signifikanzniveau auf $\mathrm{p}<0,05$ festgelegt.

Der Einsatz des Lipoxygenasehemmers Baicalein zeigte positive Effekte auf die Frakturheilung im Vergleich zu den unbehandelten osteoporotischen Kochen. Die niedrigste und mittlere Baicalein-Konzentration resultierten in einer dickeren plattennahen Kortikalis als OVX und NON OVX. Weiterhin konnte für die mit $10 \mathrm{mg}$ Baicalein behandelten Tiere eine größere endostale Kallusfläche in Relation zu OVX festgestellt werden. Hinzu kommt, dass die Frakturüberbrückung der OVX-Ratten bis zu drei Tage später stattfand als bei den Baicalein-Gruppen. Dennoch fielen die Werte der nicht osteoporotischen Knochen vor allem in Bezug auf die endostale Kallusdichte und -fläche sowie die gesamte Kallusfläche auch gegenüber den mit Baicalein behandelten Versuchsgruppen signifikant besser aus.

Abschließend sind die besseren Ergebnisse der niedrigeren Baicalein Konzentrationen herauszustellen. Die schlechte Löslichkeit des Wirkstoffes und die nachfolgende Abszess-Bildung dominierten besonders bei den Tieren, die mit der höchsten Konzentration Baicalein behandelt wurden. Die Baicalein-Applikation hat jedoch das Potential, die Heilung der metaphysären Fraktur bei manifester Osteoporose zu unterstützen und sowohl eine frühere Frakturüberbrückung als auch bessere biomechanische Ergebnisse zu erzielen. Während die weit verbreiteten Bisphosphonate und der RANK-L-Inhibitior Denosumab die Kallusreifung aufhalten [Hegde et al. 2016], scheint diese durch Baicalein beschleunigt zu werden. Allerdings bleiben die hier gelieferten Ansätze weiter zu untersuchen. Vor allem auch die phytoöstrogenen Eigenschaften und deren Relevanz für den antiosteoporotischen Einfluss des Flavonoids sind zu prüfen. Eine veränderte Darreichungsform könnte darüber hinaus die anti-inflammatorische und osteoanabole Wirkung des Lipoxygenasehemmers verstärken und genauere Erkenntnisse über den Effekt der Osteoklasteninhibition auf die Frakturheilung erbringen. Schließlich würde auch die Präzipitation des Baicaleins im Gewebe und damit die Abszessbildung vermieden werden, wenn die Darreichung beispielsweise mit dem Futter erfolgen würde. 


\section{Anhang}

\subsection{Körpergewicht der Tiere im Verlauf}

Tabelle 1: Darstellung der Mittelwerte \pm Standardabweichung der Körpergewichte der

Tiere über die Versuchswochen in Gramm

\begin{tabular}{|c|c|c|c|c|c|}
\hline $\begin{array}{l}\text { Versuchs- } \\
\text { wochen }\end{array}$ & $\begin{array}{l}\text { NON } \\
\text { OVX }\end{array}$ & OVX & $\begin{array}{l}1 \mathrm{mg} \\
\text { Baicalein }\end{array}$ & $\begin{array}{l}10 \mathrm{mg} \\
\text { Baicalein }\end{array}$ & $\begin{array}{l}100 \mathrm{mg} \\
\text { Baicalein }\end{array}$ \\
\hline $\mathbf{0}$ & $266 \pm 17$ & $278 \pm 16$ & $282 \pm 16$ & $274 \pm 16$ & $277 \pm 11$ \\
\hline 1 & $278 \pm 13$ & $292 \pm 14$ & $\begin{array}{l}298 \pm 15 \\
\left(\beta^{*}\right)\end{array}$ & $289 \pm 15$ & $291 \pm 13$ \\
\hline 2 & $277 \pm 12$ & $\begin{array}{l}324 \pm 21 \\
\left(\beta^{*}\right)\end{array}$ & $\begin{array}{l}334 \pm 20 \\
\left(\beta^{*}\right)\end{array}$ & $\begin{array}{l}315 \pm 17 \\
\left(\beta^{*}\right)\end{array}$ & $\begin{array}{l}316 \pm 13 \\
\left(\beta^{*}\right)\end{array}$ \\
\hline 3 & $290 \pm 11$ & $\begin{array}{l}355 \pm 26 \\
\left(\beta^{*}\right)\end{array}$ & $\begin{array}{l}364 \pm 26 \\
\left(\beta^{*}\right)\end{array}$ & $\begin{array}{l}341 \pm 19 \\
\left(\beta^{*}\right)\end{array}$ & $\begin{array}{l}344 \pm 18 \\
\left(\beta^{*}\right)\end{array}$ \\
\hline 4 & $296 \pm 10$ & $\begin{array}{l}367 \pm 28 \\
\left(\beta^{*}\right)\end{array}$ & $\begin{array}{l}371 \pm 29 \\
\left(\beta^{*}\right)\end{array}$ & $\begin{array}{l}351 \pm 22 \\
\left(\beta^{*}\right)\end{array}$ & $\begin{array}{l}351 \pm 25 \\
\left(\beta^{*}\right)\end{array}$ \\
\hline 5 & $304 \pm 11$ & $\begin{array}{l}371 \pm 32 \\
\left(\beta^{*}\right)\end{array}$ & $\begin{array}{l}377 \pm 31 \\
\left(\beta^{*}\right)\end{array}$ & $\begin{array}{l}356 \pm 24 \\
\left(\beta^{*}\right)\end{array}$ & $\begin{array}{l}361 \pm 25 \\
\left(\beta^{*}\right)\end{array}$ \\
\hline 6 & $304 \pm 13$ & $\begin{array}{l}372 \pm 33 \\
\left(\beta^{*}\right)\end{array}$ & $\begin{array}{l}379 \pm 32 \\
\left(\beta^{*}\right)\end{array}$ & $\begin{array}{l}358 \pm 27 \\
\left(\beta^{*}\right)\end{array}$ & $\begin{array}{l}357 \pm 23 \\
\left(\beta^{*}\right)\end{array}$ \\
\hline 7 & $307 \pm 25$ & $\begin{array}{l}381 \pm 35 \\
\left(\beta^{*}\right)\end{array}$ & $\begin{array}{l}390 \pm 34 \\
\left(\beta^{*}\right)\end{array}$ & $\begin{array}{l}366 \pm 28 \\
\left(\beta^{*}\right)\end{array}$ & $\begin{array}{l}361 \pm 23 \\
\left(\beta^{*}\right)\end{array}$ \\
\hline 8 & $307 \pm 25$ & $\begin{array}{l}378 \pm 39 \\
\left(\beta^{*}\right)\end{array}$ & $\begin{array}{l}383 \pm 20 \\
\left(\beta^{*}\right)\end{array}$ & $\begin{array}{l}367 \pm 29 \\
\left(\beta^{*}\right)\end{array}$ & $\begin{array}{l}365 \pm 24 \\
\left(\beta^{*}\right)\end{array}$ \\
\hline 9 & $297 \pm 10$ & $\begin{array}{l}346 \pm 39 \\
\left(\beta^{*}\right)\end{array}$ & $\begin{array}{l}343 \pm 15 \\
\left(\beta^{*}\right)\end{array}$ & $\begin{array}{l}334 \pm 30 \\
\left(\beta^{*}\right)\end{array}$ & $\begin{array}{l}338 \pm 22 \\
\left(\beta^{*}\right)\end{array}$ \\
\hline 10 & $303 \pm 7$ & $\begin{array}{l}350 \pm 39 \\
\left(\beta^{*}\right)\end{array}$ & $\begin{array}{l}346 \pm 17 \\
\left(\beta^{*}\right)\end{array}$ & $331 \pm 30$ & $\begin{array}{l}344 \pm 22 \\
\left(\beta^{*}\right)\end{array}$ \\
\hline 11 & $306 \pm 10$ & $\begin{array}{l}356 \pm 40 \\
\left(\beta^{*}\right)\end{array}$ & $\begin{array}{l}349 \pm 16 \\
\left(\beta^{*}\right)\end{array}$ & $\begin{array}{l}341 \pm 27 \\
\left(\beta^{*}\right)\end{array}$ & $\begin{array}{l}345 \pm 22 \\
\left(\beta^{*}\right)\end{array}$ \\
\hline 12 & $311 \pm 10$ & $\begin{array}{l}350 \pm 48 \\
\left(\beta^{*}\right)\end{array}$ & $345 \pm 17$ & $341 \pm 30$ & $336 \pm 22$ \\
\hline
\end{tabular}

$\beta=$ signifikant zu NON OVX; $* * *=p<0,001, * *=p<0,01, *=p<0,05$ 


\subsection{Uterusgewicht}

Tabelle 2: Darstellung der Mittelwerte \pm Standardabweichung der Uterusgewichte jeder Versuchsgruppe am Tag der Obduktion

\begin{tabular}{|l|l|l|l|l|l|}
\hline Messgröße & $\begin{array}{l}\text { NON } \\
\text { OVX }\end{array}$ & OVX & $\begin{array}{l}\mathbf{1 ~ m g} \\
\text { Baicalein }\end{array}$ & $\begin{array}{l}\mathbf{1 0} \mathbf{~ m g} \\
\text { Baicalein }\end{array}$ & $\begin{array}{l}\mathbf{1 0 0} \mathbf{~ m g} \\
\text { Baicalein }\end{array}$ \\
\hline $\begin{array}{l}\text { Uterus- } \\
\text { gewicht } \\
\text { (g) }\end{array}$ & $0,64 \pm$ & $0,11 \pm$ & $0,13 \pm 0,09$ & $0,14 \pm 0,04$ & $0,15 \pm 0,03$ \\
$\left(\beta^{* * *}\right)$ & & \\
$\left(\begin{array}{l}0,02 \\
\left(\beta^{* * *}\right)\end{array}\right.$ & $\left(\beta^{* * *}\right)$ & & \\
\hline
\end{tabular}

\subsection{Ergebnisse des biomechanischen Tests}

Tabelle 3: Darstellung der Mittelwerte \pm Standardabweichung der Messgrößen des biomechanischen Tests

\begin{tabular}{|l|l|l|l|l|l|}
\hline Parameter & NON OVX & OVX & $\begin{array}{l}\mathbf{1 ~ m g} \\
\text { Baicalein }\end{array}$ & $\begin{array}{l}\mathbf{1 0} \mathbf{~ m g} \\
\text { Baicalein }\end{array}$ & $\begin{array}{l}\mathbf{1 0 0} \mathbf{~ m g} \\
\text { Baicalein }\end{array}$ \\
\hline $\begin{array}{l}\text { Elastizität } \\
\text { (N/mm) }\end{array}$ & $27,97 \pm$ & $16,46 \pm$ & $14,99 \pm$ & $15,35 \pm$ & $20,36 \pm$ \\
\hline Streckgrenze & 8,69 & 7,76 & 7,79 & 5,89 & 7,95 \\
(N) & $43,09 \pm$ & $38,13 \pm$ & $14,03 \pm$ & $7,76 \pm$ & $13,90 \pm$ \\
\hline $\begin{array}{l}\text { Maximalkraft } \\
\text { (N) }\end{array}$ & 51,78 & 31,46 & 11,36 & 1,34 & 3,91 \\
\hline & 31,32 & $48,00 \pm$ & $25,97 \pm$ & $13,92 \pm$ & $19,54 \pm$ \\
\hline
\end{tabular}




\subsection{Ergebnisse der Mikrocomputertomographie}

Tabelle 4: Darstellung der Mittelwerte \pm Standardabweichung der Messgrößen der Weichteile

\begin{tabular}{|l|l|l|l|l|l|}
\hline $\begin{array}{l}\text { Weichteil- } \\
\text { parameter }\end{array}$ & $\begin{array}{l}\text { NON } \\
\text { OVX }\end{array}$ & OVX & $\mathbf{1} \mathbf{~ m g}$ & $\mathbf{1 0} \mathbf{~ m g}$ & $\mathbf{1 0 0} \mathbf{~ m g}$ \\
Baicalein & Baicalein & Baicalein \\
\hline $\begin{array}{l}\text { Mittlere } \\
\text { Dichte } \\
\left(\mathrm{g} / \mathrm{cm}^{3}\right)\end{array}$ & $\begin{array}{l}0,093 \\
\pm 0,024\end{array}$ & $\begin{array}{l}0,096 \\
\pm 0,019\end{array}$ & $0,115 \pm 0,023$ & $0,106 \pm 0,025$ & $0,118 \pm 0,014$ \\
\hline $\begin{array}{l}\text { Volumen } \\
\left(\mathrm{mm}^{3}\right)\end{array}$ & $\begin{array}{l}92,10 \\
\pm 56,10\end{array}$ & $\begin{array}{l}97,49 \\
\pm 36,20\end{array}$ & $58,03 \pm 20,95$ & $90,07 \pm 31,42$ & $71,05 \pm 31,07$ \\
\hline
\end{tabular}

Tabelle 5: Darstellung der Mittelwerte \pm Standardabweichung der Messgrößen der Kortikalis

\begin{tabular}{|l|l|l|l|l|l|}
\hline $\begin{array}{l}\text { Kortikalis- } \\
\text { parameter }\end{array}$ & $\begin{array}{l}\text { NON } \\
\text { OVX }\end{array}$ & OVX & $\begin{array}{l}\mathbf{1} \mathbf{~ m g} \\
\text { Baicalein }\end{array}$ & $\begin{array}{l}\mathbf{1 0} \mathbf{~ m g} \\
\text { Baicalein }\end{array}$ & $\begin{array}{l}\mathbf{1 0 0} \mathbf{~ m g} \\
\text { Baicalein }\end{array}$ \\
\hline $\begin{array}{l}\text { Mittlere BMD } \\
\left(\mathrm{g} / \mathrm{cm}^{3}\right)\end{array}$ & $\begin{array}{l}1,18 \\
\pm\end{array}$ & $\begin{array}{l}1,14 \\
\pm\end{array}$ & $1,20 \pm 0,04$ & $1,19 \pm 0,02$ & $1,20 \pm 0,03$ \\
\hline $\begin{array}{l}\text { Volumen } \\
\left(\mathrm{mm}^{3}\right)\end{array}$ & $\begin{array}{l}22,035 \\
0,13\end{array}$ & $\begin{array}{l}18,45 \pm \\
6,31\end{array}$ & $20,74 \pm 8,89$ & $20,01 \pm 4,01$ & $23,26 \pm 4,23$ \\
\hline
\end{tabular}

Tabelle 6: Darstellung der Mittelwerte \pm Standardabweichung der Messgrößen des Kallus

\begin{tabular}{|l|l|l|l|l|l|}
\hline Kallus- & NON & OVX & $\mathbf{1} \mathbf{~ m g}$ & $\mathbf{1 0} \mathbf{~ m g}$ \\
parameter & OVX & Baicalein & $\begin{array}{l}\mathbf{1 0 0} \text { mg } \\
\text { Baicalein }\end{array}$ & Baicalein \\
\hline $\begin{array}{l}\text { Mittlere } \\
\text { Dichte }\left(\mathrm{g} / \mathrm{cm}^{3}\right)\end{array}$ & $\begin{array}{l}0,61 \pm \\
0,04\end{array}$ & $\begin{array}{l}0,55 \pm \\
0,04 \\
\left(\beta^{* *}\right)\end{array}$ & $0,60 \pm 0,04$ & $0,57 \pm 0,03$ & $0,58 \pm 0,03$ \\
\hline $\begin{array}{l}\text { Volumen } \\
\left(\mathrm{mm}^{3}\right)\end{array}$ & $\begin{array}{l}77,70 \pm \\
50,75\end{array}$ & $\begin{array}{l}56,44 \\
\pm \\
17,24\end{array}$ & $53,84 \pm 26,03$ & $51,70 \pm 17,41$ & $\begin{array}{l}47,75 \pm 15,77 \\
\left(\beta^{*}\right)\end{array}$ \\
\hline
\end{tabular}

$\beta=$ signifikant zu NON OVX; $*=p<0,05, * *=p<0,01$ 
Tabelle 7: Darstellung der Mittelwerte \pm Standardabweichung der Messgrößen des gesamten Knochens

\begin{tabular}{|c|c|c|c|c|c|}
\hline Parameter & $\begin{array}{l}\text { NON } \\
\text { OVX }\end{array}$ & OVX & $\begin{array}{l}1 \mathrm{mg} \\
\text { Baicalein }\end{array}$ & $\begin{array}{l}10 \mathrm{mg} \\
\text { Baicalein }\end{array}$ & $\begin{array}{l}100 \mathrm{mg} \\
\text { Baicalein }\end{array}$ \\
\hline $\begin{array}{l}\text { Mittlere BMD } \\
\left(\mathrm{g} / \mathrm{cm}^{3}\right)\end{array}$ & $\begin{array}{l}0,75 \\
\pm \\
0,10\end{array}$ & $\begin{array}{l}0,70 \\
\pm \\
0,08\end{array}$ & $0,78 \pm 0,10$ & $0,75 \pm 0,06$ & $0,79 \pm 0,08$ \\
\hline $\begin{array}{l}\text { Volumen } \\
\left(\mathrm{mm}^{3}\right)\end{array}$ & $\begin{array}{l}100,73 \\
\pm \\
24,76\end{array}$ & $\begin{array}{l}74,92 \\
\pm \\
21,33\end{array}$ & $\begin{array}{l}74,31 \\
24,28\end{array} \quad \pm$ & $\begin{array}{l}71,71 \pm 18,80 \\
\left(\beta^{*}\right)\end{array}$ & $\begin{array}{l}71,0 \pm 15,77 \\
\left(\beta^{*}\right)\end{array}$ \\
\hline
\end{tabular}

$\beta=$ signifikant zu NON OVX; $*=p<0,05$

Tabelle 8: Darstellung der Mittelwerte \pm Standardabweichung der Messgrößen des gesamten Gewebes

\begin{tabular}{|c|c|c|c|c|c|}
\hline Parameter & $\begin{array}{l}\text { NON } \\
\text { OVX }\end{array}$ & OVX & $\begin{array}{l}1 \mathrm{mg} \\
\text { Baicalein }\end{array}$ & $\begin{array}{l}10 \mathrm{mg} \\
\text { Baicalein }\end{array}$ & $\begin{array}{l}100 \mathrm{mg} \\
\text { Baicalein }\end{array}$ \\
\hline $\begin{array}{l}\text { Mittlere BMD } \\
\left(\mathrm{g} / \mathrm{cm}^{3}\right)\end{array}$ & $\begin{array}{l}0,47 \\
\pm \\
0,14\end{array}$ & $\begin{array}{l}0,37 \\
\pm \\
0,07\end{array}$ & $\begin{array}{l}0,47 \pm \\
0,09\end{array}$ & $\begin{array}{l}0,40 \pm \\
0,08\end{array}$ & $\begin{array}{l}0,43 \pm \\
0,13\end{array}$ \\
\hline $\begin{array}{l}\text { Volumen } \\
\left(\mathrm{mm}^{3}\right)\end{array}$ & $\begin{array}{l}208,40 \\
\pm \\
72,13\end{array}$ & $\begin{array}{l}143,60 \\
\pm \\
10,83\end{array}$ & $\begin{array}{l}134,30 \pm \\
40,06\end{array}$ & $\begin{array}{l}161,70 \pm \\
38,55\end{array}$ & $\begin{array}{l}142,00 \pm \\
45,10\end{array}$ \\
\hline BV/TV (\%) & $\begin{array}{l}56,25 \pm \\
13,97\end{array}$ & $\begin{array}{l}44,17 \pm \\
6,74\end{array}$ & $\begin{array}{l}55,07 \pm \\
8,55\end{array}$ & $\begin{array}{l}45,47 \pm \\
10,44\end{array}$ & $\begin{array}{l}51,87 \pm \\
7,95\end{array}$ \\
\hline
\end{tabular}




\subsection{Ergebnisse der Mikroradiographie}

Tabelle 9: Darstellung der Mittelwerte \pm Standardabweichung der Kortikalismessgrößen

\begin{tabular}{|c|c|c|c|c|c|}
\hline $\begin{array}{l}\text { Kortikalis- } \\
\text { Parameter }\end{array}$ & $\begin{array}{l}\text { NON } \\
\text { OVX }\end{array}$ & OVX & $\begin{array}{l}1 \mathrm{mg} \\
\text { Baicalein }\end{array}$ & $\begin{array}{l}10 \mathrm{mg} \\
\text { Baicalein }\end{array}$ & $\begin{array}{l}100 \mathrm{mg} \\
\text { Baicalein }\end{array}$ \\
\hline $\begin{array}{l}\text { Kortikalisdicke } \\
\text { distal plattennah } \\
(\mathrm{mm})\end{array}$ & $\begin{array}{l}0,31 \pm 0,16 \\
\left(\gamma^{*}\right)\end{array}$ & $0,27 \pm 0,15$ & $\begin{array}{l}0,46 \pm 0,11 \\
\left(\beta^{*}\right) \\
\left(\gamma^{*}\right)\end{array}$ & $\begin{array}{l}0,47 \pm 0,15 \\
\left(\beta^{*}\right) \\
\left(\gamma^{*}\right)\end{array}$ & $\begin{array}{l}0,38 \pm 0,1 \\
8\end{array}$ \\
\hline $\begin{array}{l}\text { Kortikalisdicke } \\
\text { distal plattenfern } \\
(\mathrm{mm})\end{array}$ & $0,37 \pm 0,20$ & $0,42 \pm 0,15$ & $0,44 \pm 0,12$ & $0,36 \pm 0,15$ & $\begin{array}{l}0,49 \pm 0,1 \\
9\end{array}$ \\
\hline $\begin{array}{l}\text { Kortikalisdichte } \\
\text { distal plattennah } \\
(\%)\end{array}$ & $\begin{array}{l}99,07 \pm \\
0,97\end{array}$ & $\begin{array}{l}99,58 \pm \\
0,60\end{array}$ & $\begin{array}{l}99,36 \pm \\
0,74\end{array}$ & $\begin{array}{l}99,37 \pm \\
0,72\end{array}$ & $\begin{array}{l}98,73 \pm \\
1,96\end{array}$ \\
\hline $\begin{array}{l}\text { Kortikalisdichte } \\
\text { distal plattenfern }(\%)\end{array}$ & $\begin{array}{l}98,45 \pm \\
3,58\end{array}$ & $\begin{array}{l}98,59 \pm \\
2,32\end{array}$ & $\begin{array}{l}99,30 \pm \\
0,92\end{array}$ & $\begin{array}{l}99,40 \pm \\
0,68\end{array}$ & $\begin{array}{l}99,39 \pm \\
1,18\end{array}$ \\
\hline
\end{tabular}


Tabelle 10: Darstellung der Mittelwerte \pm Standardabweichung der Kallusmessgrößen

\begin{tabular}{|c|c|c|c|c|c|}
\hline Kallus-Parameter & $\begin{array}{l}\text { NON } \\
\text { OVX }\end{array}$ & OVX & $\begin{array}{l}1 \mathrm{mg} \\
\text { Baicalein }\end{array}$ & $\begin{array}{l}10 \mathrm{mg} \\
\text { Baicalein }\end{array}$ & $\begin{array}{l}100 \mathrm{mg} \\
\text { Baicalein }\end{array}$ \\
\hline $\begin{array}{l}\text { Kallusdicke } \\
\text { plattennah (mm) }\end{array}$ & $0,79 \pm 0,58$ & $0,85 \pm 0,33$ & $0,74 \pm 0,51$ & $0,57 \pm 0,44$ & $0,68 \pm 0,37$ \\
\hline $\begin{array}{l}\text { Kallusdicke } \\
\text { plattenfern }(\mathrm{mm})\end{array}$ & $0,87 \pm 0,75$ & $0,69 \pm 0,37$ & $0,58 \pm 0,39$ & $0,97 \pm 0,39$ & $0,59 \pm 0,37$ \\
\hline $\begin{array}{l}\text { Kallusdichte } \\
\text { plattennah (\%) }\end{array}$ & $\begin{array}{l}64,50 \pm \\
13,08\end{array}$ & $\begin{array}{l}47,93 \pm \\
10,68\end{array}$ & $\begin{array}{l}65,33 \pm \\
13,94\end{array}$ & $\begin{array}{l}64,57 \pm \\
18,42\end{array}$ & $\begin{array}{l}55,82 \pm \\
13,52\end{array}$ \\
\hline $\begin{array}{l}\text { Kallusdichte } \\
\text { plattenfern (\%) }\end{array}$ & $\begin{array}{l}65,09 \pm \\
15,44 \\
\left(\gamma^{*}\right)\end{array}$ & $\begin{array}{l}45,97 \pm \\
15,49\end{array}$ & $\begin{array}{l}66,31 \pm \\
14,46 \\
\left(\gamma^{* *}\right)\end{array}$ & $\begin{array}{l}55,01 \pm \\
11,69\end{array}$ & $\begin{array}{l}52,98 \pm \\
17,04\end{array}$ \\
\hline $\begin{array}{l}\text { Kallusdichte } \\
\text { endostal (\%) }\end{array}$ & $\begin{array}{l}56,50 \pm \\
16,51\end{array}$ & $\begin{array}{l}33,96 \pm \\
5,10 \\
\left(\beta^{* *}\right)\end{array}$ & $\begin{array}{l}31,32 \pm \\
10,95 \\
(\beta * * *)\end{array}$ & $\begin{array}{l}40,08 \pm \\
11,23 \\
\left(\beta^{*}\right)\end{array}$ & $\begin{array}{l}41,99 \pm \\
17,63 \\
\left(\beta^{*}\right)\end{array}$ \\
\hline
\end{tabular}

$\beta=$ signifikant zu NON OVX, $\gamma=$ signifikant zu OVX, ${ }^{*}=\mathrm{p}<0,05, * *=\mathrm{p}<0,01, * * *=\mathrm{p}<0,001$

\subsection{Ergebnisse der polychromen Sequenzmarkierung}

Tabelle 11: Darstellung der Mittelwerte \pm Standardabweichung der Messgrößen des plattennahen Kallus

\begin{tabular}{|l|l|l|l|l|l|}
\hline $\begin{array}{l}\text { Kallusfläche } \\
\text { plattennah }\end{array}$ & NON OVX & OVX & $\begin{array}{l}\mathbf{1 ~ m g} \\
\text { Baicalein }\end{array}$ & $\begin{array}{l}\mathbf{1 0} \mathbf{~ m g} \\
\text { Baicalein }\end{array}$ & $\begin{array}{l}\mathbf{1 0 0} \mathbf{~ m g} \\
\text { Baicalein }\end{array}$ \\
\hline $\begin{array}{l}\text { Gesamtfläche } \\
\left(\mathrm{mm}^{2}\right)\end{array}$ & $0,76 \pm 1,41$ & $1,08 \pm 0,96$ & $0,64 \pm 0,64$ & $1,00 \pm 0,88$ & $1,09 \pm 1,04$ \\
\hline $\begin{array}{l}\text { CG- Fläche } \\
\left(\mathrm{mm}^{2}\right)\end{array}$ & $0,44 \pm 1,02$ & $0,43 \pm 0,50$ & $0,34 \pm 0,33$ & $0,52 \pm 0,61$ & $0,54 \pm 0,58$ \\
\hline $\begin{array}{l}\text { AK- Fläche } \\
\left(\mathrm{mm}^{2}\right)\end{array}$ & $0,26 \pm 0,37$ & $0,58 \pm 0,44$ & $0,26 \pm 0,34$ & $0,44 \pm 0,39$ & $0,50 \pm 0,56$ \\
\hline
\end{tabular}


Tabelle 12: Darstellung der Mittelwerte \pm Standardabweichung der Messgrößen des plattenfernen Kallus

\begin{tabular}{|c|c|c|c|c|c|}
\hline $\begin{array}{l}\text { Kallusfläche } \\
\text { plattenfern }\end{array}$ & NON OVX & OVX & $\begin{array}{l}1 \mathrm{mg} \\
\text { Baicalein }\end{array}$ & $\begin{array}{l}10 \mathrm{mg} \\
\text { Baicalein }\end{array}$ & $\begin{array}{l}100 \mathrm{mg} \\
\text { Baicalein }\end{array}$ \\
\hline $\begin{array}{l}\text { Gesamtfläche } \\
\left(\mathrm{mm}^{2}\right)\end{array}$ & $3,20 \pm 1,05$ & $2,46 \pm 1,04$ & $\begin{array}{l}1,98 \pm 1,43 \\
\left(\beta^{*}\right)\end{array}$ & $2,59 \pm 1,23$ & $\begin{array}{l}1,65 \pm 1,02 \\
\left(\beta^{* *}\right)\end{array}$ \\
\hline $\begin{array}{l}\text { CG- Fläche } \\
\left(\mathrm{mm}^{2}\right)\end{array}$ & $2,38 \pm 0,71$ & $\begin{array}{l}1,02 \pm 0,81 \\
\left(\beta^{* * *}\right)\end{array}$ & $\begin{array}{l}1,24 \pm 0,73 \\
\left(\beta^{* * *}\right)\end{array}$ & $\begin{array}{l}1,45 \pm 0,76 \\
\left(\beta^{* *}\right)\end{array}$ & $\begin{array}{l}0,74 \pm 0,47 \\
\left(\beta^{* * *}\right)\end{array}$ \\
\hline $\begin{array}{l}\text { AK- Fläche } \\
\left(\mathrm{mm}^{2}\right)\end{array}$ & $0,72 \pm 0,58$ & $1,36 \pm 1,02$ & $0,62 \pm 0,71$ & $0,93 \pm 0,56$ & $0,76 \pm 0,68$ \\
\hline
\end{tabular}

Tabelle 13: Darstellung der Mittelwerte \pm Standardabweichung der Messgrößen des endostalen Kallus

\begin{tabular}{|c|c|c|c|c|c|}
\hline $\begin{array}{l}\text { Kallusfläche } \\
\text { endostal }\end{array}$ & NON OVX & OVX & $\begin{array}{l}1 \mathrm{mg} \\
\text { Baicalein }\end{array}$ & $\begin{array}{l}10 \mathrm{mg} \\
\text { Baicalein }\end{array}$ & $\begin{array}{l}100 \mathrm{mg} \\
\text { Baicalein }\end{array}$ \\
\hline $\begin{array}{l}\text { Gesamtfläche } \\
\left(\mathrm{mm}^{2}\right)\end{array}$ & $3,02 \pm 1,30$ & $1,66 \pm 1,24$ & $\begin{array}{l}1,42 \pm 1,13 \\
\left(\beta^{* *}\right)\end{array}$ & $2,51 \pm 1,32$ & $2,04 \pm 1,15$ \\
\hline $\begin{array}{l}\text { CG- Fläche } \\
\left(\mathrm{mm}^{2}\right)\end{array}$ & $2,23 \pm 0,99$ & $\begin{array}{l}0,28 \pm 0,38 \\
\left(\beta^{* * *}\right)\end{array}$ & $\begin{array}{l}0,74 \pm 0,62 \\
\left(\beta^{* * *}\right)\end{array}$ & $\begin{array}{l}1,37 \pm 1,36 \\
\left(\gamma^{*}\right)\end{array}$ & $\begin{array}{l}1,04 \pm 0,62 \\
\left(\beta^{* * *}\right)\end{array}$ \\
\hline $\begin{array}{l}\text { AK- Fläche } \\
\left(\mathrm{mm}^{2}\right)\end{array}$ & $0,63 \pm 0,56$ & $1,26 \pm 0,98$ & $0,57 \pm 0,53$ & $0,96 \pm 0,57$ & $0,87 \pm 0,71$ \\
\hline
\end{tabular}


Tabelle 14: Darstellung der Mittelwerte \pm Standardabweichung der Messgröße für den gesamten Kallus

\begin{tabular}{|l|l|l|l|l|l|}
\hline $\begin{array}{l}\text { Kallusfläche } \\
\text { komplett }\end{array}$ & NON OVX & OVX & $\begin{array}{l}\mathbf{1} \mathbf{~ m g} \\
\text { Baicalein }\end{array}$ & $\begin{array}{l}\mathbf{1 0} \mathbf{~ m g} \\
\text { Baicalein }\end{array}$ & $\begin{array}{l}\mathbf{1 0 0} \mathbf{~ m g} \\
\text { Baicalein }\end{array}$ \\
\hline $\begin{array}{l}\text { Gesamtfläche } \\
\text { kompletter }\end{array}$ & $7,12 \pm 2,93$ & $5,20 \pm 2,28$ & $4,04 \pm 1,90$ & $6,10 \pm 2,58$ & $4,78 \pm 2,48$ \\
$\begin{array}{l}\text { Kallus } \\
\left(\beta^{* *}\right)\end{array}$ & & & & $\left(\beta^{*}\right)$ \\
\hline \begin{tabular}{l}
$\beta=$ signifikant zu NON OVX, $*=p$ \\
\hline
\end{tabular}
\end{tabular}




\section{Literaturverzeichnis}

Aerssens J, van Audekercke R, Talalaj M, Geusens P, Bramm E, Dequeker J (1996): Effect of 1alpha-vitamin D3 and estrogen therapy on cortical bone mechanical properties in the ovariectomized rat model. Endocrinology 137 (4), 1358-1364

Akao T, Sato K, He J, Ma C, Hattori M (2013): Baicalein 6-O-beta-Dglucopyranuronoside is a main metabolite in the plasma after oral administration of baicalin, a flavone glucuronide of scutellariae radix, to rats. Biol Pharm Bull $\underline{36}$ (5), $748-753$

Augat, P, Simon U, Liedert A, Claes L (2005): Mechanics and mechano-biology of fracture healing in normal and osteoporotic bone. Osteoporos Int 16 (2), 43

Bartl R: Osteoporose. Prävention, Diagnostik, Therapie. Unter Mitarbeit von Christoph Bartl. 4. Aufl.; Georg Thieme Verlag. Stuttgart 2011

Binkley N, Bolognese M, Sidorowicz-Bialynicka A, Vally T, Trout R, Miller C, Buben CE, Gilligan JP, Krause DS (2012): A phase 3 trial of the efficacy and safety of oral recombinant calcitonin: the Oral Calcitonin in Postmenopausal Osteoporosis (ORACAL) trial. J Bone Miner Res 27 (8), 1821-1829

Blake GM, Fogelman I (2009): The clinical role of dual energy X-ray absorptiometry. Eur J Radiol 71 (3), 406-414

Bleibler F, Rapp K, Jaensch A, Becker C, König HH (2014): Expected lifetime numbers and costs of fractures in postmenopausal women with and without osteoporosis in Germany: a discrete event simulation model. BMC Health Serv Res 14, 284

Boyce BF (2013): Advances in the regulation of osteoclasts and osteoclast functions. J Dent Res $\underline{92}$ (10), 860-867

Boyd SK, Davison P, Muller R, Gasser JA (2006): Monitoring individual morphological changes over time in ovariectomized rats by in vivo micro-computed tomography. Bone $\underline{39}$ (4), 854-862

Buck J: Radiologie Träger des Fortschritts. Festschrift für Friedrich H.W, Heuck. Springer-Verlag Berlin, Heidelberg 1996

Cao Y, Mori S, Mashiba T, Westmore MS, Ma L, Sato M et al. (2002): Raloxifene, estrogen, and alendronate affect the processes of fracture repair differently in ovariectomized rats. J Bone Miner Res 17 (12), 2237-2246

Chapurlat R (2008): Epidémiologie de l'ostéoporose. J Soc Biol 202 (4), 251-255

Chen GX, Zheng S, Qin S, Zhong ZM, Wu XH, Huang ZP, Li W, Ding RT, Yu H, Chen JT (2014): Effect of low-magnitude whole-body vibration combined with alendronate in ovariectomized rats: a random controlled osteoporosis prevention study. PloS one $\underline{9}$ (5), e96181

Chen L; Yang L, Yao M, Cui XJ, Xue CC, Wang YJ, Shu B (2016): Biomechanical Characteristics of Osteoporotic Fracture Healing in Ovariectomized Rats: A Systematic Review. PloS one 11 (4), e0153120 
Chen T, Chen M, Yao X, Long W, Chen H, Li L (2008): A new three-point bending test for bone biomechanical properties of rat's tibia. J Biomech Eng 25 (2), 341-345

Chen YJ, Wu CS, Shieh JJ, Wu JH, Chen HY, Chung TW, Chen YK, Lin CC (2013): Baicalein Triggers Mitochondria-Mediated Apoptosis and Enhances the Antileukemic Effect of Vincristine in Childhood Acute Lymphoblastic Leukemia CCRF-CEM Cells. Evid Based Complement Alternat Med 2013, 19

Cheung WH, Miclau T, Chow SKH, Yang FF, Alt V (2016): Fracture healing in osteoporotic bone. Injury $\underline{47}, 21-26$

Choi RCY, Zhu JTT, Yung AWY, Lee PSC, Xu, Sherry L, Guo AJY, Zhu KY, Dong TT, Tsim KW (2013): Synergistic Action of Flavonoids, Baicalein, and Daidzein in Estrogenic and Neuroprotective Effects: A Development of Potential Health Products and Therapeutic Drugs against Alzheimer's Disease. Evid Based Complement Alternat Med 2013, 635694

Chow SK, Leung KS, Qin L, Wei F, Cheung WH (2014): Callus formation is related to the expression ratios of estrogen receptors-alpha and -beta in ovariectomy-induced osteoporotic fracture healing. Arch Orthop Trauma Surg 134 (10), 1405-1416

Cianferotti L, D'Asta F, Brandi ML (2013): A review on strontium ranelate long-term antifracture efficacy in the treatment of postmenopausal osteoporosis. Ther $\mathrm{Adv}$ Musculoskelet Dis $\underline{5}$ (3), 127-139

Claes L, Recknagel S, Ignatius A (2012): Fracture healing under healthy and inflammatory conditions. Nat Rev Rheumatol $\underline{8}$ (3), 133-143

Clemmons JJ (1955): Procedures and errors in quantitative historadiography. Biochim Biophys Acta 17, 297-321

DVO: Dachverband Osteologie e.V. (Hg.) (2014): Entwurf zur Prophylaxe, Diagnostik und Therapie der Osteoporose bei Männern ab dem 60. Lebensjahr und bei postmenopausalen Frauen. S3-Leitlinie des Dachverbands der Deutschsprachigen Wissenschaftlichen Osteologischen Gesellschaften e.V.

Danielsen CC, Mosekilde L, Svenstrup B (1993): Cortical bone mass, composition, and mechanical properties in female rats in relation to age, long-term ovariectomy, and estrogen substitution. Calcif Tissue Int $\underline{52}$ (1), 26-33.

Deschamps JD, Kenyon VA, Holman TR (2006): Baicalein is a potent in vitro inhibitor against both reticulocyte 15-human and platelet 12-human lipoxygenases. Bioorg Med Chem 14 (12), 4295-4301

Dimai, HP (2009): Diagnostik der Osteoporose. Wien Med Wochenschr 159 (9-10), 241-246

Drenckhahn D, Kugler P: Knochengewebe: Mikrostruktur des Knochens. In: Drenckhahn D (Hg.): Benninghoff Drenckhahn Anatomie. Bd: 1: Mikroskopische Anatomie, Histologie, Embryologie, Zellbiologie. Elsevier GmbH, Urban \& Fischer Verlag, München 2008, 135

Dupuis J, Meunier PJ (1994): Treatment of Vertebral Osteoporosis with Fluoride Salts. Schiff I, Lorrain J, Plouffe L, Ravnikar VA, Speroff L, Watts NB (Hg.): Comprehensive Management of Menopause. Clinical Perspectives in Obstetrics and Gynecology. Springer, New York (NY) 1994, 185-192 
Egermann M, Schneider E, Evans CH, Baltzer AW (2005): The potential of gene therapy for fracture healing in osteoporosis. Osteoporos Int $\underline{16}(2), 8$

Enderle A, Forst R, Grimm T, Ingenhorst A, Lauen J, Mortier W: Orthopädie und Orthopädische Chirurgie: Systemerkrankungen. In: L. Zichner und C. J. Wirth (Hg.): Orthopädie und Orthopädische Chirurgie. Georg Thieme-Verlag, Stuttgart 2003, 169.

Engelke K, Karolczak M, Lutz A, Seibert U, Schaller S, Kalender W (1999): MicroCT. Technology and application for assessing bone structure. Radiologe 39 (3), 203212

Engstrom A, Bellman S, Engfeldt B (1955): Microradiography. I. Microradiography: a review. Br J Radiol 28 (334), 517-532

Eriksen EF, Díez-Pérez A, Boonen S (2014): Update on long-term treatment with bisphosphonates for postmenopausal osteoporosis: a systematic review. Bone $\underline{58}, 126-$ 135

Esbrit P, Alcaraz MJ (2013): Current perspectives on parathyroid hormone (PTH) and PTH-related protein (PTHrP) as bone anabolic therapies. Biochem pharmacol $\underline{85}(10)$, $1417-1423$

Frost HM, Jee WS (1992): On the rat model of human osteopenias and osteoporoses. Bone Miner $\underline{18}$ (3), 227-236

Gandhi NM (2013): Baicalein protects mice against radiation-induced DNA damages and genotoxicity. Mol. Cell. Biochem. 379 (1-2), 277-281

Garnero P, Delmas PD (2004): Contribution of bone mineral density and bone turnover markers to the estimation of risk of osteoporotic fracture in postmenopausal women. $\mathrm{J}$ Musculoskelet Neuronal Interact $\underline{4}$ (1), 50-63

Gauthier A, Kanis JA, Jiang Y, Dreinhöfer K, Martin M, Compston J, Borgström F, Cooper C, McCloskey E (2012): Burden of postmenopausal osteoporosis in Germany: estimations from a disease model. Arch Osteoporos $\underline{7}$ (1-2), 209-218

Genant HK, Delmas PD, Chen P, Jiang Y, Eriksen EF, Dalsky GP, Marcus R, San Martin J (2007): Severity of vertebral fracture reflects deterioration of bone microarchitecture. Osteoporosis Int $\underline{18}(1), 69-76$

Gielkens PFM, Schortinghuis J, Jong JR, Huysmans MCDNJM, van Leeuwen MBM, Raghoebar GM, Bos RR, Stegenga B (2008): A comparison of micro-CT, microradiography and histomorphometry in bone research. Arch Oral Biol $\underline{53}$ (6), 558566

Grifka J, Kuster M: Systemerkrankungen: Skelettsystemerkrankungen des Erwachsenen. In: Grifka J, Kuster M (Hrsg.): Orthopädie und Unfallchirurgie. Für Praxis, Klinik und Facharztprüfung. 1. Auflage; Springer Berlin, Heidelberg 2011, 171173

Guggenbuhl P, Bodic F, Hamel L, Basle MF, Chappard D (2006): Texture analysis of $\mathrm{X}$-ray radiographs of iliac bone is correlated with bone micro-CT. Osteoporosis Int 17 (3), 447-454

Guo AJY, Choi RCY, Cheung AWH, Chen VP, Xu SL, Dong TTX et al. (2011): Baicalin, a flavone, induces the differentiation of cultured osteoblasts: an action via the Wnt/beta-catenin signaling pathway. In: J Biol Chem 286 (32), S. 27882-27893. DOI: 10.1074/jbc.M111.236281. 
Gurney EP, Nachtigall MJ, Nachtigall LE, Naftolin F (2014): The Women's Health Initiative trial and related studies: 10 years later: a clinician's view. In: J Steroid Biochem Mol Biol 142, S. 4-11. DOI: 10.1016/j.jsbmb.2013.10.009.

Hadji P, Klein S, Gothe H, Häussler B, Kless T, Schmidt T, Steinle T, Verheyen F, Linder R (2013): The epidemiology of osteoporosis--Bone Evaluation Study (BEST): an analysis of routine health insurance data. Dtsch Arztebl Int $\underline{110}$ (4), 52-57

Hao YJ, Zhang G, Wang YS, Qin L, Hung WY, Leung K, Pei FX (2007): Changes of microstructure and mineralized tissue in the middle and late phase of osteoporotic fracture healing in rats. In: Bone 41 (4), S. 631-638. DOI: 10.1016/j.bone.2007.06.006.

Harsløf, T, Husted LB, Nyegaard M, Carstens M, Stenkjær L, Brixen K, Eiken P, Jensen JE, Børglum AD, Mosekilde L et al. (2011): Polymorphisms in the ALOX12 gene and osteoporosis. Osteoporos Int $\underline{22}$ (8), 2249-2259

Hatano H, Siegel HJ, Yamagiwa H, Bronk JT, Turner RT, Bolander ME, Sarkar G (2004): Identification of estrogen-regulated genes during fracture healing, using DNA microarray. J Bone Miner Metab 22 (3), 224-235

Hegde V, Jo JE, Andreopoulou P, Lane J M (2016): Effect of osteoporosis medications on fracture healing. Osteoporos Int 27 (3), 861-871

Henriksen K, Andersen JR, Riis BJ, Mehta N, Tavakkol R, Alexandersen P, Byrjalsen I, Valter I, Nedergaard BS, Teglbjaerg CS et al. (2013): Evaluation of the efficacy, safety and pharmacokinetic profile of oral recombinant human parathyroid hormone $[\mathrm{rhPTH}(1-31) \mathrm{NH}(2)]$ in postmenopausal women with osteoporosis. Bone $\underline{53}$ (1), 160166

Hernlund E, Svedbom A, Ivergård M, Compston J, Cooper C, Stenmark J, McCloskey EV, Jönsson B, Kanis JA (2013): Osteoporosis in the European Union: medical management, epidemiology and economic burden. A report prepared in collaboration with the International Osteoporosis Foundation (IOF) and the European Federation of Pharmaceutical Industry Associations (EFPIA). Arch Osteoporos $\underline{8}$ (1-2), 136

Hollebeeck S, Raas T, Piront N, Schneider YJ, Toussaint O, Larondelle Y, During A (2011): Dimethyl sulfoxide (DMSO) attenuates the inflammatory response in the in vitro intestinal Caco-2 cell model. Toxicol Lett 206 (3), 268-275

Hollinger JO, Onikepe AO, MacKrell J, Einhorn T, Bradica G, Lynch S, Hart CE (2008): Accelerated fracture healing in the geriatric, osteoporotic rat with recombinant human platelet-derived growth factor-BB and an injectable beta-tricalcium phosphate/collagen matrix. J Orthop Res $\underline{26}$ (1), 83-90

Ibrahim NI, Khamis MF, Mod Y, Mohd F, Abdullah S, Mohamed N, Shuid AN (2014): Targeted delivery of lovastatin and tocotrienol to fracture site promotes fracture healing in osteoporosis model: micro-computed tomography and biomechanical evaluation. PloS one $\underline{9}$ (12), e115595

Ito M (2011): Recent progression in assessment of bone microstructure. Nihon Rinsho $\underline{69}(7), 1233-1238$

Jabbar S, Drury J, Fordham JN, Datta HK, Francis RM, Tuck SP (2011): Osteoprotegerin, RANKL and bone turnover in postmenopausal osteoporosis. J Clin Pathol 64 (4), 354-357 
Jang EJ, Cha SM, Choi SM, Cha JD (2014): Combination effects of baicalein with antibiotics against oral pathogens. Arch Oral Biol $\underline{59}$ (11), 1233-1241

Jee WS, Yao W (2001): Overview: animal models of osteopenia and osteoporosis. J Musculoskelet Neuronal Interact 1 (3),193-207

Josse R, Khan A, Ngui D, Shapiro M (2013): Denosumab, a new pharmacotherapy option for postmenopausal osteoporosis. Curr Med Res Opin 29 (3), 205-216

Jowsey J, Riggs BL (1972): Assessment of bone turnover by microradiography and autoradiography. Semin Nucl Med 2 (1), 3-17

Kaczmarczyk-Sedlak I, Wojnar W, Zych M, Ozimina-Kaminska E, Taranowicz J, Siwek A (2013): Effect of formononetin on mechanical properties and chemical composition of bones in rats with ovariectomy-induced osteoporosis. Evid Based Complement Alternat Med 2013, 457052

Kalu DN (1991): The ovariectomized rat model of postmenopausal bone loss. J Bone Miner Res 15 (3), S. 175-191

Kammerlander C, Erhart S, Doshi H, Gosch M, Blauth M (2013): Principles of osteoporotic fracture treatment. Best Pract Res Clin Anaesthesiol 27 (6), 757-769

Kampmann P: Untersuchung zur Osteoporoseprävalenz und Versorgungswirklichkeit von Patienten mit osteoporosebedingten Frakturen in der deutschen Unfallchirurgie. Med. Diss. München 2008

Kanis JA (2007): Assesment of Osteoporosis at the Primary Health Care Level. WHO Scientific Group Technical Report, World Health Organization Collaborating Centre for Metabolic Bone Diseases, Sheffield 2008

Keck E (2003): Therapie der postmenopausalen Osteoporose. Orthopäde $\underline{32}$ (12), 1104-1109

Kim JM, Lee SU, Kim YS, Min YK, Kim SH (2008): Baicalein stimulates osteoblast differentiation via coordinating activation of MAP kinases and transcription factors. $J$ Cell Biochem 104 (5), 1906-1917

Kim MH, Ryu SY, Bae MA, Choi JS, Min YK, Kim SH (2008): Baicalein inhibits osteoclast differentiation and induces mature osteoclast apoptosis. Food Chem Toxicol $\underline{46}$ (11), 3375-3382

Kim SJ, Kim HJ, Kim HR, Lee SH, Cho SD, Choi CS, Nam JS, Jung JY (2012): Antitumor actions of baicalein and wogonin in HT-29 human colorectal cancer cells. Mol Med Rep $\underline{6}$ (6), 1443-1449

Klinck RJ, Campbell GM, Boyd SK (2008): Radiation effects on bone architecture in mice and rats resulting from in vivo micro-computed tomography scanning. Med Eng Phys $\underline{30}$ (7), 888-895

Kolios L, Daub F, Sehmisch S, Frosch KH, Tezval M, Stuermer KM, Wuttke W, Stuermer EK (2010): Absence of positive effect of black cohosh (Cimicifuga racemosa) on fracture healing in osteopenic rodent model. Phytother Res $\underline{24}$ (12), 1796-1806

Komrakova M, Sehmisch S, Tezval M, Ammon J, Lieberwirth P, Sauerhoff C, Trautmann L, Wicke M, Dullin C, Stuermer KM, Stuermer EK (2013): Identification of a vibration regime favorable for bone healing and muscle in estrogen-deficient rats. Calcif Tissue Int $\underline{92}$ (6), 509-520 
Komrakova M, Stuermer EK, Tezval M, Stuermer KM, Dullin C, Schmelz U, Doell C, Durkaya-Burchhardt N, Fuerst B, Genotte T et al. (2014): Evaluation of twelve vibration regimes applied to improve spine properties in ovariectomized rats. Bone Rep 7, $172-180$

Komrakova M, Weidemann A, Dullin C, Ebert J, Tezval M, Stuermer KM, Sehmisch S (2015): The Impact of Strontium Ranelate on Metaphyseal Bone Healing in Ovariectomized Rats. Calcif Tissue Int 97 (4), 391-401

Krönke G, Uderhardt S, Katzenbeisser J, Schett G (2009): The 12/15-lipoxygenase pathway promotes osteoclast development and differentiation. Autoimmunity $\underline{42}$ (4), 383-385

Kubo T, Shiga T, Hashimoto J, Yoshioka M, Honjo H, Urabe M, Kitajima I, Semba I, Hirasawa Y (1999): Osteoporosis influences the late period of fracture healing in a rat model prepared by ovariectomy and low calcium diet. In: J Steroid Biochem Mol Biol $\underline{68}(5-6), 197-202$

Law MR, Hackshaw AK (1997): A meta-analysis of cigarette smoking, bone mineral density and risk of hip fracture: recognition of a major effect. BMJ $\underline{315}$ (7112), 841846

Lee JM, Park H, Noh ALSM, Kang JH, Chen L, Zheng T, Lee J, Ji SY, Jang CY, Shin CS et al. (2012): 5-Lipoxygenase mediates RANKL-induced osteoclast formation via the cysteinyl leukotriene receptor 1 . J Immunol $\underline{189}$ (11), 5284-5292

Leibbrandt A, Penninger JM (2008): RANK/RANKL: regulators of immune responses and bone physiology. Ann N Y Acad Sci 1143, 123-150

Leitlinie Osteoporose s. DVO-Leitlinie 2014

Lelovas PP, Xanthos TT, Thoma SE, Lyritis GP, Dontas IA (2008): The laboratory rat as an animal model for osteoporosis research. Comp Med $\underline{58}$ (5), 424-430

Li C, Mori S, Li J, Kaji Y, Akiyama T, Kawanishi J, Norimatsu H (2001): Long-term effect of incadronate disodium (YM-175) on fracture healing of femoral shaft in growing rats. J Bone Miner Res $\underline{16}$ (3), 429-436

Li SF, Tang JJ, Chen J, Zhang P, Wang T, Chen TY, Yan B1, Huang B1, Wang L1, Huang MJ1 et al. (2015): Regulation of bone formation by baicalein via the mTORC1 pathway. Drug Des Devel Ther $\underline{9}, 5169-5183$

Lill CA, Hesseln J, Schlegel, U Eckhardt C, Goldhahn J, Schneider E (2003): Biomechanical evaluation of healing in a non-critical defect in a large animal model of osteoporosis. J Orthop Res $\underline{21}$ (5), 836-842

Lüllmann-Rauch R: Histologie. Unter Mitarbeit von Paulsen F. 4. Auflage, Georg Thieme-Verlag, Stuttgart 2012

Maier GS, Jakobs P, Roth KE, Kurth AA, Maus U (2013): Is there an epidemic vitamin D deficiency in German orthopaedic patients? Clin Orthop Relat Res $\underline{471}$ (9), 30293035

Manolagas SC, Jilka RL (1995): Bone marrow, cytokines, and bone remodeling. Emerging insights into the pathophysiology of osteoporosis. N Engl J Med $\underline{332}$ (5), 305-311

Marsell R, Einhorn TA (2011): The biology of fracture healing. Injury $\underline{42}$ (6), 551-555 
Marshall D, Johnell O, Wedel H (1996): Meta-analysis of how well measures of bone mineral density predict occurrence of osteoporotic fractures. BMJ $\underline{312}$ (7041), 12541259

Meunier PJ, Sebert JL, Reginster JY, Briancon D, Appelboom T, Netter P, Loeb G, Rouillon A, Barry S, Evreux JC et al. (1998): Fluoride salts are no better at preventing new vertebral fractures than calcium-vitamin D in postmenopausal osteoporosis: the FAVOStudy. Osteoporos Int $\underline{8}$ (1), 4-12

Miller SC, Wronski TJ (1993): Long-term osteopenic changes in cancellous bone structure in ovariectomized rats. Anatomic Rec 236 (3), 433-441

Moch H, Komminoth P, Zimmermann DR, Odermatt B, Probst-Hensch N, Bopp M: Pathologie: Aufgaben und Methoden. In: Böcker W, Denk H, Heitz U, Moch H (Hg.): Pathologie. 4. Auflage; Elsevier, Urban \& Fischer Verlag. München 2008, 3-34

Morley P, Whitfield JF, Willick GE (2001): Parathyroid hormone: an anabolic treatment for osteoporosis. Curr Pharm Des $\underline{7}$ (8), 671-687

Nachtigall MJ, Nazem TG, Nachtigall RH, Goldstein SR (2013): Osteoporosis risk factors and early life-style modifications to decrease disease burden in women. Clin Obstet Gynecol $\underline{56}$ (4), 650-653

Nakajima A, Shimoji N, Shiomi K, Shimizu S, Moriya H, Einhorn TA, Yamazaki M (2002): Mechanisms for the enhancement of fracture healing in rats treated with intermittent low-dose human parathyroid hormone (1-34). J Bone Miner Res 17 (11), 2038-2047

Namkung-Matthai H, Appleyard R, Jansen J, Hao Lin J, Maastricht S, Swain M, Mason RS, Murrell GA, Diwan AD, Diamond T (2001): Osteoporosis influences the early period of fracture healing in a rat osteoporotic model. Bone $\underline{28}$ (1), 80-86

Niethard FU, Pfeil J, Biberthaler P: Duale Reihe Orthopädie und Unfallchirurgie. 6. Auflage; Georg Thieme-Verlag, Stuttgart 2009

Ogura-Tomomatsu H, Asano K, Tomomatsu K, Miyata J, Ohmori N, Kodama M, Ueda S, Takihara T, Tanaka K, Kamiishi N et al. (2012): Predictors of osteoporosis and vertebral fractures in patients presenting with moderate-to-severe chronic obstructive lung disease. COPD $\underline{9}$ (4), 332-337

Okyay DO, Okyay E, Dogan E, Kurtulmus S, Acet F, Taner CE (2013): Prolonged breast-feeding is an independent risk factor for postmenopausal osteoporosis. Maturitas $\underline{74}$ (3), 270-275

Oliver RA, Yu Y, Yee G, Low AK, Diwan AD, Walsh WR (2013): Poor histological healing of a femoral fracture following 12 months of oestrogen deficiency in rats. Osteoporos Int 24 (10), 2581-2589

Pang J, Guo HL, Ding DF, Wu YY, Zhao YF, Gu XF, Zheng, YX (2015): Changes of mesenchymal stromal cells mobilization and bone turnover in an experimental bone fracture model in ovariectomized mice. Int J Clin Exp Pathol $\underline{8}$ (9), 10228-10238

Peng Z, Tuukkanen J, Zhang H, Jamsa T, Vaananen HK (1994): The mechanical strength of bone in different rat models of experimental osteoporosis. Bone 15 (5), $523-$ 532 
Perilli E, Le V, Ma B, Salmon P, Reynolds K, Fazzalari NL (2010): Detecting early bone changes using in vivo micro-CT in ovariectomized, zoledronic acid-treated, and sham-operated rats. Osteoporos Int 21 (8), 1371-1382

Ralston SH (2010): Genetics of osteoporosis. Ann N Y Acad Sci 1192, 181-189

Reginster JY, Kaufman JM, Goemaere S, Devogelaer JP, Benhamou CL, Felsenberg D, Diaz-Curiel M, Brandi ML, Badurski J, Wark J et al. (2012): Maintenance of antifracture efficacy over 10 years with strontium ranelate in postmenopausal osteoporosis. Osteoporos Int $\underline{23}$ (3), 1115-1122

Rithirangsriroj K, Panyakhamlerd K, Chaikittisilpa S, Chaiwatanarat T, Taechakraichana N (2012): Osteoporosis in different age-groups and various body mass index (BMI) ranges in women undergoing bone mass measurement at King Chulalongkorn Memorial Hospital. J Med Assoc Thai $\underline{95}$ (5), 644-649

Sandberg O, Bernhardsson M, Aspenberg P (2016): Earlier effect of alendronate in mouse metaphyseal versus diaphyseal bone healing. J Orthop Res 35 (4), 793-799

Savaridas T, Wallace RJ, Salter DM, Simpson AHRW (2013): Do bisphosphonates inhibit direct fracture healing? A laboratory investigation using an animal model. Bone Joint J 95-B (9), 1263-1268

Schindeler A, McDonald MM, Bokko P, Little DG (2008): Bone remodeling during fracture repair: The cellular picture. Semin Cell Dev Biol 19 (5), 459-466

Scotland G, Waugh N, Royle P, McNamee P, Henderson R, Hollick R (2011): Denosumab for the prevention of osteoporotic fractures in post-menopausal women: a NICE single technology appraisal. Pharmacoeconomics $\underline{29}$ (11), 951-961

Seebach C und Marzi I: Pathophysiologie des Knochens: Osteoporose. In: Scharf HP, Rüter A, Pohlemann T, Marzi I, Kohn D, Günther KP (Hg.): Orthopädie und Unfallchirurgie. Facharztwissen nach der neuen Weiterbildungsordnung. 2. Aufl.; Elsevier GmbH, Urban \& Fischer Verlag, München 2011, 39-47

Sehmisch S, Dullin C, Zaroban A, Tezval M, Rack T, Schmelz U, Seidlova-Wuttke D, Dunkelberg H, Wuttke W, Marten K et al. (2009): The use of flat panel volumetric computed tomography (fpVCT) in osteoporosis research. Acad Radiol $\underline{16}$ (4), 394-400

Sehmisch S, Erren M, Kolios L, Tezval M, Seidlova-Wuttke D, Wuttke W, Stuermer KM, Stuermer EK (2010): Effects of isoflavones equol and genistein on bone quality in a rat osteopenia model. Phytother Res 24 (2), 74

Silverman SL, Komm BS, Mirkin S (2014): Use of FRAX(®)-based fracture risk assessments to identify patients who will benefit from osteoporosis therapy. Maturitas $\underline{79}$ (3), 241-247

Sims NA, Martin TJ (2014): Coupling the activities of bone formation and resorption: a multitude of signals within the basic multicellular unit. Bonekey Rep $\underline{3}, 481$

Sobieszczanska M, Jonkisz J, Tabin M, Laszki-Szczachor K (2013): Osteoporosis: genetic determinants and relationship with cardiovascular disease. Adv Clin Exp Med $\underline{22}(1), 119-124$

Standal T, Johnson R, McGregor N, Poulton I, Ho P, Martin TJ, Sims NA (2014): gp130 in late osteoblasts and osteocytes is required for PTH-induced osteoblast differentiation. J Endocrinol $\underline{223}$ (2), 181-190 
Stürmer EK, Seidlova-Wuttke D, Sehmisch S, Rack T, Wille J, Frosch KH, Wuttke W, Stürmer KM (2006): Standardized bending and breaking test for the normal and osteoporotic metaphyseal tibias of the rat: effect of estradiol, testosterone, and raloxifene. J Bone Miner Res 21 (1), 89-96

Stürmer EK, Sehmisch S, Rack T, Wenda E, Seidlova-Wuttke D, Tezval M, Wuttke W, Frosch KH, Stuermer KM (2010a): Estrogen and raloxifene improve metaphyseal fracture healing in the early phase of osteoporosis. A new fracture-healing model at the tibia in rat. Langenbecks Arch Surg $\underline{395}$ (2), 163-172

Stürmer EK, Komrakova M, Werner C, Wicke M, Kolios L, Sehmisch S, Tezval M, Utesch C, Mangal O et al. (2010b): Musculoskeletal response to whole-body vibration during fracture healing in intact and ovariectomized rats. Calcif Tissue Int $\underline{87}(2), 168$ 180

Stürmer EK, Komrakova M, Sehmisch S, Tezval M, Dullin C, Schaefer N, Hallecker J, Stuermer KM (2014): Whole body vibration during fracture healing intensifies the effects of estradiol and raloxifene in estrogen-deficient rats. Bone 64, 187-194

Tarantino U, Saturnino L, Scialdoni A, Feola M, Liuni FM, Tempesta V, Pistillo P (2013): Fracture healing in elderly patients: new challenges for antiosteoporotic drugs. Aging Clin Exp Res $\underline{25}$ (1), 8

Thorndike EA, Turner AS (1998): In search of an animal model for postmenopausal diseases. Front Biosci $\underline{3}, 26$

Tong L, Wan M, Zhang L, Zhu Y, Sun H, Bi K (2012): Simultaneous determination of baicalin, wogonoside, baicalein, wogonin, oroxylin A and chrysin of Radix scutellariae extract in rat plasma by liquid chromatography tandem mass spectrometry. J Pharm Biomed Anal 0ㅡ, 6-12

Waarsing JH, Day JS, van der Linden JC, Ederveen AG, Spanjers C, De Clerck N, Sasov A, Verhaar JA, Weinans H (2004): Detecting and tracking local changes in the tibiae of individual rats: a novel method to analyse longitudinal in vivo micro-CT data. Bone $\underline{34}$ (1), 163-169

Wade SW, Strader C, Fitzpatrick LA, Anthony MS, O'Malley CD (2014): Estimating prevalence of osteoporosis: examples from industrialized countries. Arch Osteoporos $\underline{9}, 182$

Wang JW, Li Wei, Xu SW, Yang DS, Wang Y, Lin M, Zhao GF (2005): Osteoporosis influences the middle and late periods of fracture healing in a rat osteoporotic model. Chin J Traumatol $\underline{8}$ (2), 111-116

Wang Y, Yang J, Li X, Wang J (2012): The metabolism of baicalin in rat and the biological activities of the metabolites. Evid Based Complement Alternat Med 2012, 404529

Wang Y, Han E, Xing Q, Yan J, Arrington A, Wang C, Tully D, Kowolik CM, Lu DM, Frankel PH et al. (2015): Baicalein upregulates DDIT4 expression which mediates mTOR inhibition and growth inhibition in cancer cells. Cancer Lett 358 (2), 170-179

Welsch U: Lehrbuch Histologie. Unter Mitarbeit von Deller T. 3. Auflage; Elsevier, Urban \& Fischer Verlag, München 2010 
Wen Y, Gu J, Chakrabarti SK, Aylor K, Marshall J, Takahashi Y, Yoshimoto T, Nadler JL (2007): The role of 12/15-lipoxygenase in the expression of interleukin-6 and tumor necrosis factor-alpha in macrophages. Endocrinology 148 (3), 1313-1322

Wölfl C, Schweppenhäuser D, Gühring T, Takur C, Höner B, Kneser U, Grützner PA, Kolios L (2014): Characteristics of bone turnover in the long bone metaphysis fractured patients with normal or low Bone Mineral Density (BMD). PLoS ONE $\underline{9}$ (5), e96058

World Health Organization (2004): WHO Scientific Group on the Assesment of Osteoporosis at Primary Health Care Level. Summary Meeting Report 5-7 May 2004. WHO. Genf, Brüssel 2004

Xiao WJ, Ke YH, He JW, Zhang H, Yu JB, Hu WW, Gu JM, Gao G, Yue H, Wang C et al. (2012): Polymorphisms in the human ALOX12 and ALOX15 genes are associated with peak bone mineral density in Chinese nuclear families. Osteoporos Int $\underline{23}$ (7), 1889-1897

$\mathrm{Xu}$ SW, Yu Ren, Zhao GF, Wang JW (2003): Early period of fracture healing in ovariectomized rats. Chin J Trauma $\underline{6}$ (3), 160-166

Xu SW, Wang JW, Li W, Wang Y, Zhao GF (2004): Osteoporosis impairs fracture healing of tibia in a rat osteoporotic model. Chin Med J (Eng) $\underline{84}$ (14), 1205-1209

Zhang Y, Song L, Cai L, Wei R, Hu Hao, Jin Wei (2013): Effects of baicalein on apoptosis, cell cycle arrest, migration and invasion of osteosarcoma cells. Food Chem Toxicol 53, 325-333

Zhao R (2012): Immune regulation of osteoclast function in postmenopausal osteoporosis: a critical interdisciplinary perspective. Int J Med Sci $\underline{9}$ (9), 825-832 


\section{Danksagung}

Mein Dank gilt an erster Stelle Prof. Dr. med. Klaus Michael Stürmer, unter dessen Leitung ich meine Doktorarbeit begonnen habe, und weiterhin dem aktuellen Abteilungsleiter der Unfallchirurgie an der Universitätsmedizin Göttingen Prof. Dr. med. Wolfgang Lehmann für die weitere Förderung dieses Projekts.

Außerdem möchte ich mich herzlich bei meinem Doktorvater Herrn Prof. Dr. med. Stephan Sehmisch bedanken, der mich in seine Arbeitsgruppe aufgenommen und mir damit die Durchführung einer spannenden und lehrreichen experimentellen Doktorarbeit ermöglicht hat. Dankbar bin ich auch für die schnelle und gründliche Korrektur meiner Dissertation.

Besonders dankbar bin ich meiner Betreuerin Dr. rer. nat. Marina Komrakova für ihre tolle Unterstützung und fachkundigen Ratschläge, die mich immer wieder vorangebracht haben. Durch ihre Präsenz, Geduld und Professionalität im Rahmen dieser Arbeit konnten Fragen zügig geklärt und Änderungen schnell umgesetzt werden. Nicht zuletzt ihre Erfahrung als Betreuerin und Wissenschaftlerin hat die Grundlage für das Gelingen dieser Arbeit gelegt.

Auch möchte ich mich sehr herzlich bei den im Labor tätigen MTAs Frau Ramona Castro Machguth und Frau Annette Witt bedanken, die mir ebenfalls mit Rat und Tat zu Seite gestanden und durch eine umfassende Einführung in die Thematik und Methodik dieses Projektes dessen Durchführung sehr erleichtert haben.

Herrn Christian Dullin gebührt mein Dank für die Unterweisung im Umgang mit dem verwendeten Mikro-CT und den entsprechenden Programmen.

Darüber hinaus bedanke ich mich bei der Elsbeth-Bonhoff-Stiftung Berlin, durch deren Fördermittel dieses Projekt (Projeknummer 114) finanziert und somit realisiert werden konnte. 